Searching for justice (and evidence) in public health: Exploring health equity in Canadian public health discourse and practice

\title{
by
}

\section{Adam Wildgen}

A thesis submitted to the Faculty of Graduate and Postdoctoral Affairs in partial fulfillment of the requirements for the degree of

Master

in Sociology

\section{Carleton University}

Ottawa, Ontario

○2018

Adam Wildgen 
TABLE OF CONTENTS

ABSTRACT

VI

ABREVIATIONS

VII

ACKNOWLEDGMENTS

VIII



THE GOVERNMENTAL CONDITIONS IN WHICH HEALTH EQUITY IS DEPLOYED ............1

CONCEPTUALIZING, REPRESENTING, AND THEORIZING THE SOCIAL DETERMINANTS

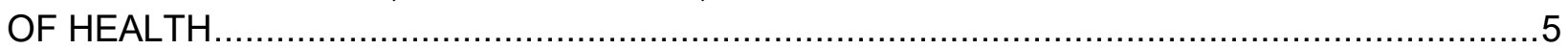

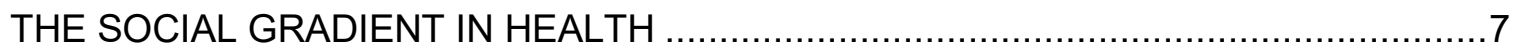

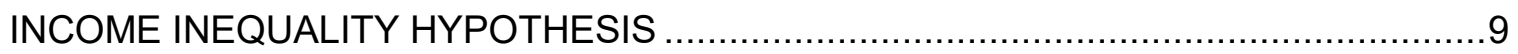

POLITICAL ECONOMY OF HEALTH INEQUALITY ...............................................

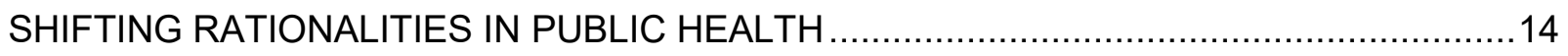

CONDITIONS IN WHICH POPULATION HEALTH EMERGED ................................17

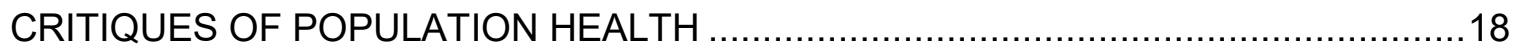

PLURALIST NOTION OF POWER AND KNOWLEDGE TRANSLATION .........18

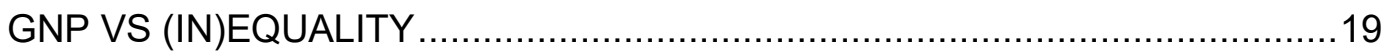

INADEQUATE THEORY OF SOCIAL CHANGE ……................................21

ESCHEWAL OF THEORY AND VALUES: DATA UNITES THEORY DIVIDES .22

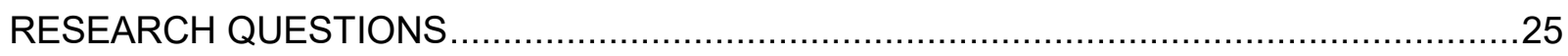

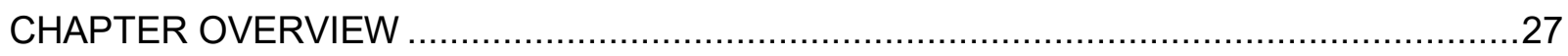



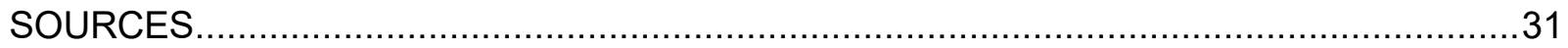

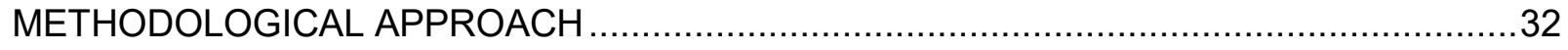

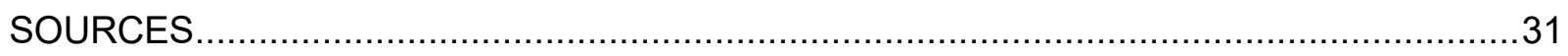

A ROADMAP TO MY LOGICALLY DIRECTED EXPLORATORY APPROACH .....................33

DISCOURSE AS A MODE OF REPRESENTATION AND REPRODUCTION ......................35

WHAT I ATTENDED TO, AND HOW I SITUATED MY OBJECTS OF INQUIRY ....................38 
CHAPTER 3: UNDERSTANDING HEALTH EQUITY THROUGH NORMATIVE ETHICS THEORY

RELATIONAL AND DISTRIBUTIVE CONCEPTIONS OF JUSTICE .

SUFFICIENTARIANISM, UTILITARIANISM, PRIORITARIANISM, AND EGALITARIANISM .45

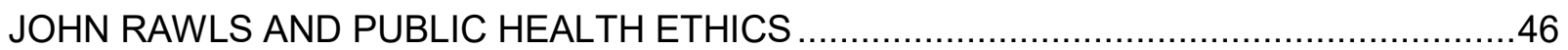



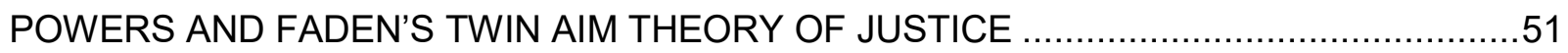

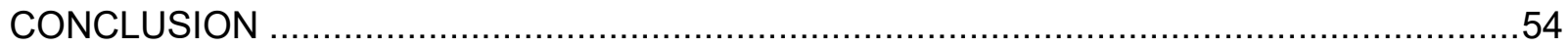

CHAPTER 4: SOCIAL JUSTICE AND THE DEPLOYMENT OF HEALTH EQUITY IN CANADA

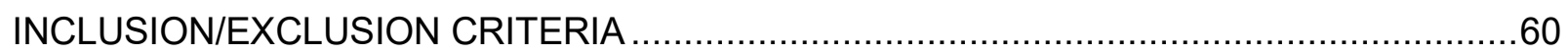

COMMONALITIES AND DIVERGENCES IN METHODS, SCOPE, AND PARADIGM ...........61

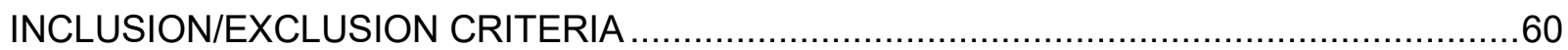

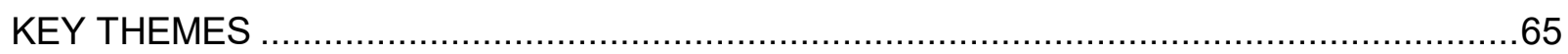

THE ROLE OF EQUITY AS A VALUE IN HEALTH POLICY ...................................65

UNDERSTANDINGS AND APPLICATIONS OF A HEALTH EQUITY LENS ...................72

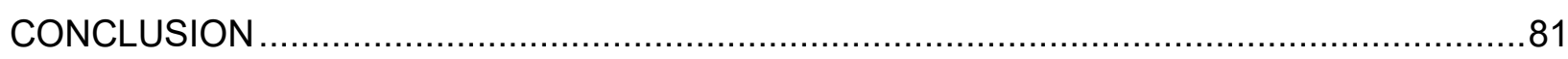

CHAPTER 5: BARRIERS TO HEALTH EQUITY ................................................... 91

EMBEDDING EXPLICIT LANGUAGE OF SOCIAL JUSTICE WITHIN PUBLIC HEALTH

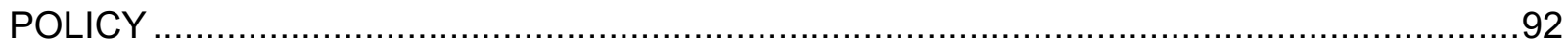

BARRIERS TO EVIDENCE-BASED PRACTICE AS BARRIERS TO HEALTH EQUITY.......93 ACHIEVING POPULATION HEALTH ALONGSIDE, OR THROUGH HEALTH EQUITY? .....95

THE CONVENIENT CONFLUENCE OF UTILITARIANISM, POPULATION HEALTH,

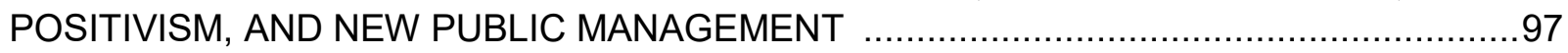

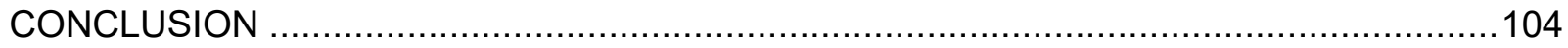

CHAPTER 6: THE LANGUAGE OF EQUITY: EXTENDABLE, MOBILE, QUANTIFIABLE, AND NEUTRAL

THE LANGUAGE AND PRACTICE OF MAKING UP POPULATIONS $\ldots \ldots \ldots \ldots \ldots \ldots \ldots \ldots \ldots$

FACTS, VALUES, AND THEORY IN THE HISTORY OF SOCIAL SCIENCE ................122 RELATIONAL CONCEPTIONS OF JUSTICE REQUIRE RELATIONAL CONCEPTIONS OF POPULATION 
CONCLUSION

CHAPTER 7: REPRESENTING HEALTH INEQUALITY AND NATURALIZING RISK 137

STRUCTURAL FACTORS: INDICATING OR EXPLAINING?.

DATA FIT FOR SCIENCE AND POLITICS: EMPIRICAL, DISCRETE, AND MEANINGLESS IN THEMSELVES.

CONCLUSION 149

CHAPTER 8: REPRESENTING HEALTH EQUITY IN ACTION: A DEARTH OF EVIDENCE, OR A DEARTH OF POLITICS?.

EVIDENTIARY IMPERATIVES AND CAUTIOUS DISCURSIVE TREATMENT OF THE SOCIAL 154

DRIFTING DOWNSTREAM AND LOCAL 158

FROM CITIZEN TO PARTICIPANT 163

CONCLUSION 172

CHAPTER 9: HEALTH EQUITY AND THE COMMUNITY. 177 COMMUNITY-ORGANIZATION-GOVERNMENT POLICY LIAISON 178 SURVEILLING AND EVALUATING 179

ACTIVE COMMUNITIES: RESPONSIBLE AND NETWORKED. 180 ACCOMMODATION, COMPROMISE, AND POLITICAL CONTAINMENT 185

RECONCILING A PARADOX WITHIN (NEO)LIBERAL DEMOCRACY 187

DOWN AND OUT: DISPLACING AND DIFFUSING GOVERNMENT 188

TECHNOLOGIES OF PERFORMANCE AND TECHNOLOGIES OF AGENCY 191

CHAPTER 10: CONCLUSION. 195

HEALTH EQUITY IN THE COMMUNITY 200

MAKING SENSE OF HEALTH EQUITY: FLEXIBLE AND CONTAINED. 201 SCIENCE, VALUES, AND WELFARE 202 IMPLICATIONS FOR UNDERSTANDING LATE MODERN GOVERNMENT: SCIENCE AND GOVERNMENT EFFACEMENT..... 203

FUTURE RESEARCH 206

PRACTICAL CONTRIBUTION TO PUBLIC HEALTH 207 


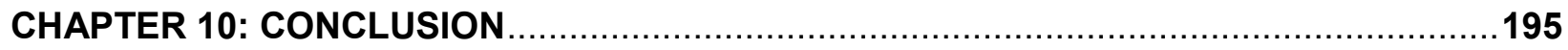

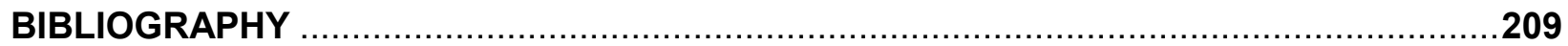




\section{Abstract}

Since its arrival in 1984, the idea of health equity has proliferated throughout public health discourse with little mainstream critique for its variability and distance from its original definition signifying social transformation and a commitment to social justice. Few researchers have taken the concept itself as an object of study, and no one has analysed how or why health equity has been able to travel so far from its originator, Margaret Whitehead's definition. In Whitehead's words, achieving health equity requires determining what is inequitable by examining and judging the causes of inequalities 'in the context of what is going on in the rest of society'. In the years since health equity's emergence and proliferation, it has taken on a seemingly endless range of invocations and deployments, but it most often translates into proactive and apolitical discourse and practice. This thesis examines the highly variable deployment of health equity in Canadian public health discourse and practice, but it also provides a theoretical account for its successful journey from its original commitment to social justice vis-à-vis injustice. By theorizing health equity as an empty signifier and as a vehicular idea, I show how the concept is invoked within an infinitely extendable field of discourse and practice. Secondly, I analyse how health equity—as an empirical phenomenon and practice-is made knowable through modes of measurement and representation used in Canadian public health organizations. I argue that possibilities for understanding and acting upon health (in)equity are shaped and limited by evidentiary norms embedded in the rules of institutional fields. I historicise these evidentiary norms—which include both imperatives and practices—as mechanisms of government which date back to the enlightenment. By legitimizing and deploying action according to scientific evidentiary productivity rather than normative-political reasoning, government can efface itself. This thesis examines the relationship between precise but incomplete knowledges and justice. However precise our knowledge is, if we do not engage with its incompleteness, we will always miss the mark, and inequities will persist. 


\section{Abbreviations}

CHC Community Health Clinics

CIHI Canadian Institute for Health Information

CPNP Canadian Prenatal Nutrition Programme

EIDM Evidence informed decision making

FLS Front line staff

HEG Health Equity Guidelines

NCCDH National Collaborating Centre for the Determinants of Health

NPM New public management

OECD Organization for Economic Co-operation and

OPHS Ontario Public Health Standards

PHAC Public Health Agency of Canada

PHU Public health units

SDOH Social determinants of health

WHO World Health Organization 


\section{Acknowledgements}

First, to my mom, Sheila Saunders, for showing me what really matters, for creating the most loving and interesting siblings I could have dreamed of having, for giving me the confidence and freedom to take risks and explore, and for supporting my outrage at all things perceived unfair; To Keith Denny, without whom this work would not have been possible, for taking the time and having the interest and patience to read through many long and poorly-written research questions, for pointing me toward exactly what I didn't know I needed to see, and for being a key part of this once-in-a-lifetime endeavour; to Neil Gerlach, for taking the time to meet, for offering academic and professional advice from the very beginning of my time at Carleton and throughout my degree; to Bruce Curtis for teaching me (and so many others) an appreciation and understanding of not only theoretical perspectives and those who advanced them, but also of sociology itself; to Alexis Shotwell for being ready to save the day when unforeseen problems emerged (I couldn't think of a wiser group of people to ease the anxieties that any graduate student inevitably incurs throughout their studies); to Irena Knezevic for her comments, questions, and words of encouragement which I will continue think about as I move forward; to Paula Whissell and Darlene Moss for their administrative support and guidance; to all those in my personal life who understood my recurrent self-imposed isolation during this time, including my family, friends, and of course, Sapna Wadhawan-all of whom made the good times better and the bad times bearable,

Thank you. I am so lucky. 


\section{Chapter 1}

\section{Introduction}

This thesis examines the deployment of health equity in Canadian public health discourse and practice. The concept was first institutionalized into public health discourse when in 1984, the 32-member states of the World Health Organization European Region made health equity the first subject of policy targets. WHO would later task Margaret Whitehead with clarifying the concept, particularly its moral and ethical dimension which distinguishes it from mathematically deduced inequalities or disparities. In what is now the highest cited source of the definition, Whitehead (1991) writes that equity "refers to differences which are unnecessary and avoidable but, in addition, are also considered unfair and unjust (1991: 219). This is the most enduring definition that has become reflected_often almost word-for-word-in every definition of health equity. However, directly following the above definition, Whitehead continues, "So, in order to describe a certain situation as inequitable, the cause has to be examined and judged to be unfair in the context of what is going on in the rest of society" (219). Unfortunately, in the years since this early articulation of health equity, the concept has proliferated throughout public health discourse with little guidance, consistency, or accountability in how it carries out this task of identifying when a situation is inequitable by examining and judging the cause as unfair in the context of what is going on in the rest of society.

As a value laden concept whose invocation ranges greatly, from gesturing to political transformation, to providing parenting classes, the very idea of health equity warrants attention given its sheer ubiquity and variability. As such, I will analyze the various invocations and enactments of the concept of health equity in relation to normative ethics - the branch of ethical philosophy that examines standards for rightness and wrongness of actions, outcomes, and processes. I also pay special attention to the ways in which the mobilization of equity in discourse and measurement produce an incomplete representation of the problem of inequity, 
ultimately limiting possibilities for action. For decades, health scholars have called for health equity's clarification (Mooney, 1987; Chang, 2002; Smith, 2014; Braveman, 2014). While these authors' calls for clarification and posited frameworks for doing so offer useful and illuminating commentary from which my study follows, none have considered how health equity's conceptual muddiness and flexibility allows for its successful extension and productivity.

In addition to 'clarifying our commitment' (Smith, 2014) to equity by showing how the concept is variably invoked, understood, and put into practice as a sort of proxy for justice, I explore how and why particular courses of action are produced, and why some are excluded. This line of inquiry is approached by studying how the idea of equity is accommodated into current regimes of public health practice. Health equity is a particularly interesting concept to explore because it is peculiar for a value-laden concept to be so widely and frequently mobilized throughout a governmental context characterized by both neoliberalism and scientific, evidencebased management. The evidence-based regime is a key mechanism of government that allows for the state's retreat from identifying and responding to social problems through political deliberation and progressive policy development. By showing how health equity's accommodation into Canada's political, institutional, and evidentiary context shapes and limits what is possible, I produce insights into the limits of 'scientific reason a public reason' (Porter, 2006). This project is very much about the interplay and interdependence of evidentiary norms, knowledge, politics, and values.

\section{The Governmental Conditions in Which Health Equity is Deployed}

In order to contextualize discourse and action around health equity, it is important to first highlight some features of the current political environment. The following cases illustrate the power of scientific reason in debates around public issues of human wellbeing which, rather than signalling social and ethical problems, simply produce technical responses. Stanhope and 
Dunn (2011) critique evidence-based policy for failing to integrate evidence and values into public debate. They argue that the success of Housing First relied on its ability to "conform to rational policy making rather than on political debate about ends - namely, who has a right to housing and how resources should be allocated among people experiencing homelessness" (277). Their research shows how Housing First was adopted by the conservative Bush Administration by framing a political and social justice issue as a technical problem to be resolved with positivist methods such as randomized control trials and cost-benefits analysis rather than political and normative reasoning.

Elliot's (2014) study of public debates around Canada's first safe injection site in Vancouver, Insite provides additional insight into the power and use of science in public debates. Insite was made legitimate as a social experiment but not as a social justice project. Insite was unable to obtain the exemption from drug laws it needed to operate, however it was granted scientific exceptions from drug laws, allowing it to operate as an experiment conducted by a research body (14). As a result, Insite was only able to continue if it was producing research. This reveals how the public health initiative could be carried out as a rational, modern, enlightenment project, but not as a response to a moral issue. Not only was Insite's initial legal operation contingent upon a scientific research agenda; the claims made in debates around its legitimacy were also contingent on scientific representations.

In September 2006, the Harper government announced It was canceling funding for the evaluation of Insite (17). The PMO then began requesting proposals from other researchers (17). This politically-solicited research would conclude that the original evaluations were not scientific and could not demonstrate a positive predictive outcome of harm reduction. This secondary analysis would become discredited in public debates by the larger scientific community (26). There is great insight to be drawn from the fact that the Harper government 
had to use science to exercise power in this context. The Harper Government could not invoke raw values in exercising political force. The government needed to equip itself with science to fight what was now an issue of science. This signals the crucial legitimating role of scientific and expert evidence in shaping, constraining, and enabling political issues of public health and social justice. This case also demonstrates how certain kinds of evidence can turn what otherwise would merely be a values-based political debate into one cloaked as evidence-based. I recognize that while in this case, there was a direct link between the Harper regime and the use of science to meet ideologically-driven ends, in many other cases, we must look beyond the state to examine how some ways of knowing reign over other ways of knowing, and how these epistemological practices link to institutional practices, imperatives and/or wider cultural sentiments regarding the stature of particular forms of knowledge production. While these processes are not ideologically-driven, they can be ideological in their effects. ${ }^{1}$ It is this line of inquiry that my project follows.

Politics increasingly assumes a form characterised less overtly by struggles over values, and more often by struggles over and through evidence. What it often actually is, of course, is struggles over values made through the deployment of evidence. Other times, governance is sustained through technical reason without having to deploy explicit political rationality at all. If these are the grounds on which politics and governance are performed, 'what counts as evidence' is fundamental to these processes of representing problems and their solutions. These conditions of possibility, although technical, are effectually political in that they are both productive and exclusionary. Interrogating what counts as evidence then, along with how evidentiary norms shape problems and their solutions, at the least by rendering them thinkable

\footnotetext{
${ }^{1}$ These non-ideological, technical processes can produce a precise but incomplete representation of the world which simultaneously stabilizes the meaning that they do produce while mystifying that which they do not, effectually sustaining unequal social relations.
} 
and actionable, is of the highest importance to understanding contemporary forms of politics, governance, and possibilities for social change.

Evidence-based practices overtly and transparently shape public problems and their solutions, albeit through technical means, below the level of political or democratic deliberation. However, in the case of health equity's mobilization, what we see are evidenced-based practices rather than solutions to problems of inequity. The problem of inequity is not even explained, but merely described. While the problem of inequity escapes exposition and theorization in both political and scientific institutional fields, the effects of inequity, and a range of practices are systematically measured, mobilized, and evaluated in accordance with the principles of Evidence-Based Decision Making (EBDM).

\section{Conceptualizing, Representing, and Theorizing the Social Determinants of Health}

Health equity is commonly invoked as a public or societal goal to be achieved through collective action on $\mathrm{SDOH} .{ }^{2}$ Although actual practices guided by a health equity 'lens' or 'principle' stray from direct action on, or even advocacy for correcting $\mathrm{SDOH}$, the idea of fairness inherent in almost every definition of health equity is articulated in relation to those socially controllable and therefore unnecessary (and unfair) factors. SDOH are those social and material aspects of our working and living conditions that affect our health. SDOH can be identified as those specific determinants for which pathways can be identified, or they can be

\footnotetext{
${ }^{2}$ Even when health equity occasionally gets conflated with health care equity within the grey literature, health equity is most often defined within those same documents as health inequalities that are socially determined or controllable, and therefore unfair. The connection between $\mathrm{SDOH}$ and health equity is more clearly and consistently held within both academic publications and non-governmental grey literature such as WHO's (2008) Closing the Gap in a Generation. Health equity's strong discursive focus on SDOH and its link to fairness configures it as a distinctly public and political idea, in contrast to other public health ethics frameworks drawing from bioethics. See Lee (2012) for a review of public health ethics frameworks from 1996-2010. These public health ethics frameworks focus on foundational values and operating principles such as autonomy, beneficence, and nonmaleficence in the biomedical context, without speaking to issues of social justice as fairness in broader social, political, and economic relations.
} 
discussed as socially constituted and constituting factors which are shown to correlate with particular population health outcomes. They are generally categorized as either behavioural, psychosocial, material, or structural. They operate through various mechanisms, affecting our health through one another and independently of one another. I will not spend much time on parsing out research and debates around specific mechanisms by which various SDOH affect health interdependently and dependently of one another to varying degrees. Aside from material harms - for example, those caused by food insecurity or hazardous work places - a range of socially determined experiences such as social position and control create chronic stress which modify neuroendocrine and physiological functioning — specifically the hypothalamic-pituitaryadrenocortical (HPA) axis, ultimately contributing to chronic disease. The precise way in which this system activates physiological responses such as bronchodilation, raised blood pressure, and haemoconcentration depends on different stressors and their durations, including perceived financial strain, job insecurity, low control and monotony at work, stressful life events, and poor social networks (Brunner, 1997).

In Canada, research has identified a range of work dimensions that predispose individuals to high blood pressure, cardiovascular diseases, and development of physical and psychological difficulties such as depression and anxiety. These include employment security; physical conditions at work; work pace and stress; working hours; and opportunities for selfexpression and individual development at work (Jackson, 2009). Many SDOH intersect, however the manner by which they influence one another and ultimately health is not static but shaped by public policies. Being unemployed or having low income does not mean the same thing in each country. Out of the Organization for Economic Co-operation and Development (OECD) member nations, Canada provides some of the lowest employment protection with only U.K and U.S.A behind (OECD, 2010). Depending on the range of social protections and decommodified social goods offered within a particular society, SDOH such as income will 
determine the quality of other social determinants of health such as food security, housing, and education to various degrees. In Canada, public education until grade 12, necessary medical procedures, and libraries are de-commodified, while individuals are largely responsible for purchasing childcare, housing, post-secondary education, recreational opportunities, and retirement pensions. The point is that although education, employment, and income are commonly discussed as important determinants of health, the degree to which they influence health and one another is determined by broader public policy.

The WHO (2008) document, Closing the gap in a generation: Health equity through action on the social determinants of health sets out recommendations for addressing health inequity. At the level of daily living conditions, the report's recommendations include addressing barriers to education, investing in early childhood, applying urban planning and design that promotes healthy behaviours and safety; ensuring fair employment and decent work achieved by reducing precarious work, improving working conditions, and ensuring fair representation of workers in the development of national policy agendas; and enhancing social protection across the life-course through implementing universal and generous social protections. To address health inequity at the level of power, money, and resources, some of WHO's (2008) suggestions include advancing fair financing through progressive taxation and debt relief; ensuring market responsibility through the use of health equity impact assessments in economic agreements; and improving gender equity through legislation that would promote women's education and economic participation, as well as including women's economic contribution in national accounts and protecting sexual and reproductive rights.

The social gradient in health. Perhaps the most simple and cogent mode of representing health inequality and inequity is the social gradient in health. Several seminal studies such as the Black report, and the Whitehall studies have demonstrated the inverse 
relationship between class—indicated by occupational category or employment grade-and health—indicated by mortality or specific diseases such as coronary heart disease. In 1978, an expert committee chaired by Sir Douglas Black was commissioned by the then Labour government to produce a review of health inequalities for the Department of Health and Social Security in the United Kingdom. By the time of the report's completion, Margaret Thatcher's government was in power, and because the findings were unfavorable to Thatcher's neoliberal agenda, the report was famously (but unsuccessfully) suppressed by Thatcher's government. By reviewing long-term trends in mortality inequalities by occupational social class, Black and colleagues (1980) found that rates of age-standardized mortality per 1000 (England and Wales in 1971) for both males and females in class 5 (unskilled) are almost twice that of those in class 1 (Professional)—with males' mortality almost twice that of their wives' (OPCS, 1978: 37). This not only revealed a gap, but a gradient in mortality, as disparities existed between each of the five occupational classes. After considering alternative causal explanations, including artifact, selection, and culture, the Black report concluded that structural/material inequalities were the primary cause of health inequality. The broad-based policy recommendations made in the report, such as child-poverty reduction policies and increases in welfare benefits, were immediately rejected by Thatcher's government. Later, the 1987 report, The Health Divide, authored by Margaret Whitehead, would review progress in the seven years since the Black report, concluding that health inequalities had consistently grown during the 1980s. However, these findings and accompanied broad-based policy recommendations were once again rejected (Scott-Samuel et al., 2015: 60).

Around the same time as the Black report's development, Marmot and colleagues (1978) began leading the Whitehall studies. These longitudinal studies demonstrated an employment hierarchy gradient among approximately 18,000 British civil servants. Specifically, they found that employment grade was inversely related to coronary heart risk factors, and coronary heart 
disease mortality. This was again replicated in the Whitehall II studies which showed that even those high in the hierarchy faired less well than those even higher, with men in the lowest positions experiencing coronary heart disease three to six times higher than men in the highest employment hierarchy. Even though men in the lower employment grades were shorter, heavier for their height, had higher blood pressure, higher plasma glucose, smoked more, and reported less leisure-time and physical activity than men in the higher grades, the inverse association between grade of employment and coronary heart disease mortality was still strong when the influence of these factors on mortality were included. Therefor, Marmot and colleagues (1978) conclude that the occupational-class health gradient can only be partly explained by the established behavioural and biomedical coronary risk factors.

By using occupational category and organizational position as a means of approximating social class, we can say the Black report and Whitehall studies are neo-Weberian. Although material and structural factors were highlighted, the idea is that social hierarchies produce and/or exacerbate disease because low self esteem is associated with lower status. Showing that relative rather the absolute income is what matters, these studies led to a shift in attention away from purely material inequalities and absolute poverty or income to psycho-social status hierarchies.

Income inequality hypothesis. Moving beyond the demonstration of a health gradient representing the relationship between relative income, social status, and health, Wilkson (1996) made an important contribution by showing that the actual height of the gradient is shifted down when its slope is reduced. He finds that among wealthy nations, those nations with lower income inequality are healthier. From here, he develops the income inequality thesis to explain health inequalities between as well as within nations. Now taking income inequality itself is a determinant of health, Wilkson develops a theory in which income inequality is linked to social 
cohesion and health. He develops this hypothesis separately from his own empirical demonstration of the link between income inequality and health. To make this analytical leap, he uses secondary findings on the relationship between social cohesion and health. Aspects of social cohesion discussed by Wilkinson result as individual psychological manifestations (such as emotions, stress, helplessness, motivation, self-perception, and disrespect. Once confident about the relation between social cohesion and health, and between income inequality and cohesion, his theory is complete. ${ }^{3}$ This marks a theoretical departure from what would have otherwise been a descriptive account of the relationship between health inequality and income inequality based on epidemiological data. By implying that deficient social cohesion, indicated at least in part by income inequality, is the source of health inequalities, Wilkinson enlists a neoDurkheimian explanation (Muntaner and Lynch, 1999). This marks a sociological difference from the earlier Black report whose operationalization of employment categories can be read as Weberian.

By understanding income inequality in isolation from any political determinants, Wilkinson neglects considerations of class relations, thereby limiting its explanatory power and its ability to inform public policies aimed at reducing income inequality (Muntaner and Lynch, 1999). The problem is that Wilkinson's analysis focuses on income, but not the way it was generated through social relations. The significance of the modelled relationships between income inequality, social cohesion, and health is based on how income is used to consume various social goods-not on how income results from particular social relations (e.g., Wilkinson, 1996: 191, 211 as cited in Muntaner and Lynch, 1999). In Wilkinson's (1996) framework, one's class position is characterized more by their capacity to consume than by their

\footnotetext{
${ }^{3}$ While Wilkinson stressed the reduction of income inequalities as the principal piece of his policy recommendations, government administrations in the U.K and U.S. stressed the need for increased social cohesion as an alternative to reductions in income inequality (Muntaner and Lynch, 1990: 70).
} 
particular (social) relation to the acquisition of wealth. Wilkinson's model takes as its starting point that through some unnamed process, income is distributed unevenly, consequently affecting health. Without attending to how income inequality is produced, evidence-based actions cannot be directed toward anything higher in the causal chain. Conversely, various lines of class analysis seek to explain how relational positions in a social system generate income inequalities in the first place. For example, moneylender, landlord, manager, and worker stand for different positions in economic (social) relations which each generate various sources of income and income inequality (Muntaner and Lynch, 1999: 64).

Political economy of health inequality. If income inequality can actually be taken as a proxy for a number of socially determined conditions, then perhaps an emphasis on social cohesion as the solution is misplaced. The degree to which income is even socially relevant to health can vary across welfare states with different levels of de/commodification-the degree to which one can get what they need independently of the market (for example, through social insurance schemes or direct public provision of goods and services. ${ }^{4}$ For example, Muller (2002) finds educational level more important than income inequality in the USA (as cited in Coburn, 2004: 43). In contrast to Weberian and Durkheimian analyses, Marxian class-based explanations reveal the social mechanisms of exploitation that produce particular income distributions in the first place, and which become so important to health outcomes.

Several authors have pointed out this advantage of class-based, Marxian, political economy, or conflict, models over Neo-Durkheimian or Weberian models (Muntaner and Lynch, 1999; Coburn, 2004). Others have provided comprehensive, systematic reviews of research

\footnotetext{
${ }^{4}$ Different benefits schemes vary in what they include but also range from means tested and/or contribution based, to universal and/or multi-tiered universal models (Esping-Andersen, 1990). These are some of the metrics used by Esping-Andersen to categorize different countries' welfare states as either liberal-democratic, conservative/corporatist, or social-democratic. His typologies have been drawn upon to explore the political economy of health inequalities.
} 
analysing the relationship between political traditions/parties and welfare state characteristics, and population health outcomes (See Muntaner et al., 2011; Barnish et al., 2018). This literature is informed by a political economy of health, often employing welfare regimes frameworks and other historical and international comparative evidence within their analyses. Historically, leftleaning regimes and social democratic welfare states tend to have greater population health. Barnish and colleagues (2018) produced an updated systematic review of Muntaner and colleague's (2011) analysis, which includes an additional 100 studies ( $\mathrm{N}=176)$. This constitutes the largest systematic review of evidence in this field to date. Like the previous analysis, they review international comparisons of relationships between population health outcomes and one of four key political features (conceptualized as democracy, welfare state, political tradition and globalisation). The review concludes that welfare state generosity, left-of-centre democratic political tradition, and democracy are generally positively associated with population health. ${ }^{5}$ The distinctive feature of these studies is that they use more open models by including political factors, and by comparing different countries and time periods. These studies allow us to understand how different nations with different historically embedded class relations and institutional structures constituting their welfare states allow them to resist neoliberal doctrines to various degrees.

A more sociological analysis of the causes of inequality can be distinguished from a purely epidemiological description of the consequences of income inequality by taking unequal

\footnotetext{
${ }^{5} 77 \%$ of studies provided evidence that increased welfare state generosity was positively correlated with population health (this changes to $82 \%$ when economic factors are taken into consideration); $20 \%$ were inconclusive and $3 \%$ were negative. $88 \%$ of studies showed a positive correlation between left-of-centre political tradition and population health. $12 \%$ were inconclusive. $77 \%$ of studies addressing the democratic theme found a positive correlation between democracy and population heath. $18 \%$ were inconclusive and $5 \%$ were negative. Out of the studies addressing the globalization theme, $25 \%$ were positive, $25 \%$ inconclusive, and $50 \%$ negative. It should be noted that all globalization studies included data from developing countries.
} 
power relations between business classes and working classes within its purview of inquiry. This necessarily requires an interpretive or theoretical explanatory dimension. Single-country evidence such as that produced by Scott-Samuel and colleagues (2015) draw on a range of data to highlight the impact of Margaret Thatcher's policy reforms on health. Under Thatcher's tenure and her government's subsequent policy reforms, the wealth of the richest $0.01 \%$ increased from 28 times the mean national average income to 70 times between 1978 and 1990. Around the same time, between 1975 to 1985, poverty rates almost doubled in the UK from 6.7 percent in 12.0 percent due to welfare state retrenchment, high unemployment, and falling wages for many poorer workers (due to the decreased bargaining power of trade unions). Other key SDOH including inequalities in educational outcomes, housing tenure, and access to health care also dramatically grew during this time. Widening health inequalities and causespecific mortalities such as alcohol- and drug-related deaths, suicide, and violence increased during the same time period in which key SDOH such as unemployment, poverty, and income inequality all rose. In contrast to the improving trends in other parts of Europe, these causespecific deaths increased dramatically during the late 1980s and early 1990s in the UK. These particular causes of death are clearly socially produced rather than due to biological or physiological mechanisms (63).

More recently, other critical public health scholars have looked at how macro economic policies such as trade agreements influence the distribution of money, goods, services and quality of daily living conditions, which can ultimately impact health equity within and between countries (Townsend et al., 2018). These researchers looked at how policy actors frame their interests in order to shape government priorities related to the Trans Pacific Partnership agreement. By analyzing submissions from industry actors, non-profit organisations, unions, researchers, and individual citizens to the Australian government during treaty negotiations, this study's approach provides valuable insight into what the competing agendas across policy 
communities and interest groups are and how they are deployed. By taking unequal power relations and competing interests within their field of inquiry, this study offers a more sociological analysis of the causes of inequality rather than a purely epidemiological description of the consequences of some measure of inequality.

Whereas the Black report and Whitehall studies revealed a health gradient showing the significance of income and status, and Wilkinson's work showed the significance of income inequality itself on health outcomes and the slope of the gradient, others explain why the slope and population health outcomes would be different. These are the result of ideological forces and unhealthy public policy which are empirically located in countries with less generous welfare regimes, right of centre political histories, and weaker democratic functionality. Although the political-economic determinants of health are well established, they have been edged out of public health discourse and policy action along with the critical sociological approach which, rather than describing distributions of outcomes, analyses the causes of health inequality. This exclusion can be traced to shifting rationalities within the government of public heath.

\section{Shifting Rationalities in Public Health}

This paper treats health equity as an historically conditional idea whose current form and productive capacities are conditioned by previous discourses and the socio-political and economic conditions in which they were formed. To this end, it is important to sketch out a brief history of changing public health discourses and practices in Canada and their relation to legitimate ways of knowing. This history marks a shift away from working class political movements, to lifestyle approaches, health promotion, and finally to population health. The most recent transition from health promotion to population health is accompanied by a shift from critical political rationality to quantifying and ostensibly neutral rationality. 
Robertson (1998) critically examines this shift from health promotion to population health as a guiding discourse for public health policy and practice in Canada. Following an era of lifestyle focus which was critiqued for victim blaming, a new health discourse, 'new public health' or the 'new health promotion' emerged. Health promotion traditionally supports broad-based policy changes ('Healthy public policy') including local economic development, progressive taxation, and directing resources toward housing and employment. Furthermore, health promotion challenges the dominance of economic rationalism in public policy. ${ }^{6}$ In contrast to economic rationalism, health promotion permits theorizing the role of power in relation to health (Labonte, 1997: 10). It also maintains an explicit concern with values and a vision of what type of society, economy, and political system is preferred by whom and why (10). Health promotion's concern with wider experiences of well being, meaning and purpose, and contentment further distinguishes itself from its successor's focus on crude indicators of physical functioning such as morbidity and mortality risks (10). The new health promotion discourse was expressed in documents such as The Epp Report (Health and Welfare Canada, 1986) which explicitly recognizes that health is affected by factors outside of health care, including poverty, unemployment, poor housing and other social and economic inequities. Health promotion did not represent a new discourse as much as it did a return to an earlier era of public health in the late 19th century characterised by social reform (Robertson, 1998: 157). However, in the early 1990s, this structurally oriented health promotion guided by political rationality becomes replaced by a 'population health' research paradigm guided by a technical and seemingly neutral rationality.

\footnotetext{
${ }^{6}$ This contemporary predominance of economic rationalism stems from liberal values espoused by enlightenment philosophers such as Locke, Hume, and Bentham, among others (Labonte, 1997: 9). These liberal enlightenment philosophers maintained that rational individuals pursuing their own economic gain would benefit society as a whole, and that the state's regulatory role ought to be minimal (9).
} 
The ascendancy of population health carries a shift in models of knowledge production. This shift marks a return to a reductionist epidemiological explanation of health which is now fused with economic rationality (158). This new era of public health discourse and practice as population health grew out of the Canadian Institute for Advanced Research (CIAR) which is primarily made up of economists and epidemiologists with little representation from health promotion or public health professionals (158). In contrast to health promotions' explicit focus on experiences of wellbeing, explanatory theory, and above all, society, including power relations, the economy, political systems, and public policy in relation to health, population health exclusively relies on epidemiology, employing quantifiable biomedical indicators to produce statistical descriptions of systematic differences in the average health of populations of different regions, occupations, and education levels (Labonte, 1997: 11).

Population health is an internationally influential model developed within CIAR, with significant development contributed by Canadian health economists Robert Evans and Greg Stoddart of the CIAR. In 1991, Evans and Stoddart published a highly influential paper in Social Science and Medicine (Evans and Stoddart, 1990) entitled, Producing health, consuming health care. This paper laid out what were to become the central features of a newly emerging discourse on health, namely, population health. They invoke the relationship between overall health, measured as life expectancy, and economic growth as measured by gross national product (GNP). ${ }^{7}$ Population health's early proponents' major recommendation for improving health outcomes was to take money out of the health care sector and place it in the 'wealth producing' sectors of the economy to increase GNP (Robertson, 1998: 158). The assumption is that any increase in GNP will improve overall (average) levels population health (158). Evans

\footnotetext{
7 This was identified by Wilkinson, $(1990,1992)$, although he later shows that beyond approximately $\$ 5000$ GNP per capita, it is it health differentials within countries rather than wealth differentials between countries that matters to overall population level health.
} 
and Stoddart's argument is grounded in the McKeown thesis (see McKeown, 1979) which theorizes the health of populations as largely determined by factors outside of health care in the wealth producing aspects of the economy.

Conditions in which population health emerged. The ascendency of population health must be placed within the context of the rise and fall of the welfare state in the postWorld War II period. Universal health insurance was the last major addition to welfare before the Canadian government's roles in regulating the marketplace, and in creating new welfare measures were severely circumscribed by international treaties such as the Free Trade agreement, and later, NAFTA (Poland et al.,1998: 794). In other words, these trade agreements placed new limits both on governments' abilities to regulate markets, and on their capacity to ensure citizens' welfare independently of their ability to perform in the market. These policy attributes were largely the result of businesses and conservative groups in the 1980s who were able to successfully influence trade policy and broader socio-political culture (794). This new sociopolitical culture placed government deficits and debt, shrinking revenues, deferred corporate taxes, and welfare state costs at the centre of political discourse and economic policy (794). The erosion of the welfare state took place in a period of economic recessions, internationalization of capital, weakened union movements and left-movements generally, and the rise of neoliberal ideological forces in Canada, including the Business Council on National Issues, the C.D. Howe Institute, and the Fraser Institute (794). These groups, in addition to mainstream media, naturalized the inevitability of welfare retrenchment (794). This context is relevant to the discussion of population health because it was in this context in which CIAR was founded in 1982 out of 
a concern that Canada was "falling behind other industrial nations" and needed to "boost its innovative capacity" (CIAR, 1993 in Poland et al., 1998: 795)

Critiques of population health. Although population health and health promotion agree that increasing health care expenditures does not necessarily produce more health, they differ in their epistemological and theoretical assumptions and related policy implications. Many who have applauded Evans and Stoddart for bringing attention to broader determinants of health which lay outside of health care and the biomedical field also take issue with how the problem and solutions are framed (Poland et al.,1998; Robertson; 1998; Coburn et al., 2003). The most fundamental critique of population health is that Evans and Stoddart present an oversimplified relationship between wealth and health which lacks any reference to theory of society and of social change, or how social forces reproduce poverty, inequality, and injustice. While it is purportedly politically neutral, its ambivalence to social relations leaves it open to conservative interpretation and cooptation.

Pluralist notion of power and knowledge translation. Underlying the assumption that wealth equals health irrespective of any planned distribution is the presumption of a balanced diversity of interest groups in which the common good prevails through democratic processes. This pluralist notion of power and knowledge translation fails to consider how unequal conflicts over interests compromise public health, and how political struggles have historically brought about and could continue to bring about healthier societies. ${ }^{9}$ Critical public health scholars

\footnotetext{
${ }^{8}$ The reason why CIAR is relevant, is because Evans and Stoddart's seminal population health work grew out of the CIAR's programme in population health, centred on the relationships between wealth and health, and was financed partly by the Honda Motor Corporation (Poland et al., 1998: 795).

${ }^{9}$ Neither does it consider how political struggles in which neoliberal parties prevail have made societies less healthy (See Scott-Samuel et al., 2015).
} 
assert the importance of considering social context as an essential determinant of health because it helps us understand why some groups' interests supersede those of others.

"We start by assuming that Canada is a capitalist society with a specific history and a particular location in the continental/world capitalist economy. In this context, the drive for profit (capital accumulation), the class and patriarchal nature of Canadian society, the particular role of the state in Canada, and Canada's role vis-a-vis the United States and "globalization" requires consideration" (Poland et al.,1998; 793).

This attention to historical context and broadly interdependent and dynamic social relations stands in contrast to Evans and Stoddart's preconception of a pluralist interest group perspective of power. The pluralist perspective of power does not help us understand why some groups' interests are served over others. Against this inadequate perspective, we must understand the SDOH as "those forces that produce both a particular distribution of 'interest' within the health system and which determine health inequalities more broadly" (794).

Population health is also critiqued for carrying implicit assumptions about the way in which knowledge is translated to policy (Coburn et al, 2003). This implicit theory of social change is seen today in PHAC's statement that "[a]ction on social determinants of health and health equity can be strengthened through stronger partnerships and integration across science, practice, and policy" (2018: 429). Without considering the interplay of unequal power relations and competing group interests, science will not inevitably lead to policy action on SDOH and health equity, and neither will economic growth.

GNP vs (in)equality. Poland and colleagues (1998) argue that we must theorize distributions of health status as parts within a larger interrelated system of advanced industrial 
capitalism. Without theorizing how inequalities are reproduced, it is dangerous to assume that the savings accrued from defunding health care would necessarily be reinvested into socially protective areas. The question that they say is crucial to address, which population health does not, is this: 'Why pursue wealth generation unless fundamental mechanisms for distributing that wealth are also addressed?' (791). This is an important political question because an emphasis on economic growth which does not explicitly attend to its distribution is misplaced, given its diminishing 'health returns'.

Research shows that in developed nations, inequality is a more important factor than overall economic growth in determining population health. As Poland and colleagues (1998) point out, a look at Wilkinson's $(1994,1996)$ findings shows that population health gains resulting from economic growth plateau between $\$ 3000$ and $\$ 6000$ GNP, after which the degree of income inequality most closely correlates with higher population health. The same researchers provide examples showing that even at lower levels of national prosperity, equity profoundly effects population health. McKibben (1996) notes that in Kerala, one of the poorest states in India, where average income is around $\$ 300$ per year, life expectancy is close to that of the U.S.A. (70 vs 72 for males). McKibben (1996) attributes these numbers to structural reforms in its political economy following the election of a progressive government that improved literacy, political participation, health service utilization, equalization of income, female participation in the work force, pensions, and other social security benefits. These structural reforms also addressed sources of negative health effects, including the rigid caste system, and child labour (790). ${ }^{10}$ If Canada has long since surpassed the level at which GNP per capita correlates with health status, public policy should focus on equitable wealth distribution and not

\footnotetext{
${ }^{10}$ As I will discuss throughout this project, addressing these 'negative' structural sources of inequality are far more neglected than attempts to focus on 'positive' assets and strengths, promote 'positive mental health', and produce active and empowered communities, in addition to expanding service utilization.
} 
simply wealth generation. This requires engaging in political reasoning and deliberation with a consideration of how power relations and competing group interests influence social change.

Inadequate theory of social change. Neither McKeown's work or that of CIAR consider the role that human agency and lower-class struggles have played in improving conditions of decent living, or the role that the opposing forces of the dominant classes have played in opposing these improvements (Poland et al., 1998: 788). Historically, advances in health can be attributed more to political action and social reform than to biomedical advances or economic growth (Szreter, 1988). Critical public health scholars assert that political actions of market and class coalitions, respectively, have shaped both inequalities and the structures designed to eradicate these inequalities (Tesh, 1988; Labonte, 1997; Poland et al., 1998; Robertson, 1998 Coburn et al., 2003). We cannot view the healthcare system either as a natural result of modern progress. Its genesis must be understood in relation to the welfare state and its relation to capital accumulation and political-ideological struggle. Taking the Canadian example of universal health care insurance, it is significant that it was initially strongly resisted by elites and was only eventually achieved through political struggle led by labour (792). In 1971, health insurance was won after 52 years of political struggle led by provincial and national workingclass political parties, the CCF/NDP (Taylor, 1978; Maioni, 1995; Swartz, 1977 cited in Poland et al., 1998). However, beginning in the early 1980s, and continuing into our contemporary period, the autonomy of nation states and their ability to extend welfare benefits are challenged by powerful transnational business interests seeking to reverse Keynesian economic policy and to dismantle the welfare state and labour market policies (794). In view of these historical antecedents to the rise and compromise of health reform, and the increasing influence of market ideology on the general erosion of social programmes, we must adopt a political economy perspective that explicitly accounts for class politics behind policy. This is particularly important if we are to lend any explanatory power to our models of knowledge production. Explaining why 
an inequality exists is the most fundamental task required for identifying and acting on health inequities - a task which today's public health institutions neglect, despite their wide invocation of health equity. I argue that this neglect is not due to ill will on the part of those working in public health, but to the models of knowledge production that have became normative in a techno-cultural sense, and which have become necessary to comply with to meet the various institutional requirements for neutral and quantifying data.

Considering then that historically, the greatest advances in health can be attributed more to political action and social reform than to biomedical advances and that greater GNP does not naturally result in greater population health or health equality (Szreter, 1988; Wilkinson, 1996; 2009), and that we are in economic and sociopolitical conditions which compromise public health, it is imperative that we grapple with politics, values, and competing group interests seriously. Despite the cogency and urgency of this perspective, it remains outside the what is now the legitimate purview of public health. As historian of science, Barabara Rosenkrantz remarks, beginning in the mid-twentieth century, a paradigm shift occurred, emphasizing biomedical interventions based on empirical evidence, and discrediting social reform as "subjective and politically tainted" (as quoted in Henig, 1997).

Eschewal of theory and values: Data unites theory divides. The CIAR model of population health does not just represent a shift away from upstream determinants of health. It represents a more fundamental shift in rationality. Population health models are critiqued for having 'atomized social pathology of social and economic inequity, effectively masking the social, economic, and political forces that perpetuate inequity' (Poland et al., 1998: 791). This model of research locates plausible biological and psychological mechanisms to explain the relationship between class and health while ignoring mounting evidence that class, as a social relation, is a powerful determinant of health (791). Although a theory of social change that takes 
political power into account is important, it is rejected by proponents of population health and excluded from its models of measurement and representation. To appear neutral, population health remains descriptive but not analytical:

"In the numerous conferences he attends to discuss the CIAR perspective, one of Robert Evans' frequent observations is that "data unites, theory divides". The implication is that inquiry can be value-free, and objective, that there is a single knowable "truth" or reality "out there" awaiting discovery, and that data determines theory in its totality" (792).

The problem with this belief that facts speak for themselves is twofold: For one, because researchers must ultimately choose what to include and exclude from their analyses, an incomplete representation of reality will always result. Even though it is merely descriptive, this representation is always incomplete, and so any eventual analysis and action based on this incomplete representation will be shaped by what it includes as much or more as by what it omits. Secondly, there is often an implicit social theory which is present but not engaged with because the mere possibility of its existence is denied. As a result, when one moves from description to proscription, underlying implicit assumptions about how the world works (its interpretive components) are not critically engaged with (Robertson, 1998). Interestingly, Poland and colleagues (1998) note that the popularity of this mode of knowledge production lies in this very ambiguity and ostensive neutrality, as it allows diverse actors with their own interests, constraints, and interpretations to support the vision of greater population health.

Inherent in the notion that theory 'data unites, theory divides' is the assumption that knowledge and its production are separate from politics or morality (Robertson, 1998), but as an asocial and putatively neutral research and policy paradigm, population health strips away the 
context in which unequal interests compete, some prevailing, negatively affecting health, allowing the unhealthy status quo to continue (Coburn et al., 2003). Rooted in natural sciences, the population health model of knowledge production assumes the social world can be separated into isolated variables, and that by correlating them with one another within a closed system of relations, one can produce an accurate representation of the real world. This necessarily partial and closed model excludes and implicitly fixes the broader conditions actively structuring the examined relationships between variables. These static representations of the world shape and limit what is imagined as possible, producing a constrained idea of social change. In order to push beyond the conceptual and methodological limits of population health models, "we need to develop analyses that not only demonstrate the relationships between variables but tackle the social processes that produce them. That is, we must incorporate the broader context of politics and economics into our analytical models" (394-5).

Although population health incorporates socioeconomic status (SES) into its models, the proxy is critiqued for only representing a simple ranking of individuals by income, education, or status while failing to represent relational and structural characteristics of society (Coburn et al., 2003: 95). As a result of this lacuna, social processes that underlie empirical measures of social inequality and health are excluded from the field of inquiry. Examining these social processes underlying empirical indicators would help us understand 'why some capitalist countries with strong social democratic political parties and welfare states have lower health inequalities and higher average population health than Canada or the U.S.A.' (394). ${ }^{11}$

\footnotetext{
11 This rationalist model also has policy implications: If we do not have available analyses of the cause of social problems, we are left without a way to assess competing claims among political actors that their programs will improve health (Coburn et al., 2003: 392).
} 
Against all of the critiques, there is a governmental and organizational advantage to abstaining from open models of knowledge production and interpretation. Robertson (1998) suggests that by privileging unity and closure over difference and openness, population health produces reductive but tidy representations of reality. If inherently social and moral problems of human needs can be framed as technical problems to be addressed through objective scientific knowledge, then we can avoid the messiness of political and moral reasoning. Political scientist Deborah Stone (1988) calls this 'the rationality project'. This can be looked at as an extension from enlightenment era thinking when scientific reason was inserted into public reason as a way to curb arbitrary and corrupt government decision making (See Porter, 2006). I argue that this appeal to closure and unity produces conditions of possibility that are contained by its own imposed walls of understanding. The flexible field of practice is created by this technical closure which mystifies the causal weight, direction, and genesis of various factors which are all represented independently of the welfare state and government decision-making. I theorize equity as an 'empty signifier' which works within a system that privileges unity and closure to the effect of scientific certainty and precision, but at the cost of accuracy and theoretical explanation. When the flexible, mobile, and 'empty' concept of equity is mobilized within a field of practice whose possibilities for action are structured by technically produced representations of reality characterized by closed, but diversely interpretable asocial associations, the various associations can be targeted to achieve any one of the many equally legitimate ideas of equity through disparate actions.

\section{Research Questions}

Against this backdrop of scientific rationality and neoliberalism, we see the term 'health equity' broadly invoked across public health discourse. In light of the dominance of quantifying and ostensibly neutral rationality in public health, and the prevailing neoliberal conditions in which it operates, the central research question that guides this study is this: 
- How is health equity, a normative moral idea, variably accommodated discursively and practically into public health discourse and practice?

In terms of accommodation, several sub questions direct the trajectory of this study:

- How does the actual practical deployment(s) of equity compare to some idea(s) of social justice as conceptualized in normative ethics theory?

- What role might normative ethics play in lending some concreteness to a more consistent, transparent, and socially and ethically meaningful commitment to health equity? What might the existing barriers be?

A key part of understanding how the concept of health equity is accommodated requires analysing what is not accommodated, and how these lacunae reproduce what is and what is not present in discourse and action around health equity. The following questions were developed to yield insights into these issues of exclusion and discursive production:

- How does equity operate as an empty signifier and vehicular idea? And, what does this produce?

- How do evidentiary norms and technical modes of representation produce and preclude particular ways understanding inequity both as an empirical phenomenon, and as a normative ethical problem? And how does this produce and preclude means of correcting it?

- What is represented as static and as dynamic in public health discourse and models of knowledge production?

- How do evidentiary imperatives sustain ideology ${ }^{12}$ and the incessant deferral of policy action aimed at health inequity?

\footnotetext{
12 By ideology I mean the symbolic relations - consciously engaged with or not - that stabilize and perpetuate relations of power and domination by obscuring their full content, operation, and effect. This incomplete and legitimate representation of reality naturalizes particular social relations and their effects while masking others' existence altogether. It is the relational and productive processes that produce a particular understanding of the world. This is especially relevant to this project's framework which pays critical attention to how action is not just
} 
- How is health equity instrumentalized? What is the instrumental relationship between health equity and other goals, rationalities, standards, and values?

- How is community engagement (and the deployment of the concept of health equity in public health generally) a discourse/practice which reconciles the difference between the neoliberalism and the positivist field of public health, and public health's socialdemocratic commitment to the common good?

These questions address the interplay and interdependence of values, knowledge, and discourse. Answering these questions requires us to look at the discursive attributes and treatment of equity as a mobile and 'empty' idea. It also requires us to look at the specific attributes and logics of knowledge production used to objectify and legitimize the targets of health equity action. This line of inquiry requires us to look at how the way we discuss health equity and health inequity are shaped and constrained by not only the discursive attributes of equity, and not only the models of knowledge production that produce a particular account of health in relation to its social determinants, but also those institutional and cultural norms and imperatives that reproduce the imperatives for particular forms of evidentiary support and productivity which have become so important for producing a legitimate understanding of a public problem, and a legitimate strategy for acting on it.

\section{Chapter Overview}

The next chapter provides an overview and defense of my sources and the methodological approach I employed to analyse them. Here is where I defend my exploratory methodological approach, my particular use of discourse analysis, and where I outline what I

contingent on material resources and a presence or absence of coercion, but on what is knowable and thinkable, and on those conditions that produce the possibility of something to be knowable and thinkable. The symbolic relations that sustain and are (re)produced by this system of legitimacy, representation, and possibility, are what I mean by ideology. 
attended to and why this was a productive approach for yielding insights into my research questions. Chapter Three draws on theories and concepts from normative ethics theory and health justice scholars to provide an overview of possible groundings for the social justice component of health equity. In addition to providing a theoretical and conceptual background for understanding the different ways that equity-as-justice can be understood in relation to public health, I explain the interdependence of the in/completeness of knowledge and realization of particular values pertaining to fairness in health.

Chapter Four reviews the existing literature on the deployment, function, and understanding of health equity as an ethical and practice-guiding value in Canadian policy documents. Chapter Five continues the secondary analysis of the studies reviewed in the previous chapter to highlight some of the barriers to progress on health equity.

I theorize the sheer ubiquity of health equity as well as the inadequacy of its disparate, proactive, but not counteractive action as a result of the infinitely extendable field of legitimate discourse and practice around the idea and signifier that is equity. Equity's capacity for successful extension and mobility is thoroughly addressed in Chapter Six where I provide an indepth analysis of health equity as an empty signifier, and as a vehicular idea. I argue that engaging with normative ethics allows public institutions to impose some concrete content on the idea of equity thereby reducing its capacity to function as an empty signifier. But as I show in chapters seven through nine, we must also transform the evidentiary norms and imperatives that shape and limit what kinds of normative ethical ideals are possible to work toward.

In Chapter Seven, I highlight how an institutional incapacity to understand the actual problem of inequity hinders capacities to achieve an ethically consistent and socially transformative goal of equity. This chapters draws upon the model used by PHAC to objectify 
the problem of health inequality. I describe how this operates as a closed model which conflates the determinants of health with the effects of the determinants of health. I then criticize the PHAC model for leaving visible and operable a flexible yet limited range of health inequity's precise, but meaningless locations. In Chapter Eight, I further analyse the PHAC publication, Key health inequalities in Canada: A national portrait (2018) to show how actual and potential actions for tackling health inequities and ameliorating SDOH are evaluated and represented in public health discourse. I analyse how evidentiary imperatives, productivity, and norms around what counts as evidence shapes the extent to which interventions are represented as actionable. I also draw from the entire catalogue of health equity interventions listed in the PHAC's best practices portal—and where possible, interventions' respective evaluation processes and outcomes—to further corroborate my argument that evidentiary requirements for interventions to be amenable to scientific evaluation results in a dearth of upstream interventions which would require political reasoning and argument. I argue that the large number of rather downstream interventions exist not only because they are socially nondisruptive, but because they are compatible with dominant modes of evaluation. In the final chapter preceding the conclusion, I look at how the value-laden, but empty and non-disruptive language of community inclusion and empowerment function as an optimistic nodal point in health equity's discursive and actionable extension which is implicated in the simultaneous diffusion and containment of collective action and progressive sentiments. 


\section{Chapter 2: Sources and Methodological Approach}

This chapter outlines my sources, defends the relevance of my selection, and provides an overview of my methodological approach and theoretical assumptions.

\section{Sources}

- PHAC (2018) Key Health Inequalities in Canada: A national portrait

- $\quad$ CIHI (2018) In Pursuit of Health Equity: Defining Stratifiers for Measuring Health Inequality

- Ontario Health Equity Guidelines (2018)

- NCCDH provincial case study documents

- PHAC Best and Promising Practices Portal

- Programme websites linked from best and promising practices pages

- Canadian Prenatal Nutrition Programme (CPNP) Evaluation

Public Health Agency of Canada's (2018) document, Key Health Inequalities in Canada: A National Portrait was developed as part of the Pan-Canadian Health Inequalities Reporting Initiative. This document was selected because it offers a national perspective, but also because it has several chapters relevant to my study of how SDOH and health equity are objectified. These include the following chapters: Health determinants-Daily Living Conditions, which includes subsections on health behaviours, and physical and social environment; Health Determinants-Structural Drivers, which includes subsections on early childhood development, and social inequities, with further subsections related to housing, food insecurity, and working poor Canadians. These chapters were particularly important for answering research questions related to how public health institutions produce knowledge used to understand and act upon 
health inequities, and how this mode of knowledge production shapes, enables, and limits actions and understandings of health in relation to its social determinants. Finally, PHAC's (2018) discussion and implications chapter is highly relevant for providing insights into how various health equity interventions are rendered actionable or inoperable in public health discourse. The $\mathrm{CIHI}$ (2018) document was also useful for addressing these questions related to technical modes of representation because it provides insights into how health inequity is identified through the use of various constructs known as health equity stratifiers. This document is particularly useful because it discusses the criteria and reasoning behind the construction of each equity stratifier. The 2018 Health Equity Guidelines were selected not only because Ontario is Canada's most populous province, but also because the analysis of the new 2018 documents permits a supplementary analysis to previous analyses of the 2008 Ontario Public Health Standards. NCCDH case studies were useful for providing accounts of how equity is discussed and practiced at regional levels. This was important because of the regionalized character of public health in Canada, and health equity interventions. The PHAC Best and Promising Practices Portal, and the websites linked from it and the CPNP evaluation became crucial sources which I used for drawing out and analyzing examples and attributes of legitimate health equity interventions. These sources were also used to examine how the legitimacy of health equity interventions are related to their evidentiary productivity. These sources were also used for analyzing the processes, content, and absences within evaluations.

\section{Methodological Approach}

My first stage of analysis loosely followed an open coding process. This involved reviewing the primary documents for examples of how the idea of health equity is conceptualized as a goal, and how it is put into practice. This review sensitized me to any recurring concepts or practices that are invoked alongside or in relation to health equity as a goal. For example, 'gathering evidence'; 'surveilling'; and 'measuring' were recurrently identified and subsequently interpreted within their context as part of a practice. Other words such as 
'local'; 'inclusion'; 'community'; and 'advocacy' were also apparent. These were separated into a theme of community. In subsequent readings, I looked for how these different themes were used as parts of strategies, enacted within contexts characterised by systems of constraints. This was key to my general approach to analysis and required me to attend to any discussion of barriers or constraints. It became clear that having 'the right evidence' is integral to action on health equity. As a strategic practice, operating within a system of constraints, some of the words I noted included 'performance indicators'; 'evidence-informed recommendations'; 'synthesize scientific evidence'; 'quality standards'; quality standards'; and 'data limitations'. Selections such as, 'soften the harsh impact of wider social exclusion and inequality'; 'take account of the long-standing and deep-seated nature of social and economic inequalities'; and 'high quality care that is fair an appropriate' led me to develop the initial theme of 'recognizing ${ }^{13}$ and mitigating injustice'. Community and inclusion were discussed as a goals, but community was also discussed as a site of intervention and production. Some codes such as 'sustainability'; and 'communicating' were identified but discarded when they did not either confirm or counter emerging themes. In terms of the goal of equity, I considered formal definitions, but I also looked into the contents of strategies for echoes of normative ethical concerns or orientations. This preliminary open coding phase, combined with a review and analysis of the literature, sensitized me to what was relevant. This interpretation of the literature guided my subsequent exploratory round of analysis. Subsequent analysis beyond this initial open coding phase did not follow any systematic, grounded approach. Therefor, it is important for me to account for how I approached the texts.

A Roadmap to my Logically Directed Exploratory Approach. I approached the above documents and relevant literature on health equity in a particular way which diverges from a

\footnotetext{
${ }^{13}$ By recognizing, I mean the mere token acknowledgement. This never translated into structural change beyond cultural sensitivity in service delivery.
} 
systematic, grounded approach. I took a more exploratory route led by interpretations of existing research findings. Part One of this project directed my location of inquiry in Part Two. This project did not start out by searching for how evidence is mobilized in relation to health equity. I started by merely looking at how equity was understood and practiced, and how this diverged from, matched up with, and/or fell short of different normative ideas of justice. After reviewing the empirical literature on how health equity is deployed in Canada, key barriers were identified. First, this involved the flexibility and inconsistency of the concept of health equity as it is articulated in public health discourse. Secondly, this involved evidentiary barriers related to the imperatives of EIDM.

After concluding that evidentiary imperatives are a barrier to reducing inequities by addressing the $\mathrm{SDOH}, \mathrm{I}$ turned my attention to how evidence is made, and how particular features of the models objectify the problem of health inequality in a certain way (because health inequality the main phenomenon that people in public health are trying to comprehend as a way to understand health inequity). Again, following my previous secondary analysis of others' findings that upstream actions are difficult to implement and evaluate, I looked at how upstream actions are represented by PHAC. This line of inquiry led me to examine what is represented as actionable. One example cited in the PHAC document was discussed as a best practice, so I searched for more best practices. This led me to PHAC's Canadian Best Practices Portal. From here, I examined those practices and their attributes. I needed to account for why some are inactionable and why some are not, so already having identified reasons discussed in the PHAC relating to evidence and evaluation, I analysed the attributes of the actual evaluation outcomes of the various best practices. From here, I was also able to locate one primary evaluation document for CPNP to gain a more comprehensive understanding of how a programme based in a commitment to health equity is evaluated. I was able to compare attributes of actual best practices and those of more structural interventions in relation to their amenability to this type of 
evaluation. This allowed me to provide some explanation as to why we are left with what we are left with when we accept the current evidentiary threshold used for designating a legitimate practice.

Discourse as a mode of representation and reproduction. Critical discourse analysis is a research method that carries several theoretical assumptions about discourse, knowledge, and power. Critical discourse analysis is a productive method for yielding insight into my research questions because its theoretical import deals with issues of representation and power. As a mode of representation that shapes and limits our understandings of the world, discourse is a social practice which is both structured and structuring. As such, discourse analysis is useful for examining practices of representation. In this study, I ended up looking at both the discursive elements of representation as well as the technical quantifying processes of representation that objectify health inequity and our responses to it. This was an unexpected aspect of this project which became necessary as the link between evidence, discourse, and practice around health equity became clearer and more meaningful as this project went on.

The reason why discourse analysis is appropriate for this study is because of my attention to a particular conception of power and ideology. The theoretical foundation of critical discourse analysis stems from a relational conception of power that operates between the production, distribution, and consumption of discourse in particular social contexts (Fairclough, 2014: 9). Under this view, power operates by sustaining discursive practices to the effect of sustaining a particular set of relations, ideology, and interests. Secondly, by sustaining particular social imaginaries, alternative practices and perspectives are subjugated without having to even engage with them, let alone coercively suppress them (2). And so, analyzing absences is just as important as analyzing what is present in text (5). Attending to the blind spots in the regimes of knowledge production that make health equity knowable and actionable was a key part of my 
analytical approach. However, the way in which I use critical discourse analysis departs from Norman Fairclough's conception of it.

Typically, in critical discourse analysis, the general objective of analyzing textual data is to analyze how language is involved in contemporary capitalist society (Fairclough, 2014: 1). This is an important objective of my analysis, but I do not limit my analysis to relations between linguistic discourse and capitalist relations. Beyond the historical context of health equity, public health, and social science more generally, I speak very little about health equity in relation to neoliberalism as an agenda which is willfully advanced by, for example, conservative think tanks, lobbyists, and other like-minded political actors. ${ }^{14}$ Although these are all impactful sources of neoliberal influence, I pay attention to how technical modes of representation and closure reproduce ideological effects through seemingly neutral, technical processes, ultimately manifesting in the ways we understand, discuss, and work toward a particular conception of equity-as-social justice. Central to this conception of ideology are the incomplete or inaccurate representations that stabilize a particular understanding of social relations, closing off alternative possibilities of knowing and changing them. This specific conceptualization of ideology requires incomplete representation of some aspect of reality or a phenomenon. This is crucial to understanding politics and power. We need to understand how incomplete representations are

\footnotetext{
${ }^{14}$ Ideology can also be described as a set of ideas and ideals - that is, ideas about how things are, and how they ought to be, which are constructed by a set of normative beliefs and values. One could say that neoliberal ideology encompasses a belief that people are rational and naturally competitive, in addition to values placed on the normative idea that people ought to be competitive, that markets should be as unregulated as possible, and government as small as possible. Under these conditions, people ought to compete and take responsibility for improving their own lot in life without help from government or society. This definition is not at odds with my use of the term, ideology. However, I would argue these aspects of the neoliberal idea and ideal are actually successfully manifested ideological sentiments. We can think about this kind of ideological effect as distinct from ideological process. I recognize that this is potentially thorny ground given that ideology, as a discursively embedded phenomenon, is necessarily reproductive. Indeed, I would not reduce ideology or discourse to an effect or an origin, but it is analytically useful to identify those easy-to-miss points where ideology is sustained through particular configurations of constraints and practices that are not ideologically driven and therefor, not ideological in and of themselves, but in their effects.
} 
produced in the first place, how they are reproduced by evidentiary imperatives and norms, and what the effects of this are.

Any study which requires attention to absence and partial accommodation requires some broader knowledge of whatever it is that one is studying in order to recognize that it is partial in the first place. In other words, an analysis of absence requires a theoretical framework for understanding absence, partial accommodation, and the power relations that make incompleteness possible. This is why a grounded approach would not be productive given this project's purpose. This point draws from the following insight put forward by Rosiek and Heffernan (2014):

When a coherent interpretation of a phenomenon is lacking within a community or is suppressed by social power dynamics, a mere description of the lack is not very informative. An analysis of what prevents the community from forming a coherent view of a phenomenon is needed to inform action and intervention" (730).

In other words, researchers have to go beyond describing what is present and absent, and to account for this we must attune ourselves to power relations which pre-structure people's understanding and resultant actions. This task requires some amount of theory or knowledge of wider social conditions and power relations to direct the researcher's interpretation, but only if used tentatively and reflexively. A purely grounded critical discourse analysis is neither useful or possible, regardless of its systematic and objective appeal. A systematic, grounded content analysis would not be appropriate given the goals of my research, however I am careful to steer clear of theoretical imposition. 
As stated, this project's design followed a secondary analysis of others' findings which allowed me to identify important issues to further explore. These issues relating to the mobilization(s) of equity under a regime of evidentiary norms directed me to particular objects of inquiry. I take as a starting point that it is not possible to free oneself of preconceptions in the collection and analysis of data and nor is it necessarily desirable. This would limit my study to description. It is my intent to go further in looking for and theorizing what is and what is not present in discourse, and how this discourse is productive in shaping the conditions for possibility, inevitably excluding and including particular courses of thought and action. Initial readings of texts and prior theoretical knowledge sensitized me to parts of the text which were subsequently made meaningful through further analysis. I avoided theoretical imposition and atheoretical description. This meant using apriori theory to make sense of the data, but equally, using the unravelling logic of the data to change prior lines of interpretation (Thorne et al., 2004:11). For example, when analysing how upstream actions are represented by PHAC, I noticed that different actions were represented with different amounts of decisiveness. At this point, I considered the following question: How are these differences situated within a field of practice whose constraints are either implicit or explicitly stated within this text? By allowing this question and my existing knowledge of the historical functions of scientific reason in public reasoning to direct my interpretation and understanding of what is relevant, I was able to make decisions about what to analyse next. Since exploratory decisions were influenced by the unravelling logic of my interpretation between myself and the text, my study is not systematic, but it is logically and reflexively directed.

What I attended to, and how I situated my objects of inquiry. My analysis of the deployment of health equity followed a particular line of inquiry in which I paid particular attention to relational processes of constraints, strategies, and closure. This helped me understand not only what is happening, but how the constraints within a particular context are 
reproduced and how they shape strategies. I paid attention to the role of closure because it is important to understanding the interplay between practice, discourse, representation, and a particular conception of ideology which operates through incomplete representations. My first task is descriptive and requires me to look for concrete examples of action or recommendations of concrete actions related to health equity. This descriptive task is followed by a particular line of inquiry which requires attending to how these actions and inactions are situated within a field of constraints. By thinking in terms of contextualized strategies, I am forced to consider the structured and structuring context of actors and their agency. This allows me to approach theoretical questions about what is going on, such as, 'What is present?', 'What is absent?', 'How do we account for what is present and what is absent in discourse and practices?', 'To what extent does an absence, and/or the cause of that absence explain what is present, if at all?', 'How do the different themes relate to one another, if at all?', and 'Are they an end in themselves, and/or are they instrumental to another end?'.

I pay particular attention to the relationship between knowledge, discourse, and practice, which together form a sort of discursive configuration. Solidifying this configuration are its external institutional constraints, (e.g. performance management regimes, funding requirements, and various organizational standards), as well as internally reproduced constraints relating to evidentiary norms, and the very limits of understanding inherent within the legitimate ways of knowing reproduced within this configuration. It is important to note that throughout the project, I distinguish between 'technical' and 'discursive' features of health equity's deployment, primarily for clarity. In practice, the technical practices of measurement and evaluation structure possibilities for meaning, discourse, and action on health inequity. In addition to examining what is absent from the discourse, I had to analyse how this incompleteness is produced. This led me to analyse models of knowledge production and the absences within them. For example, if the way in which we discuss the problem of inequity is 
shaped by what we know about the problem, and if population health models do not measure government decision-making related to working and living conditions, then we can account for the stabilized and incomplete discursive representation of inequity by looking at the blind spots within the stabilizing technical features of health equity's deployment. In this sense, my methodical approach employs a critical and technical discourse analysis. 


\section{Chapter 3: Understanding Health Equity Through Normative Ethics Theory}

This chapter draws on theories and concepts from normative ethics theory and health justice scholars to provide an overview of possible groundings for the social justice component of health equity. This overview is not intended to serve as an exhaustive review of debates relating to theories of justice. Instead, the review will outline prevailing responses to the fundamental questions, 'What does social justice require?' in addition to more practical theoretical questions, 'Why is health of moral importance?', 'Why is inequality of moral salience?', and 'Which inequalities matter most?'. This will provide the theoretical and conceptual background for understanding the different ways that equity as justice can be understood in relation to public health. My project's goal is to provide insights into the research question, 'How is health equity, a normative moral idea, accommodated discursively and practically into public health discourse and practice?'. The contents of this chapter are important for answering this study's most basic descriptive sub-question: 'How does the actual practical deployment of equity compare to some idea of social justice as conceptualized in normative ethics theory?'. Most importantly, the theoretical background provided in this chapter is integral to exploring research questions in later chapters related to the intersection of facts, values, and theory where I argue that producing social knowledge about the relational production of unfair health distributions allows for public institutions to address relational concerns of justice.

\section{Relational and Distributive Conceptions of Justice}

Many normative ethical frameworks and theories espouse both distributive and relational concerns, even if some attend to one type more than the other. These are merely categories of moral concern, each attuning to a different judicandum. ${ }^{15}$ On their own, neither relational or

\footnotetext{
${ }^{15}$ In Latin, Judicandum means 'that which can be judged'. It is used for its brevity and because there is no suitable English alternative.
} 
distributive conceptions of justice encompass any particular normative ideals. What is accepted as a just distribution of some socially beneficial good will depend on other normative ethical positions. Different distributive ideals will become evident in this chapter's overview of various normative ethical positions and theories. For example, a strict distribution-egalitarian and a libertarian will both be concerned with institutional issues (as judicandum) while holding very different distributive ideals.

Distributive justice is concerned with the distribution of benefits and burdens among individuals and social groups. Although issues of distributive justice can overlap with other conceptions of justice, it can be generally distinguished from relational justice by its attention to the distribution of goods rather than the way people are related to the production, exchange, and use of those goods. Material goods and services such as wealth and healthcare can be considered objects of the distribution which is to be judged (judicandum), however it is difficult if not impossible to take relational manifestations such as power, domination, exploitation, and respect as goods which can be distributed. There are several possible targets that questions of distributive justice might address. These include the composition of what it is that will be distributed (what is to be distributed?); the total amount, or pool, of those various goods that will be distributed (how much should be available for distribution?); the actual distributional pattern of goods (what is a fair distribution?); and the mechanisms for ensuring this distribution (by what means will this distribution be achieved?).

Distributional actions may be taken to mitigate or offset some unjust manifestation of social relations, without directly correcting those unfair social relations. For example, as a socially beneficial good, health care ${ }^{16}$ can be distributed according to need. This can be taken

\footnotetext{
${ }^{16}$ Although there is a clear distinction between health and healthcare in health justice scholarship, this distinction is not always clear in the grey literature. For example, Norman Daniels wrote a Rawlsian inspired book, Just Health
} 
as the sole end of such distributive justice, or as a way to mitigate the effects of unfair social relations or the unfair distribution of some other good correlating with health, such as wealth. In this hypothetical case where only the distribution of health care is taken as the judicandum, the distributive requirement of justice may be met if remaining health inequalities are not the result of an unfair distribution of healthcare. In light of these examples, it should be clear that what is fair under a distributive concept of justice depends on what outcome and social goods are taken as the judicandum, and what principle(s) are used to determine a fair distribution.

The distinction between distributive and relational orientations toward justice are made clear in Sen's (1998) critique of John Rawls for "tak[ing] primary goods as the embodiment of advantage, rather than taking advantage to be a relationship between persons and goods" (366). This is an important distinction to be aware of, because theoretical muddiness can occur when the same goods that can be considered as existing outside of a social relationship can be treated as the product of un/just social relations. Wealth, for example, can be treated as an abstract good independent of social relations, or it can be treated as the product of social relations. If one employs a relational concept of justice, justice would attend to those social relations which produce fair or unfair distributions of income. Guided by this perspective, policy implications may include legislation mandating higher wages (if taken as a means to lessen exploitative social relations). On the other hand, policies guided solely by a distributive concept of justice may take social relations such as the prevailing wage labour relationship of our time

Care, but after realizing that health care is not the most important factor to fair health outcomes, he came out with the book, 'Just Health', which I cite and draw from. There is also a literature on bioethics and 'public health ethics' which is usually concerns patient care and issues of autonomy in the clinical context (See Lee, 2012). This version of public health ethics does not engage with SDOH or the idea of equity at all. Because of SDOH's total absence from this literature, rather than conflation with health care, one could assert there is a clear distinction. The literature I draw from does make the distinction though, taking a more wholistic and social approach. While the distinction is clear in most opening definitions in grey literature documents, e.g. (2018) OPHS, further actionable discourse often relates health equity back to issues of equitable access. Furthermore, I briefly discuss the conflation and interchanging of health equity and equity in health care in later chapters where I gesture to parts of the $\mathrm{ClHI}$ (2018) document. 
as natural, and thus not something which is to be judged and intervened upon. As a result, an intervention following from this perspective may include redistributive tax policies which redistribute wealth without attending to what could be judged as unjust social relations. To further illustrate, a distributive aim of justice may entail urging governments to ensure some fair distribution of an environmental bio-hazard without assigning some kind of responsibility to those who produce the hazard in the first place. In contrast, a relational aim of justice may place a burden on those who contribute to and benefit most from the hazard, and even determine that the hazard ought not to be created in the first place.

As an active concept of justice, relational justice diverts some distributional attention from those experiencing justice or injustice to those who produce them (Pogge, 2004). Under a relational justice scheme, we should be concerned with how social institutions that people are involved in shape, uphold, and contribute to the incidence and exacerbation of medical conditions. The point is that moral assessment of institutions must maintain a concern not only for the distribution of outcomes, but for how these outcomes are produced (133). As an active concept, relational justice draws attention to what we owe to each other, to differential responsibilities for judicanda, and toward their particular recipients. A relational idea of justice necessarily involves attending to the real-world social context in which agency, structure, power, and competing but unequal interests shape and are shaped by social relations. This attention can be contrasted with classical utilitarianism which is distinguished by impartiality and agent neutrality wherein everyone's wellbeing counts as equal value.

The active form of justice does not tie justice to an outcome alone, but to what is or is not done through a judicandum to particular recipients. Under this perspective, the strength of our moral reasons to prevent or mitigate medical conditions depends not only on distributional factors, but also relational considerations of how people are related to the medical conditions they suffer (133). For example, an individual would have stronger moral reason to mitigate the harm they were materially involved in causing, than that which is caused by others negligence. 
This illustrates how a relational conception of justice is an active concept of justice. In contrast, a passive concept of justice would play out through a comparative assessment of alternative health systems based on the distributions of health outcomes they are expected to respectively produce (143). This exemplifies a passive form of justice because it focuses moral attention on those who already experience justice or injustice, but not the individuals or social relations that produce unjust suffering (143).

\section{Sufficientarianism, Utilitarianism, Prioritarianism, and Egalitarianism}

Answers to the normative ethical questions of justice mentioned at the beginning of the chapter will appeal to range of schools of thought and their related concerns. However, despite the myriad of different schools of thought with their own respective primary concerns and 'jobs of justice', their concerns are not always mutually exclusive in answering questions of justice. Amartya Sen (1979) makes this clear in his Tanner Lecture, Equality of What? in which he

explains many theories and schools of thought take equality as a central concern, yet the forms it takes, and the espoused means to achieving it vary considerably. If inequities are those inequalities that are unfair or unjust, it is important to decide which inequalities matter and why. The point is that equality itself as an abstract idea does not hold much potential for directing the job of justice either in theory or in policy. The real work to be done is to specify which variables should be equalized. The question becomes, 'equality of what?' and 'equality in what form?' (Sen, 1979), and others would add, 'to what end?' (Powers and Faden, 2006).

While many different normative theories espouse egalitarian values, strict egalitarians value equality in itself, believing "[i]t is bad in itself that some people are worse off than others" (Parfit, 1998: 3). Conversely, non-egalitarians may still find an instrumental value in some ratio of equality while not considering equality itself to be of intrinsic value. For example, utilitarian theories do not necessarily consider inequality unjust and in need of moral justification, however they may still find instrumental value in some ratio of in/equality. A utilitarian may value some 
ratio of equality only to the extent that some higher ratio of inequality makes the majority better off. Other utilitarian thinkers might value some ratio of inequality to the extent that it maximizes overall utility irrespective of any distributional pattern (Sen, 1979: 198). For prioritarians, the job of justice is to benefit the worse off, but unlike the egalitarian, they hold no relational ideal. Holding no relational ideal, prioritarians take absolute levels rather than relative inequalities as the most morally important to redress. As Derek Parfit (1998) explains, "[b]enefits to the worse off matter more, but that is only because these people are at a lower absolute level. It is irrelevant that these people are worse off than others" (13). Similarly, sufficientarians also eschew a specific relational ideal and instead take absolute levels of some good or quality as the central moral concern. What is important for them is that individuals have enough of a given good to satisfy justice, not whether everyone has an equal amount. Under this perspective, inequalities are not unjust as long as everyone has enough. As Frankfurt (1987) argues, "[i]f everyone had enough, it would be of no moral consequence whether some had more than others" (21). Under a sufficiency principle like Frankfurt describes, the health/income gradient would not be seen as unjust as long as everyone was above some minimal standard of well being. This inclusion of sufficiency distinguishes sufficiency theories from others in one significant way. By arguing that justice is met when a sufficient level of some good or index of goods is achieved, one is arguing that justice requires an ideal end. This distinction, which I will return to later, resonates in critiques waged by sufficiency and capability theorists against alternative normative justice frameworks such as Rawls' social primary goods approach.

\section{John Rawls and Public Health Ethics}

John Rawls' (1971) Theory of Justice as Fairness warrants attention, not only for being one of the most influential contributions to moral and political philosophy in the twentieth century and revitalizing interest in what social justice means, but also for stimulating new debates and discussions around and extensions of the praxis and conceptualization of social justice. 
Moreover, several justice scholars have developed extensions of the theory to specifically deal with issues of social justice in the context of public health (Peter, 2001; 2004; Daniels, 2007), while others have created alternatives which variably reject and draw on aspects of Justice as Fairness to deal with issues of social justice in the context of public health.

Comprised of two main principles, Liberty and Equality, the theory of Justice as Fairness attempts to set out the just distribution of social goods. The Principle of Equality can be subdivided into two principles: The Difference Principle, and Fairness of Opportunity. These principles are intended to form a single comprehensive conception of justice on which the basis of society's basic social structures should be formed. The Difference Principle governs the distribution of wealth in this scheme. It allows for inequalities only when inequalities work to the greatest advantage of the worst-off. Both the Difference Principle and the Opportunity Principle are compatible with what would be considered just forms of inequality. Under the Opportunity Principle, if all have equal opportunity, unequal outcomes may still be considered fair. Rawls is not concerned with the extent to which an individual successfully converts their resources or opportunities into well-being. Under the Opportunity Principle, the mere equality of opportunity for doing so is what is of moral salience.

Under Rawls' scheme, these are principles that free and rational persons concerned with advancing their own interests would accept in a starting position of equality as the basis of all future mutual association (Rawls, 1971: 10). Rawls asks us to imagine all persons in this ahistorical, hypothetical situation of equal liberty in which we choose together, 'once and for all' the principles assigning basic rights and responsibilities, and the division of social benefits and burdens (10-11). He likens what he calls the 'original position' to the state of nature in traditional theory of the social contract. Several features mark the original position: No one knows what their place in society will be, including their class position or social status, or any other kind of 
advantages or disadvantages they will incur from the unknowable distribution of 'natural' assets and abilities, intelligence, strength, and the like (11). Nor are individuals in this original position aware of their psychological inclinations or preferences (11). This is what Rawls calls the 'veil of ignorance' from which the principles of justice are chosen behind, ensuring no one is advantaged or disadvantaged as the result of natural chance or social circumstances (11). Whatever fundamental agreements are reached under these ideal conditions are said to be fair.

Rawls' primary social goods include liberty, powers, opportunities, incomes and wealth, and the social basis of self respect (Rawls, 1971: 54). These are taken as objective measures of wellbeing which can be contrasted with subjective measures of welfare economics or utilitarian perspectives, including happiness or desire satisfaction. An ideal initial arrangement in which the primary goods are perfectly equally distributed becomes the benchmark which all actual distributive conditions can be measured against. From this ideal benchmark, some inequality, with the exception of the social basis for self respect, is permitted as long as it operates to the advantage of everyone (54). Rawls considers other primary goods, including health, intelligence, and imagination to be natural goods, influenced by the basic structure of society, but not directly controlled by it and thus, outside of the moral purview of distributive justice (54). While Rawls chooses not to theorize the role of health in his theory of Justice as Fairness, several health justice scholars have used the theory to judge which health inequalities are unjust (Peter, 2001; 2004), and why health is of moral importance (Daniels, 2007).

Rather than expanding Justice as Fairness, Peter $(2001 ; 2004)$ takes Rawls' theory of justice as it stands, arguing that we ought to judge health inequalities as inequities when they stem from unjust social arrangements. Secondly, she regards health as a primary good to be distributed according to the difference principle. The logic is as follows: If the basic structure of society is just, it follows that all outcomes of these arrangements are just. Whether these 
arrangements are just will depend on the principles of fairness of opportunity and the difference principle. For example, if the social arrangements cause health inequalities that benefit the better off groups at the expense of the worse off, these social arrangements would be unjust according to the difference principle, and any health inequalities that are a result of these unjust arrangements would be judged as inequities. For Peter (2004), the moral emphasis lies not on the specific distributional pattern of health outcomes, but on the broader distributive and social processes underlying health inequalities.

Rawlsian approaches to determining which inequalities are unfair, and why health is of moral importance can be contrasted with strict egalitarianism, utilitarianism, and some forms of prioritarianism, and which all fall under the direct approach. Under a direct approach, something (e.g. a distribution of disease or health outcomes, or a relational state of affairs) is judged as inequitable insofar as it strays from a perceived ideal end. They also place inherent value on specific ends such as health. On the other hand, indirect approaches treat health inequality not as a morally problematic end in itself, but only when it manifests from unjust social arrangements (Peter, 2004: 98). Peter (2001) argues that an indirect approach is beneficial for providing a basis for assessing and explaining particular social groups' social inequalities in health. This is based on the premise that under an indirect approach, selecting relevant social groups is based on an explicit judgement about unjust social arrangements that disadvantage certain groups (165).

It is important to note that what makes health of moral importance is related to, but different from the question of what makes health disparities unfair and unjust. While Peter offers an argument for determining which health inequalities are unfair, Norman Daniels offers an additional argument which addresses why health is of moral importance. In his highly cited book-length work, Daniels $(2002 ; 2007)$ accounts for the moral salience of health by reference 
to the opportunity principle, which he extends by considering health as a special moral good. Daniels extends the opportunity principle so that it not only must guarantee fair opportunity to compete for employment and offices (as in Rawls' perspective), but also so that it guarantees to each individual a fair share of the normal range of opportunities for someone with their respective talents. The crux of Daniels' argument is that since health is a necessary precondition for accessing the normal opportunity range for one's talents, a commitment to the principle of fair equality of opportunity requires us to treat health as a special good to be equalized. This commitment to equality is distinct from more general commitments to egalitarian distributions of goods because equality of health is valued for its instrumental role in upholding the principle of equality of opportunity, and not as part of some ideal end in itself.

Daniels (2002) recognizes that health inequalities exist not only between the richest and the poorest, but instead persist as a gradient all the way between the poorest and the richest. However, he does not necessarily consider all health inequalities along this gradient as unjust, as one adopting a radical egalitarian view of justice may (28). Instead, he sees those inequalities persisting as a gradient from the poorest to the richest that do not conform to the difference principle as inequities. As long as equality of political liberty, and the requirements of equality of opportunity are not violated, the difference principle allows inequality if it maximally benefits the worst off. Under this framework in which inequalities are permitted as long as they make the worse off better than alternative arrangements, relative disadvantage is less important than absolute well-being. In short, health derives its moral importance from its impact on opportunities, and health inequality is unjust when it derives from an unjust distribution of the socially controllable factors affecting population health and its distribution. For Daniels (2007) a just distribution of socially controllable factors derives from how Rawls' principles of justice as fairness would distribute them (27). 


\section{Capabilities and the Ends of Human Development}

Some normative frameworks, such as the Rawlsian social primary goods approach, value particular means to well-being rather than the ends. In contrast, capability and sufficientarian approaches such as Amartya Sen and Powers and Faden's respective works place primary importance on the actual achievement of ends rather than the means. This is because people differ in their ability to convert means into valuable opportunities (capabilities) or outcomes (functionings) (Sen, 1992). For Sen, the ultimate concern of justice is quality of life assessed in terms of capability to achieve functionings (1993: 31). Sen cares about what we can actually do with the goods that are distributed to us, which will depend on our own unique needs, and on our relationships with others. This sentiment is reflected here in his distinction between opportunities as realizable capabilities and primary goods: "Primary goods are means to freedoms, whereas capabilities are expressions of freedoms themselves" (Sen, 1997: 48). Capabilities and sufficiency approaches posit that if ends are what ultimately matter, it would be wrong to neglect natural and socially determined inter-individual differences which could impede one's ability to successfully convert opportunities into wellbeing or functioning (Sen, 1992; Powers and Faden, 2006). Focusing on the ends rather than only the means involves determining some ideal end through political deliberation. Conversely, normative frameworks such as those offered by Rawls do not propose any ideal ends of human development out of respect for pluralism. This is critiqued by Powers and Faden (2006) for evading the messy, but necessary role of collective decision making, since ultimately, some collective political will have to be exercised under actual non-ideal conditions.

\section{Powers and Faden's Twin Aim Theory of Justice}

Powers and Faden's (2006) twin-aim theory is the only theory presented by its authors as explicitly aligned with the commitments and practices of public health (80). Power and Faden's twin-aim theory is also unique for basing their theory on the idea that we must start with 
some contextualized conception of human well-being. They argue that one cannot establish the best set of distributive principles independently of a detailed account of the ends of human action, and that the adequacy of any distributive principles of justice ought to be evaluated based on the ends of human action they are meant to achieve. They reject the 'separate spheres' view that one can understand issues of justice relating to, for example, health policy, education, employment opportunities, or social policy more generally by developing a specific set of distributive principles for each respective sphere (3). For the them, the role of justice is not to equalize or maximize a given priority such as freedom of choice, economic efficiency, age-based rationing, or quality adjusted life years (x). Instead, they address the social conditions under which we can deliberate whether these formulas are morally unacceptable, acceptable, or obligatory in non-ideal, real-world contexts.

Power and Faden's (2006) Twin Aim theory is further distinguished from other theories of justice in that it maintains two mutually reinforcing aims. One aim is described as positive, requiring the achievement of the six dimensions of well-being. The negative function is the remedial aim of vigilantly policing social relations which systemically compromise the positive aim (9). The six essential dimensions of well-being include health; personal security from physical and psychological harm as well as the threat of such harm; the development of reasoning; personal attachments; respect of others; and self-determination. Each dimension has independent moral significance within a theory of justice, however some are also valued for their impact on other dimensions of wellbeing. The only criteria for the distinction of each dimension is that it is a 'morally salient aspect of human flourishing' that cannot be reduced to one of the others (21). For example, the ability for reasoning may be impeded by health. Therefore, there is an overlap, but since health cannot be reduced to reasoning and reasoning cannot be reduced to the dimension of health, they remain separate, albeit overlapping dimensions or wellbeing. 
They assert we can only answer the question, 'Which inequalities matter most?' by engaging with all of the cumulative and interactive effects of social determinants on human wellbeing (5). Posing and engaging with this question distinguishes them from other theories discussed so far which centre on questions of why health is of moral importance, and when or how inequalities can be determined to be unfair. They argue that those inequalities that cause cascading and interacting effects on deprivation (70), or those systematically overlapping social determinants that affect multiple dimensions of wellbeing are the most urgent to address (72). Answering the question, 'which inequalities matter most?' will depend on contextual information about how actual institutional practices and social arrangements affect differentially socially situated persons and groups in various ways (31).

The strength of Power and Faden's context-dependent non-ideal theory lays with its ability to take as its starting point the recognition that the world is a non-ideal world where we cannot assume full compliance with some set of distributional principles, even if they would be reasonable to follow. They take issue not only with the reality of noncompliance with an ideal set of distributive principles, but also with the idea that distributive principles can be developed separately from the ends that distributive principles serve. For them, justice is not a task of conforming society to an antecedent set of distributive principles. It is an 'remedial' task which requires "vigilance and attentiveness to changing impediments to the achievement of enduring dimensions of well-being that are essential guides to the aspirations of justice" (5). Their practical conception of justice as a context-dependent, on-going corrective praxis can be contrasted with the Rawlsian idea that we can decide 'once and for all' the principles assigning basic rights and responsibilities and determining the division of social benefits and burdens (Rawls, 1971, p.10-11). This is an important distinguishing feature of their framework because this remedial task requires on-going monitoring and political reasoning. In light of these defining features, Powers and Faden's theory is a sufficiency theory goes beyond distributive concerns 
to uphold a strong active and relational conception of justice. This is made clear where they state that "justice will demand vigilance against the development of social structures that permit winners in some spheres from determining the winners and losers in all of the other spheres" (69).

\section{Conclusion}

The purpose of this chapter was not to argue for one theory or framework over another for understanding health equity and guiding public health policy and practice. Determining which principles and frameworks to draw from in creating a coherent and strong conception of health equity will inevitably be a political task aided by knowledge about how and why inequalities are produced, and how these inequalities affect other dimensions of well-being. To answer the questions presented at the beginning of the chapter, health and health equality can be considered a morally important end in itself as welfare, capabilities, and sufficiency theories would maintain. Conversely, health and health quality can be considered morally important for serving an instrumental purpose to achieving some other morally salient end or state such as equality of opportunity (Daniels, 2007), or it can be taken as an important indicator for wider injustices as Peter (2001) suggests. The various perspectives can be delineated according to whether they attend to specific ideal ends, requiring on-going political discussion about what matters as an issue of justice and what compromises what matters in actual changing social contexts, or whether they operate through static principles developed independently of social context.

This chapter has also provided an overview of the theoretical landscape and some conceptual tools for understanding social justice in relation to public health. The purpose of this is twofold. First, it provides concepts and perspectives that will be used in this study for understanding how health equity is conceptualized and put into practice in public health. Secondly, as a practical matter, by showing that there is a vast set of perspectives, principles, 
frameworks, and theories for understanding equity-as-justice, this chapter serves the purpose of showing that equity-as-justice does not need to be relegated as an inevitably relative and opaque term. By providing the vocabulary for discussing and understanding justice in terms of what it is that can be determined as just or unjust, and the various terms (e.g., relational or distributive) on which the judicandum should matter, we are able to identify where a particular idea of justice is realized, and where one is not.

This language permits a consistent and transparent moral evaluation of what form equity takes in practice, and which it does not. For example, through a secondary analysis of the empirical literature on how health equity is practiced, one can interpret current action on health equity as distributive and mitigative rather than action which disrupts and corrects unfair social relations leading to unequal health outcomes. As I will later show, the ways in which the idea of health equity are deployed are in the service of mitigating the effects of unfair social relations, or the unfair distribution of some other good(s) correlating with health, such as wealth. As mentioned, within the hypothetical case in which only the distribution of health care is taken as that which should be judged, the distributive requirement of justice may be met if remaining health inequalities are not the result of an unfair distribution of healthcare. When thinking of action in these terms, it becomes clear which form of justice that action on health equity follows, and which it does not. A greater understanding of different ideas of justice and their underlying logic helps us collectively decide which should prevail in particular contexts, and by extension, how to assess when we achieve or fall short of fairness. The upshot is that equity-as-justice ought to be taken seriously as a meaningful and potentially edifying concept for guiding policy action attending to health inequities and SDOH. Later chapters touch on how the meaning and ownership of health equity has been extended, and as a result, 'emptied'. The ideas within this chapter provide some of the possible theoretical anchoring points from which discourse may be kept from drifting too far. 
Not only does engaging with normative theory allow us to think about equity-as-justice with consistent and categorical reason required for transparent democratic decision-making; it also permits reflexive knowledge production. By building an awareness of the different assumptions carried by different ideas of justice, an awareness of the different kinds of knowledge required to support those ideas of justice can follow. This interdependency of knowledge and the realization of particular values is a recurring theme of this project. A first step is to collectively decide which ideas of justice to pursue in real-world contexts. The knowledge requirements of a particular object and orientation of justice can steer and evaluate models of knowledge production and practice-evaluation. For example, taking goods such as income or housing as the embodiment of advantage, rather than the embodiment of a relationship between persons and goods produces a very different picture of reality in terms of what matters and thus what should be made known. The latter understanding, which takes the relationship between persons (and society) and goods to be the embodiment of advantage requires a different type of knowledge of the world than if we were merely concerned with relationship between goods and advantage.$^{17}$ A relational concern of justice requires knowledge of social relations. Additionally, to be a relational issue of justice in the first place, we have to determine

${ }^{17}$ I ask the reader to recall that Wilkinson's analysis focuses on income, but not the way it was generated through social relations. This is partly the product of an omission of those political factors that determine income inequality. This exclusionary closure imposes a limit on fully understanding the phenomenon we are trying to comprehend. There is an ethical implication of this type of closed model. The epistemological implication is perhaps clear: one cannot know the origins of income distributions as located within political and economic social relations if models do not include them as factors. Following from this, is a limit on our ability to understand the ontological and ethical relevance of what is measured. For example, if as in Wilkinson's (1996) model, one's class position is operationalized more by their capacity to consume than by their particular social relation to the acquisition of capital enabling that consumption, then goods themselves (e.g. income, education etc.) become the embodiment of advantage rather than ones' position in the social system-and the very configuration of that social system - that allows one to accrue goods over (and through) others. This marks the distinction between distributive and relational orientations toward justice which are made clear in Sen's (1998) critique of John Rawls for "tak[ing] primary goods as the embodiment of advantage, rather than taking advantage to be a relationship between persons and goods" (366). The upshot is that what matters as an issue of justice, and what can be done about it, depend on what is made known. This is why interrogating models of knowledge production is so important. 
that something is at least socially determined in addition to how and why it is socially determined. Chapters five onward analyse how our dominant models of knowledge production, as ways of representing the world to ourselves, and our dominant ideas about what counts as evidence, as ways of evaluating action, render the injustices that we normatively care about in/visible and un/changeable. 


\section{Chapter 4: Social Justice and the Deployment of Health Equity in Canada}

This chapter examines how the concept of health equity is variably understood and mobilized in Canada. I do not review studies within the SDOH literature on the existence of health inequities and related factors. I focus on a much smaller field of emerging research by reviewing empirical studies on how health equity is understood, practiced, and discussed in public health documents and by those working in public health in the Canadian context. To assess the relevance of scope or topic, I looked for whether literature explored the perspectives and practices of individuals involved in policy development, advocacy, and practice (e.g. public health policy-makers, practitioners, and public health unit executives). In addition to perspectives and practices, I review literature exploring the textual representation of organizational and institutional practices, standards, strategies, frameworks, or mandates supporting a commitment to health equity.

This review diverges from a conventional literature review by critically analyzing findings to present key themes and questions for further exploration. By drawing on these existing insights I delivery some preliminary answers to the following questions:

1) What role does the concept of health equity play in health policy documents generally (e.g. foundational or decorative?)

ii. What kinds of concrete actions are prescribed as part of a health equity lens?

2) How do people working in public health understand and apply a health equity lens?

ii. How do people prioritize which health inequalities matter most?

There is only a small and recent literature that investigates how 'health equity' is operationalized which likely accounts for why existing research does not explore key themes or 
findings of others' work on the topic. Lastly, by highlighting how health equity is understood and practiced in the everyday institutional settings of public health work, this chapter provides important background context to support this project's analysis in chapters five onward. These chapters look at the mobilization of health equity within a particular discursive and technical field of action in which neutrality and quantification is paramount.

\section{Inclusion/Exclusion Criteria}

Literature was found by searching the ProQuest Sociology Database, PubMed, and the MacOdrum Library Catalogue for articles containing the words 'public health' and 'equity' and 'qualitative' and/or 'empirical' and/or 'perspectives' and/or 'social justice'. Social justice was included because this study is exploring the normative justice component of the concept of equity in public health. ${ }^{18}$ Inclusion/exclusion criteria was based on place, methodology, scope, and topic. A methodological inclusion criterion was that literature had to be empirical. This criterion excluded various editorial, review, commentary, and discussion papers which may also be termed 'conceptual', 'philosophical' or 'theoretical'. To be considered empirical, research could have interpreted existing sources of data, (e.g. by analyzing documents) or generated data (e.g. by conducting interviews). Research had to take as its explicit aim to understand

\footnotetext{
${ }^{18}$ While the two concepts of equity and justice sometimes appear separately-for example, in PHAC's Core Competencies for Public Health document-they are indistinguishable from one another for the following reasons: First, equity, and a similarly synonymous but perhaps even more vague word, fairness, commonly appear along side one another as the single conceptual entity, 'justice, fairness, and equity'. Both in dictionary definitions and common philosophical literature, there are no distinctions made between one another, and each term is regularly used to add circular definition to one another. Secondly, the two concepts are folded together in the oft cited definition of health inequities in public health discourse in which health inequities are taken as those health inequalities that are unjust and avoidable.

For the following reasons, I will also defend my reason for including the search query 'social' justice and not other variants: First, while there are other forms of justice besides social justice, such as criminal justice or retributive justice, on the grounds of common sense, it is reasonable to hold these other forms of justice as irrelevant to the conceptualization and operationalization of health equity in public health discourse and policy action. Secondly, the many other categories of justice, such as environmental justice, racial justice, economic justice, and health justice which are indeed relevant can be placed under social justice.
} 
some dimension of health equity itself as a concept, programmatic goal, or practice. As a result of this criterion, research on health inequities and health inequalities was excluded.

\section{Commonalities and Divergences in Methods, Scope, and Paradigm}

A review of empirical research on health equity's deployment in public health yielded 11 studies, three of which did not principally focus on health equity but provided valuable insights into the questions guiding this chapter. Most of the empirical literature on health equity as an idea and practice is relatively recent, with approximately half of the research published in the past two years. Because of the Canadian centric focus of this study, and because existing research on health equity is predominantly Canadian, the three articles focusing on health equity outside of Canada was excluded from analysis. To date, most research on health equity employs grounded theory, whether taking the form of document analyses, or interviews. Studies analysing public health policy documents provided me with insights into how and to what extent the idea of equity and related values such as social justice inform the content and direction of concrete actions (See Giacomini et al., 2003; Edwards and Davison, 2008; Giacomini et al., 2009; Pinto et al., 2012). Other empirical literature centres on how the idea and operationalization of health equity is understood from the perspectives of public health professionals in the context of their daily work (Rizzi, 2014; McPherson et al., 2016; Smith, 2016; Cheff, 2017; Hassen and Tyler, 2017; Pauly et al., 2017; Anne et al., 2018).

While standing as methodologically strong contributions in their own right, the majority of the studies remain largely uncritical, and atheoretical. With few exceptions (e.g. Smith, 2016; Pauly et al., 2017; Anne et al., 2018), existing research does not attempt to make sense of their data in relation to other relevant literature. Nor do they attempt to make sense of findings through relevant theoretical perspectives. Additionally, current empirical literature on 
understandings and applications of health equity in public health policy and practice fall short of accounting for health equity as a meaningful, comprehensible, and potentially edifying concept.

As Smith (2016) points out, despite the fact that health equity and social justice are normative concepts, no studies exploring perspectives on health equity analyze their descriptive findings in reference to the vast normative theoretical literature. Even when study participants acknowledge the difference between equality and equity by virtue of the latter's link to justice, this is not treated with further consideration. For example, Rizzi's (2014) study found that public health front line staff understood health equity as fairness or justice in contrast to merely equality. Yet, despite identifying this relationship between social justice and understandings of health equity, the author makes no attempt to further understand justice or its place in public health. Instead, they merely decree that what is fair is subjective, implying that it is impossible to hold up to further analysis. This avoids the many epistemological, moral, political, and ontological beliefs about human nature, freedom, and responsibility that shape one's understanding of what is unjust and avoidable. It would be unfortunate if these understandings were treated as unintelligible and unfit as objects of research. ${ }^{19}$ This critique follows that waged by Smith (2016), who makes the following comments on the concept of social justice:

Unfortunately, treating the concept of social justice as 'subjective' simply acts to reify the problem at hand, which is that social justice cannot be meaningfully defined, discussed, and operationalized. Acknowledging the putative importance of the value of social justice to public health should warrant a serious investigation of its contents, role, and scope rather than dismissing it as merely 'subjective' (92).

\footnotetext{
${ }^{19}$ Even if discussions about what kind of relationship between individual and society exists are often muddled by what kind of relationship between individual and society ought to exist (Elias, 1956), sociology is uniquely poised to produce knowledge about what kind of relationships do exist.
} 
Despite this cursory treatment of equity-as-social justice, Rizzi's (2014) study is useful for identifying social justice as a salient value that is held among front line public health workers, and which plays an important role in how health equity is understood.

Although almost none of the literature on health equity discusses the concept in reference to the myriad of robust normative ethical theory and its frameworks for understanding social justice and its attributes, two noteworthy exceptions include a paper by Edwards and Davison (2008), and Smith's (2016) PhD dissertation on policy-makers' perceptions of social justice in public health. Smith's (2016) work stands apart from others' by engaging with the rich and nuanced literature on normative ethics theory. Although this depth of engagement is not shared by Edwards and Davison, their article is novel in that it mentions social justice can be interpreted in various ways in reference to the philosophical literature. The authors allude to this literature by listing the names of influential justice philosophers, including Aristotle, Amartya Sen, Martha Nussbaum, Norman Daniels, John Rawls, Jeremy Bentham, and Robert Nozick, among others (131). Despite the article's brevity and only passing reference to some of the influential voices within normative ethics theory, Edwards and Davison make an important contribution by producing the first empirical paper on the social justice orientation of public health in Canada. My study is unique not only for treating the normative components of health equity as meaningful by engaging with moral theory, but also for examining the social justice orientation of public health through an analysis of health equity discourse, which, as I will demonstrate clearly in chapter six, is a socially significant, discursively productive object of study on its own. My study is also unique for being the first to analyse the social justice orientation of public health in relation to constraints imposed by evidentiary norms and imperatives. While others have studied the epistemological barriers to progress on SDOH (Brassolotto et al., 2014), I focus less on individual epistemological variations and internalised 
neoliberal discourses, and more on evidentiary norms, imperatives, and constraints within a historicized institutional context. These constraints related to evidentiary norms and imperatives shape and limit which dimensions of inequity are made known, and determine which interventions are professionally strategic and institutionally possible to deploy and evaluate.

While not focusing on the concept of health equity exactly, Raphael and colleagues' (2011) discourse analysis of the social determinants of health warrants attention because of the common links between social determinants of health and health equity, and for producing a useful schema for identifying how SDOH are mobilized in public health practices through different discourses. Furthermore, the authors' focus on discourse and practice is relevant to this study's theoretical orientation which recognizes that discourse shape and constrain possibilities for understanding and acting upon the social world.

Raphael and colleague's (2011) identify seven discourses of SDOH. Each of the seven discourses support particular key concepts; dominant research paradigms; and practical implications (225). The first discourse centres on identifying those in need of health and social services. The second discourse focuses on identifying modifiable individual-level behavioural and medical risk factors. Discourse three represents the interacting material, psychological, and behavioural pathways in relation to health, but social structures are only referred to broadly by referencing general structural categories such as neighborhood characteristics, housing, and employment and working conditions (226). This discourse does not emphasize the specific public policies and policy antecedents of these structured material conditions (227). This absence leaves flexibility for which particular policies ought to attend to the SDOH. As a result, potential responses to addressing material determinants of health could take the form of breakfast programs or clothing drives rather than considerations of how public policies cause financial and food insecurity in the first place. Discourse four also focuses on material living 
circumstances, but specifically how they differ as a function of group membership. Despite this added degree of nuance, research and practical implications are still limited to providing evidence of the relationship between different living conditions and inter-group health differentials. Furthermore, discourses three and four can be distinguished from the first two by indicating material living conditions, and they can be further distinguished from discourses five through seven which consider the health-related effects of specific policies, political and economic structures, and antagonistic class interests.

Discourses five through seven can be distinguished by their gradated recognition of the ways in which these material conditions are not immutable, but the result of public policy, economic and political structures, legitimating ideology, and the power and influence of those who benefit from inequalities. To this end discourses five, six, and seven offer the strongest language and potential for social change. These discourses do not take the distribution of social determinants of health as an immutable structural attribute for which individuals must learn to cope with. Neither do they lend toward a purely distributive aim of justice. Instead, they represent the unequal distribution of the $\mathrm{SDOH}$ as an active process rooted in public policy decisions (discourse five), jurisdictional economic and political structures and justifying ideologies (discourse six), and the influence of power of those who create and benefit form social and health inequalities (discourse seven). As such, these discourses permit the realization of relational conception of social justice.

\section{Key Themes}

This review can be split into two parts: The first section reviews findings related to how equity is conceptualized and communicated as a value in public health policy documents. The second section synthesizes findings from studies related to how health equity is understood and 
practiced in the context of public health, for example, through advocacy or by applying a health equity lens.

This review is structured to present empirical findings addressing the following questions:

1) What role does the concept of health equity play in health policy documents generally (e.g. foundational or decorative?)

ii. What kinds of concrete actions are prescribed as part of a health equity lens?

2) How do people working in public health understand and apply a health equity lens?

ii. How do people prioritize which health inequalities matter most?

\section{The role of equity as a value in health policy}

Studies commonly yielded insights into the implicit, ambiguous, and flexible use of the concept of equity. Although equity is ubiquitous in health policy documents, it appears to primarily assume its place within boiler plate statements before disappearing from subsequent sections containing concrete directives. This is apparent in research by Edwards and Davison (2008) in which they review the social justice orientation of the Public Health Agency of Canada's (PHAC) Core Competencies for Public Health in Canada, and the process undertaken to develop the core competencies. ${ }^{20}$ While social justice and equity are described in the document as important core values of public health, the document does not explicitly reference any of the essential attributes of social justice within the core competencies themselves. The

\footnotetext{
${ }^{20}$ Core competencies are the essential knowledge, skills and attitudes which make up the foundation of all public health practices and core functions, regardless of topic, disciplinary, or programmatic boundaries (PHAC, 2008). The impetus for the development of these core competencies was partly the experience with SARS; the selection of competencies was guided by the Advisory Committee on Population Health; and the core competencies are informed by similar work in other countries - notably the United States, England, Australia and New Zealand (PHAC, 2008). It may be relevant that these are all liberal welfare states, with no social democratic welfare states informing the development of competencies.
} 
document provides an explanation for this, stating values such as equity and social justice are not listed as specific core competencies "because they are difficult to teach and even harder to assess" (PHAC, 2008: 3). As a value, social justice only appears in the document's preamble, then again in the glossary of definitions along with equity. Edwards and Davison (2008) ultimately argue that essential attributes of social justice principles should be explicitly integrated into each core competency rather than stand on their own. ${ }^{21}$ They justify this position on the grounds that social justice is a core foundational value for all work in public health, and not merely a separate, optional competency. The authors' conclusion that the social justice orientation of the core competencies document is merely superficial is corroborated by Giacomini and colleagues' (2003; 2009) findings on the role of values in Canadian health policy documents.

Although Giacomini and colleagues (2003; 2009) research was not centrally focused on equity, their work provides insights into the ambiguity and inconsistency of equity as a value in Canadian health policy documents. Their analysis of health system reform documents shows there is great disparity and ambiguity in terms of how health reformers understand what values are in terms of their fundamental substances. Nearly every document analyzed clearly highlights and promotes specific values in the form of some number of overarching tenets (Giacomini et al, 2003: 20). In a less enshrined form than formal tenets, values like equity also appear in lists of considerations or goals.

The authors assert the way stakeholders see values reveals different ontological assumptions about the nature of values. The substance of values comes in different forms of

\footnotetext{
${ }^{21}$ Edwards and Davison provide serval examples of how the attributes of social justice might be defined: "identifying inequities and their underlying determinants; advocating for human rights and dignities; establishing just economic, social and political institutions; supporting equity; and when appropriate, equality; and demonstrating concern for civil rights" (2007: 131).
} 
goodness-for example, as a physical entity such as the health system or services and programs; in principles; specific goals; or attitudes and feelings. Equity fell under the rubric of principles, or general ethical imperatives (19). This lays in contrast to less abstract, more specific goals such as access, prevention, and health states. This distinction is important because different values and their corresponding ontologies will require different approaches (19). For example, achieving specific goals might simply require empirical evaluation while something like equity, falling under the rubric of principle might require moral and legal reasoning $(19) \cdot{ }^{22}$

These findings support Giacomini and colleagues' later (2009) research which found that ethical frameworks of 24 Canadian health policy documents published between 1998 and 2005 mainly functioned as aesthetic frames or 'window dressing'. As they point out in their earlier work as well, these frameworks typically appear as a list of principles or values, offering little more than 'decorative framing'. This decorative framing is contrasted with a 'foundation' on which policy is built and its success lays. Ethical frameworks are also figuratively contrasted with 'scaffolding' which generates the policy without playing an ongoing role in its implementation. If we are to use these typologies, it is evident, drawing from studies outlined throughout this review, that equity often plays a 'scaffolding' role in provincial policy documents, by generating an orientation or 'equity lens' without specifying a specific course of action to achieving some morally worthy end. When a course of action is provided, it is flexible and unclear as to how directives will actually improve health equity. However, as I will later show,

\footnotetext{
${ }^{22}$ That the authors make this distinction between the requirements of values by virtue of their ontological status is interesting because as the literature in this review shows, practices directed at improving equity are often underrealized as they are often reduced to some task of measurement-and as I argue is significant-at the local level. This solicits the following question: Is public health in its current ostensibly neutral political and epistemological orientation up to the task of moral reasoning? If not, this should raise concerns about public institutions' ability to advance health equity-a goal dependent upon a state of social relations whose means of achievement are inextricably linked to moral reasoning.
} 
looked at as an 'empty signifier', we can see how health equity's flexible invocation and mobilization does not always fit into these categories.

When ethical frameworks share the concept or value of equity, one finds six divergent interpretations of the same term in five documents (62). ${ }^{23}$ The authors found ethical elements are rarely related to specific policies, with only one third of the documents doing so (58).

Elements of public health ethics frameworks varied in the extent to which they reflected abstract principles on one end, and concrete goals on the other (61). Equity was identified as an abstract principle, while evidence, population health, prevention, public goods, quality, and safety were elements supporting concrete policy processes or goals. In the middle, stood accountability, collaborations, access, efficiency, public involvement, and diversity (61).

Not only are values such as equity often inconsistent and vague, subsequently failing to be articulated in concrete directives, but they also lack any trace of authorial or intellectual

${ }^{23}$ Interpretations of "Equity" (Retrieved from Table 3 in Giacomini, 2009: 64):

(a) "Equity: access to health services should be based on need and need alone, not on other factors such as wealth, origin, the region where people live, their gender or age."

(b) "Equity: all Canadians are equally entitled to access our health system based on health needs, not ability to pay."

(c) "Equity: no one should face financial hardship because of illness, disease or disability. Wealth should not be able to buy better treatment, higher-quality care or a better chance at a cure."

(d) "Equity: every person has a fair opportunity to attain his/her full health potential. Policies and services are developed to reduce the differences in health status that are associated with factors such as socio-economic status, gender, age, ability, and culture"

(e) "Equity: no one should face excessive financial hardship or possible bankruptcy because of illness, disease or disability. Access to timely and medically necessary health services should be available to all, regardless of income. These two access issues are fundamental to Canadian health care and are tenets almost all British Columbians would agree with.

This does not mean, however, that British Columbians should not bear some responsibility to keep healthy or to contribute to the future sustainability of the health care system, which will be discussed in more detail further in the report. Rather, it means that any funding mechanism or financial involvement should be equitable and fairly distributed. No one disease profile, demographic or sector of society should bear a disproportionate burden of the health care costs."

(f) "Equity: participation, access, and the sharing of benefits and risks, taking into account the characteristics of each population." 
origin. In other words, ethics frameworks rarely justify the inclusion of equity with any reference to where the concept came from or why it should present. This signals a failure to engage with normative ethics which might lend it some coherent and consistent structure. Only three frameworks including equity indicate where the concept came from and why it is present (62). What is more, is that the rationale offered by two of these three frameworks for including equity are only inferred from another policy document or process that produced the entire framework (62). The authors also discuss the problem of not articulating which values constitute instrumental means, and which constitute ultimate ends:

"In lieu of academically rigorous constructs, health policy analysts typically invoke implicit, intuitive formulations. [...] These definitions offer limited insight into what values are made of, where they are found, and how they relate to both ideas and action in the policy world. A vague definition of values allows stakeholders and policy analysts to argue at cross purposes about vastly different things without realizing it $[\ldots][\mathrm{H}]$ ealth system values may be arranged by their instrumental relationships; the analyst's task is to clarify which values constitute ultimate ends, and which represent means to these ends" (22).

Indeed, the vague conceptualization and lack of intellectual origins of a highly normative and variable value-laden concept like equity could translate into 'vastly different things without realizing it' as it travels through and between different actors. The problem of ascertaining which values constitute instrumental means and which constitute ultimate ends is addressed in this study. This is achieved by interpreting the ultimate ends of health equity action, processes of evaluation, and how problems of social justice become instrumentalized toward specific ends within different fields. 
Decorative values which appear with no authorial origin before disappearing are not inadequate for simply leading to inaction. They are inadequate for failing to direct policy and practices to consistent and meaningful ends. By meaningful ends, I mean the successful achievements of conditions or outcomes that align with some normative ethical ideal, framework, or process of what is decided as just. An additional barrier to advancing health equity which is conceptually close to ambiguity is that of flexibility. This flexibility allows it to function as a 'floating' or 'empty signifier', while its many conceptual and actionable proxies constitute its 'chain of equivalence'. Thought of in another way, equity's flexibility and wide adoptability allows for its successful extension (within a chain of equivalences) across a range of actions and actors. Several studies investigating the experience and perspectives of public health staff applying a health equity lens highlight how the flexibility afforded to health equity and its proxies in provincial standards impedes progress on health equity and SDOH (Rizzi, 2014; Hassen and Tyler, 2017; Pauly et al., 2017). But, as I will show further in Chapters Six and beyond, the language of health equity and its proxies do not only create confusion and impede action. They are also discursively productive.

Beyond the confusion that its flexibility induces, the language of health equity and its proxies produce the possibility for legitimately employing any one of a range of alternative actions under the banner of health equity. The language of health equity and its proxies constitute what Ernesto Laclau (1996) calls a chain of equivalences. From this chain of equivalences, as an expanding discursive field, various groups can develop or select from any number of actionable strategies to secure their role in achieving some legitimated goal of equity. The range of alternative practices vary in their impact on health inequities but are equally acceptable at face value. As an empty signifier supporting a chain of equivalences, health equity produces the discursive conditions for actors of different fields to successfully mobilize the concept within their particular field's constraints. It produces a way of discussing, measuring, 
representing, and acting upon health inequity regardless of who 'owns' the concept at a given point in time, or the constraints that structure action within a particular field (for example, institutional, political, epistemological, etcetera). Different versions or elements of equity are espoused and acted upon as the concept travels from its origin in WHO, between PHAC and $\mathrm{CIHI}$ models of knowledge production and representation, provincial public health standards and those who use them to identify priority populations, and other public health and third sector groups' development, implementation, and evaluation of health equity-oriented interventions. Without engaging with normative ethics or considering the problem of inequity, health equity can be proactive in an infinitude of ways without being counteractive. Engaging with normative ethics allows public institutions to impose some concrete content on the idea of equity thereby reducing its capacity to function as an empty signifier.

\section{Understandings and Applications of a Health Equity Lens}

Pinto and colleagues' (2012) research suggests contextual factors may account for differences in the flexibility and ambiguity of health equity and related policy directives and standards. Their study was unique in that they produced a comparative analysis of public health documents related to equity from Ontario and British Columbia (BC). Their comparative study identified how health equity is conceptualized and integrated into standards for public health during a time of public health renewal in the two provinces. Mirroring Margaret Whitehead's influential definition, both provinces define inequities similarly as those health inequalities which are unnecessary and avoidable as well as unfair and unjust. Against this conceptual similarity, the study identified several key differences between the two provinces' practical considerations of health equity.

In the Ontario documents, the discussion of health equity remains in the introductory material. In contrast, the $\mathrm{BC}$ Core Functions Framework and related documents maintain a 
focus on addressing health inequities throughout. Additionally, the BC equity lens is more explicit in prescribing specific actions aimed at the SDOH while the Ontario documents only focus on measuring priority populations. Notwithstanding these differences, both provinces' health equity orientations share a primary focus on measuring priority populations and lowering barriers to public health programs by tailoring programs to meet local populations' health needs.

In Ontario, priority populations are considered the proxy for those experiencing health inequities, however the Ontario Public Health Standards (OPHS) do not discuss what should be done when inequities are found. This carries an implicit assumption within the OPHS that "measuring health inequities will lead to action to reduce them" (5). Furthermore, few of the specific protocols declare reducing inequities as a goal. This lack of specificity within the Ontario documents appears to temper the strong theoretical commitment to achieving health equity (4). Conversely, the $\mathrm{BC}$ documents reference populations with greater specificity, for example, by highlighting health inequities between Aboriginal and non-Aboriginal populations, or those who were formerly incarcerated. In addition to identifying populations and producing 'snap shots' of high-risk subgroups, the $\mathrm{BC}$ documents also emphasize taking specific actions on SDOH through housing and community food policies, urban design and transportation, strengthening community services, and collaborative efforts to address community food security and poverty (6).

The BC documents were also distinguished from the Ontario documents by the language and metrics used to define populations. In the Ontario documents, priority populations are defined as "those populations that are at risk and for whom public health interventions may be reasonably considered to have a substantial impact at the population level" (OPHS, 2008: 2 in Pinto et al., 2012: 4). While both provinces' documents direct action toward identifying 'priority' populations, some of the $\mathrm{BC}$ documents use the language of 'vulnerable' or 'at risk' to reference populations. The term vulnerable populations is defined as "those with a greater-than- 
average risk of developing health problems. . by virtue of their marginalized sociocultural state, their limited access to economic resources, or personal characteristics such as age and gender" (PHABC, 2007: 3 in Pinto et al., 2012: 5). By relating risk of negative health outcomes to specific factors external to the individual, the BC definition of vulnerable populations differs from Ontario's definition and measurement of priority populations.

Both provinces acknowledge that addressing health inequity through action on SDOH cannot only be the responsibility of public health. In Ontario, the OPHS identify the reduction of health inequities as a societal outcome rather than as a Board of Health Outcome, and health equity and $\mathrm{SDOH}$ becomes a shared responsibility among community partners, and not solely that of local public health. In BC, health policy documents acknowledge that political commitment is required for broader health equity action. This is followed with an emphasis on the importance of action on SDOH through advocacy and community collaboration. For example, the Food Security MCP paper states: "It is well known that poverty is a major determinant in food insecurity. Significant improvements in food insecurity can be achieved through collaborative efforts to address community food security and poverty issues" (PHABC in Pinto et al., 2012: 6). While both provinces address the need for broader support from communities and organizations outside of public health, BC more clearly articulates the political requirements and specific goals of broader action.

Beyond research on health policy documents, studies of public health leaders' understandings and application of a health equity lens also highlights the need for community engagement, intersectoral collaboration, and advocacy. This comes out of a common recognition that achieving health equity requires changes to wider, upstream, structural determinants of health which lay outside public health's purview. Cheff (2017) draws on qualitative interviews conducted with community health centre $(\mathrm{CHC})$ executive directors (EDs) 
to provide an overview of $\mathrm{CHC}$ health equity advocacy work, and to highlight opportunities and obstacles for advancing health equity in Toronto. The study is unique for producing an account of concrete examples of advocacy initiatives that $\mathrm{CHCs}$ have led or participated in, and for capturing EDs' understandings of health equity advocacy in the context of their work. EDs explain that their capacity to advocate for policy change is constrained by service delivery priorities, accountability to funders, resource constraints, and non-profit restrictions. CHCs practice advocacy through two strategies. The first involves integrating individual and organisational level advocacy initiatives into service delivery. The second involves influencing municipal, provincial, and federal policy. In terms of concrete actions, $\mathrm{CHCs}$ focus on increasing access to services at CHCs and other organizations; expanding funding for local health and social services; raising awareness about health conditions within communities; increasing client networks; and growing civil engagement and capacity (5). Understandings of health equity, and advocacy initiatives range from the individual and organizational level, to the neighborhood and municipal, provincial, and federal policy levels.

At the individual level, CHCs advocate for individual clients on a one-on-one basis by providing referrals and guidance on how to access health and social services, such as specialist care, housing supports, and social assistance benefits (5). CHCs also tailor existing services to meet new needs of 'client populations'. For example, one CHC ED understood advocacy for health equity at the individual and organizational level as "identifying a need or a gap in services and saying well these services are available in English but not available in French" (6). At the organizational level CHCs also enhance service access by training staff to meet the needs of trans and disabled individuals. Broader advocacy initiatives at this level involve securing multiservice funding and partnering with other service organizations to make additional health and social services available to clients, such as community gardens, eviction prevention, supervised injection sites, and legal clinics. 
At the neighborhood and municipal policy level, $\mathrm{CHCs}$ advocate for reversing City budget cuts, and installing new bike lanes. $\mathrm{CHCs}$ also engage with municipal policy making by giving deputations and working with local counsellors to advocate for affordable housing, increased shelter space, community recreation, and affordable and accessible transportation. Some CHCs support resident-led advocacy groups, such as neighbourhood tenant associations, anti-racism campaigns, and anti-poverty action groups by providing space, food, child care, capacity-building, or administrative support. Others work with residents, legal clinics, and landlords to improve housing quality, support tenant rights, and increase resident involvement in neighbourhood redevelopment projects.

At the provincial level, CHCs direct health equity advocacy initiatives toward updating the Ontario sexual health education curriculum, expanding OHIP eligibility for babies born in Ontario to parents without citizenship status, reducing provincial employment insurance waiting periods, and increasing the provincial minimum wage. Finally, examples of advocacy aimed at the federal policy level include national prescription drug coverage, and reversing cuts to the Interim Federal Health program for refugees. Although this upstream work on the SDOH was recognized by EDs as crucial to progressing health equity, CHCs primarily organize resources and practices toward enhancing equity within service provision due to political and institutional constraints.

In addition to a recognition of the general problem of political will, EDs explained how the capacity for $\mathrm{CHCs}$ to advocate for policy change directed at the structural sources of health inequity are constrained by performance management imperatives and funding stipulations. CHCs are primarily funded through regional Local Health Integration Networks (LHINs) which prioritize the funding and delivery of primary health care. Additionally, LHINs evaluate CHC's 
performance predominately using clinical indicators, such as client encounters, and cancer screening rates. As a result, $\mathrm{CHCs}$ are careful to organize practices to produce measurable outputs in line with performance management and funding regimes.

In addition to clinical and quantitative performance regimes, $\mathrm{CHC}$ advocacy work is significantly tempered by the CRA's prohibition of any action approximating partisan political activity, and its restriction on the use of non-profit resources for political activities. To ensure advocacy work is non-partisan, CHCs must refrain from dedicating more than $10 \%$ of their revenue to non-partisan political activities. EDs found distinguishing between partisan and nonpartisan political activities confusing. Though EDs recognized the importance of political advocacy work, they indicated this could only be done outside of work as individuals rather than as representatives of their respective CHCs. These institutional constraints made advocacy difficult even where public health leaders supported upstream SDOH and HE action. This also affirms the difference between individual understandings of health equity and how it is practiced in the daily context of public health organizations. This distinction is most evident where EDs describe what counts as success relative to what is possible within current conditions of constraint:

"I mean success I think would be having legislative change and things like that but for us it's a different kind of advocacy that's not always the end result sometimes for us, it is just two more youth were served or got the service they need" (in Cheff, 2017: 5).

"We advocated for [housing support services] and I think it's been very successful but that's a very small kind of one-to-one success. It's not making more affordable housing, it's not really impacting on poverty as an issue overall but it is obviously having an effect for that individual" (in Cheff, 2017: 5) 
"The advocacy in service is centred around individualized clients, or individual groups, or not individuals but groups of clients. So the ability to pull back and look at the system and to look at systematic change is diminished" (in Cheff, 2017: 5).

Although advocacy mostly occurs at the level of individuals accessing services, these EDs acknowledge that legislative and systemic change is necessary to achieving success.

Rizzi's (2014) research also reveals some of the differences between how health equity is understood in practice, health documents, and in theory. Her study of Ontario front line staff (FLS) perspectives on health equity highlights several alignments and divergences between FLS descriptions of equity in public health practice and how equity is addressed in provincial policy documents. While both focused on equity in relation to SDOH and priority populations, FLS perspectives and provincial policy documents differed along a number of dimensions. As an ideal end, FLS defined and understood health equity through terms such as 'social determinants of health', 'equal access', 'equal opportunity to health and services' and 'fairness'. When discussing health equity in practice, it was discussed in terms of 'priority/vulnerable populations', 'economic and political constraints', 'participation in policy making processes', and 'population-wide vs targeted action'.

In terms of FLS' individual understandings of equity, FLS acknowledged equity as distinct from equality, and used terms like justice and fairness to describe the concept (47). However, no attempt was made to interpret how justice or fairness was understood. Nevertheless, Rizzi's (2014) study is useful for identifying social justice as a salient value that is held among front line public health workers and which plays an important role in how health 
equity is understood. This study was also useful for describing how an application of a health equity lens almost exclusively takes the form of identifying priority populations.

In similarity to other studies in this review, Hassen and Tyler's (2017) research also shows how those working in Ontario public health units (PHUs) in accordance with OPHS apply a health equity lens in their work exclusively by identifying priority populations. The researchers conducted interviews with policy makers and used survey data collected from 36 PHUs to examine how the newly introduced term, 'priority populations' is applied by those working in public health. They also sought to understand how the new language of the priority populations mandate (PPM) ${ }^{24}$ helped or hindered PHU action on health equity and SDOH. Ultimately, the focus on priority populations was not found to translate into action on health equity and SDOH.

The researchers found practitioners often understand equity in relation to the SDOH, but often do not identify populations based on SDOH due to the requirements to support actions with epidemiological evidence. They identified a theoretical divide between those who identify populations based on $\mathrm{SDOH}$, and those who identify populations based on burden of disease. If health inequities are those inequalities which are unfair, it would seem identifying priority populations based on burden of disease is an inadequate means of addressing unfair health differentials. This inadequacy and the institutional rationalities that maintain it will be discussed in the next chapter.

Outside of Ontario, as part of the Equity Lens in Public Health (ELPH) programme of research ${ }^{25}$, Pauly and colleagues (2017) studied how health system leaders in British Columbia

\footnotetext{
${ }^{24}$ In 2008, the updated OPHS introduced a new policy mandate requiring public health units (PHUs) to identify priority populations as a way to address health equity. This has been referred to as the priority populations mandate (PPM).

${ }^{25}$ The Equity Lens in Public Health (ELPH) was a program of research "implemented to study and
} 
construct health equity and apply a health equity lens. They found that many public health workers in $\mathrm{BC}$ rarely use the term health equity. Responding to requests to define health equity, participants frequently noted the salience of health programs targeted at specific populations, termed 'targeted', 'special', 'at risk', or 'vulnerable' (496). These variably referenced populations are considered proxies for those experiencing health inequities. ${ }^{26}$

Health system leaders in $\mathrm{BC}$ discuss health equity and actions to reduce health inequities in terms of population health, determinants of health, accessibility, and challenges of 'health equity talk'. Participants indicated that challenges of health equity talk reflect different understandings of health equity in relation to vulnerability (e.g. individual versus structural), and determinants of health (e.g. material versus non-material social determinants). These challenges to health equity talk were attributed to the lack of strong guidance available for applying an equity lens within the health system. This uncertainty created confusion and conflict over whether health systems should develop programmes that are targeted, or based on proportionate universalism. This study further reinforces the importance of creating a shared understanding of health equity within public health that can guide the application of a health equity lens toward meaningful ends. Furthermore, these findings mirror the experiences of those working in in Ontario public health institutions where a lack of strongly worded policies was found to inhibit action on health equity and SDOH (Rizzi, 2014; Hassen and Tyler, 2017 McPherson et al., 2017). Lastly, Pauly and colleague's (2017) article stands apart from the

\footnotetext{
facilitate learning about the use of an equity lens during a period of complex system change in public health in BC, with an aim to inform systemic responses for reducing health inequities" (Pauly et al., 2017: 493)

${ }^{26}$ This is significant for several reasons. If equity is already used in place of justice because equity is perceived as more countable and objective (Smith, 2016: 160), then using a further proxy for equity such as 'at risk' strays discursively even further from equity's foundation in social justice. Furthermore, risk is a vague and flexible concept with close relations to actuarial methodologies. Because of this flexibility, its distance from normative ethical reasoning, and its proximity to quantitative assessment, a term like risk may work well within dominant regimes of public health practice while failing to facilitate the job of justice.
} 
existing research on health equity for being the only study to adopt a critical orientation to knowledge production. This allowed for a critique of limited and reductive understandings of health equity. Additionally, applying a critical perspective allowed them to highlight important shifts needed for public health to advance health equity. These include the need for a health equity lens to encompass both the production and distribution of health inequities, and for social justice to inform action.

\section{Conclusion}

Although few of these studies centred on answering the specific questions posed at the beginning of this review, one is able to glean an account of how equity functions in health policy documents, and how a health equity lens is understood and practiced. Given the regionalism characterising Canadian public health organizations, and that most of the research on the deployment of health equity focuses on the $\mathrm{BC}$ and Ontario contexts, this review's findings do not necessarily support pan-Canadian conclusions. Despite these limitations, this review still yielded insights into the following questions:

1) What role does the concept of health equity play in health policy documents, generally?

If we are to use Giacomini's $(2004 ; 2009)$ typologies, the studies outlined throughout this review indicate that at times, equity plays a 'decorative role', (e.g. as a core value in PHAC Core Competencies document) while at others, it plays a 'scaffolding' role (e.g. in provincial public health policy documents) by generating an orientation or 'equity lens' without specifying a specific course of action to achieving some morally worthy end (Pinto et al., 2012; Tyler and Hassen, 2015; Hassen and Tyler, 2017; McPherson at al., 2017; Pauly et al., 2017). In some provincial documents, the concept of health equity offers an orientation coupled with actionable 
language around identifying vulnerable or priority populations, however it is unclear how the prescribed actions lead to more equity. While equity's practice-guiding role lack specificity, particularly with respect to how action is to achieve a morally significant and consistent end, it does take on a productive or role as well. It is equally unclear as to what an equity lens is, as to what it is not. Through its very ambiguity and lack of clear direction, the language of equity produces an accommodating space of action and discourse.

More of my own analysis will follow in subsequent chapters, but it worth noting here two of my own findings which relate to how the value of equity functions in health policy documents. My primary analysis of the 2018 OPHS indicates that success does not depend on the theoretical version of equity outlined in the documents, but some principled commitment to equity does guide practices in concrete ways. If concrete action is taken to be measurement, then including constructs such as equity stratifiers or health determinant indicators aimed at measuring health inequities is not merely window dressing as equity is embedded in the very action of measurement. If policies such as those within the OPHS' (2018) Health Equity Guidelines take measurement to be concrete action guided equity, then it becomes difficult to categorize actions as decorative, scaffolding, or foundational, however short of achieving a more ambitious idea of equity this falls. I attribute this difficulty to the flexibility of equity itself as an empty signifier which allows practices to produce success by always measuring up to whatever equity is purported to be and do at a given time. What we are left with at this point is a strong critique of the incongruity between theoretical definitions of equity set out in documents, and the actions those documents proscribe for achieving them.

Further research may follow Giacomini and colleagues' $(2004 ; 2009)$ work by delving into the ontological status of equity as a value. The authors assert that the way stakeholders see values reveals different ontological assumptions about the substance and form of values. 
These come in different forms of goodness, such as principles; specific goals; attitudes and feelings; or a physical entity such as the health system or services and programs. For them, equity fell under the rubric of principles, or general ethical imperatives, in contrast to less abstract, more specific goals such as access, prevention, and health states. This distinction is important because different ontological forms of equity translate into vastly different ends requiring just as different means. For example, whether equity is opportunity to access services, a feeling, such as empowerment, an outcome, a distribution, or a fair state of social relations will require different commitments from public institutions. The substance, form, and location of the real-life manifestations of values like equity will also require different commitments from our models of knowledge production and evaluation.

\section{ii. What kinds of concrete actions are prescribed as part of a health equity lens?}

Equity is often listed in value statements with no relation to concrete actions (Giacomini et al., 2004; 2009). When concrete actions are prescribed, public health policies direct organizational action toward measuring populations and using statistics to produce snapshots of at-risk sub groups. By focusing on local needs rather than the production of deficits, this implicitly indicates a distributive justice perspective. As Pinto and colleagues' (2012) analysis of policy documents from $\mathrm{BC}$ and Ontario reveals, both provinces primarily focus on measuring priority populations, however the specificity and range of actions prescribed can depend on regional context. Ontario documents only focus on identifying priority populations where priority populations may be based on SDOH or burden of disease while BC policy documents direct public health organizations to measure priority populations using with a consideration of material $\mathrm{SDOH}$. Despite any regional contrasts between these sets of organizational directives, research examining how public health leaders and frontline staff in both provinces actually apply a health equity lens shows that priority populations are often identified based on burden of disease or 
some need that can be met within existing organizational capacities, and for which actions can produce and be supported by epidemiological evidence (Rizzi, 2014; Tyler and Hassen, 2015; 2017; Pauly et al., 2017).

As my primary analysis in subsequent chapters shows, PHAC and $\mathrm{CIHI}$ also emphasize measuring sub populations as a way to progress health equity:

"Health equity is the absence of unjust, avoidable differences in health care access, quality or outcomes. It is a growing priority for Canada's health care systems, as it is a key component of health system performance, including quality of care. Measuring inequalities across relevant population subgroups allows us to identify differences in health care and health service utilization that can be acted on and used to measure progress toward achieving health equity" (CIHI, 2018: 7).

This selection adds to this review's conclusion that much of applying a health equity lens involves identifying populations or identifying gaps in existing services. This definition of health equity is unique for several reasons. First, it provides a clear description of what is unfair while providing logic for why it is unfair. This excerpt also outlines how a concrete action (measuring inequalities across population subgroups and differences in health service use) is functionally related to the preceding definition of health equity (it permits acting on differences in health service use and measuring progress toward achieving health equity). It is clear that what is to be judged are health outcomes in relation to service access and quality, and that supporting this particular conception of equity involves ensuring the equal distribution and quality of health care. This marks a departure from taking socially determined health inequalities as that which can be judged, and the transformative action that tackling this would require. The stated concrete actions and justifying logic show an implicit commitment to distributive conception of justice to 
be realized through equalizing access to health care. By identifying differences in health care as a way to measure progress toward achieving health equity $(\mathrm{CIHI}, 2018: 7)$, this concrete action is mitigative and managerial. As mentioned in the previous chapter, when only the distribution of health care is taken as that which should be judged, the distributive requirement of justice may be met if remaining health inequalities are not the result of an unfair distribution of healthcare. When thinking of action in these terms, it becomes clear which form of justice that action on health equity follows, and which it does not.

While I have interpreted current health equity action as reflecting an implicit distributive idea of justice, an important task is to examine the degree to which applying a health equity lens means taking people and their conditions 'as they are' and working with whatever resources we already have, and within whatever social conditions we already find ourselves in. This is still ambiguous though. Recall the questions I presented in Chapter Three for making sense of the aims of distributive justice within particular contexts: 'What is to be distributed?'; 'How much should be available for distribution?'; 'What is a fair distribution?'; and 'By what means will this distribution be achieved?'. These help us understand to what degree we 'take people as they are' because we can now direct inquiry toward the what will be districted, the total amount, or pool, of those various goods that will be distributed; the actual distributional pattern of goods; and the mechanisms for ensuring this distribution.

When looked at through a normative ethics lens, what is clear is that the current emphasis on measuring inequalities while neglecting the individuals or social relations that produce unjust suffering indicates a passive form of distributive justice for only focusing moral attention on those who already experience or suffer justice or injustice (See Pogge, 2004: 143). Communities can be empowered, and services can be 'oriented and tailored' and perhaps expanded, but relational questions about who is responsible for causing the injustice, and who 
is responsible for rectifying injustice, are absent. Neglecting these necessary questions for acting on a relational idea of justice is the result of several barriers which will be discussed in the following chapters.

2) How do people working in public health understand and apply a health equity lens?

Other actions directed at progressing health equity involve addressing problems of political commitment and sectoral boundaries through advocacy and community engagement. This was most clearly elucidated by Cheff who provided the clearest and broadest range of examples of how a health equity lens is actually practiced. It is worth delimiting the different types of demands that various forms of collaboration, engagement, and inclusion place on individual agency and public institutions. This line of inquiry will be pursued further in Chapter Nine which specifically explores the role of community as a nodal point in health equity's extended invocation in public health discourse. Advocacy and community engagement were discussed as integrated practices rather than separate. Cheff (2017) indicates that any advocacy work approximating political action is chilled by CRA's restrictions on charity-status organizations. Instead, community engagement is practiced as an alternative means of acting on those SDOH which lay outside the narrow purview of public health. Some CHC EDs spoke of supporting resident-led advocacy groups; raising awareness about health conditions within communities; increasing client networks; and growing civil engagement and capacity. This strategy mirrors that which is promoted within BC health policy documents which support community engagement as a way to meet equity's needs for 'political commitment throughout' (Pinto et al., 2012). My primary analysis of the 2018 OPHS also indicates a strong and recurring emphasis on community collaboration and engagement. 
While the advocacy initiatives that were found to be the easiest to achieve operated at the individual level, or involved expanding services, Cheff pointed out several examples of broader advocacy initiatives involving expanding material resources and intervening on socialeconomic relations. Broader advocacy initiatives aimed at expanding services involve securing multi-service funding and partnering with other service organizations to make additional health and social services available to clients, such as community gardens, supervised injection sites, and legal clinics. CHC EDs are also involved in municipal policy making by advocating for community recreation, and affordable and accessible transportation. Advocacy initiatives aimed at expanding material resources involved engagement with municipal policy-making by giving deputations and working with local counsellors to advocate for affordable housing and increased shelter space. This can be read as a form of upstream mitigative distributive action. Examples of CHCs advocacy work aimed at national prescription drug coverage, eviction prevention, reducing provincial employment insurance waiting periods, increasing the provincial minimum wage are interventions aimed at social-economic relations. Intervening on employment insurance and drug coverage can be interpreted as a more protective/preventative aim, rather than a mitigative distributive aim, while eviction prevention and increasing the provincial minimum wage can be interpreted as relational aims of justice because they intervene on the employment relationship and the tenant-landowner relationship.

\section{ii. How do those in public health prioritize which inequalities matter most?}

Individuals working in public health do not appear to have a coherent way of identifying which inequalities are unjust, or which are the most morally worthy of addressing. There is, however, a rationality which guides the prioritization of health inequalities independently of their moral significance. As will be further explicated in the following chapter, those working in public health often measure priority populations based on burden of disease or service needs, 
irrespective or moral salience. These empirical indicators are easy to use for constructing and surveilling subpopulations. Because of local data constraints, and the imperatives necessitating their use, we are unable to identify which inequalities matter most based on a relational framework. From a welfare-sufficientarian-relational perspective such as that advanced by Powers and Faden (2006), the inequalities that matter most are those that cause cascading and interacting effects on deprivation (70), or those systematically overlapping social determinants that affect multiple dimensions of wellbeing (72). Answering the question, 'which inequalities matter most?' will depend on contextual information about how actual institutional practices and social arrangements affect differentially socially situated persons and groups in various ways (31).

Furthermore, public health staff do not identify inequalities according to their effects on human wellbeing or relation to their agency or responsibility for self managing their wellbeing. Those health inequalities that matter most are those that have the most impact on the population level. Conversely, others in public health adopt an 'equity first' approach by using their theoretical knowledge of $\mathrm{SDOH}$, and by exercising context-based knowledge of community needs. This approach transgresses institutional emphases on evidence-based-decision-making laid out in provincial standards, leading many working in public health to adopt a burden of disease approach. Research shows that those in Ontario and BC do not necessarily measure or prioritize which inequalities matter most in relation to a conception of fairness or injustice. Instead, those in public health prioritize which inequalities matter most according to which can be supported by EIDM, and which can make the greatest impact on overall population health. This is troubling given inequities are specifically those inequalities that are unfair, and that the task of determining which inequalities matter most is widely considered the primary task of 'doing the job of justice' in public health. In addition to failing to identify which inequalities are unfair, and which matter most, current practices of making up populations do not produce 
knowledge about what might be taken as practical targets structural intervention. ${ }^{27}$ Throughout this project, I suggest that what becomes morally important in health equity action is that which lends to measurement and evaluation. This allows us to explain the current moral orientation of health equity as the result of a particular strategy's' evidentiary productivity and conformity rather than as the result of careful ethical deliberation.

The next chapter draws from this chapter's literature review to elucidate some of the practical barriers faced by those working in public health to practicably support some idea of health equity. It will also parse out some of the empirically identified problems that I place in more historical context in Chapter Six.

\footnotetext{
${ }^{27}$ A further task would be identifying alternative social arrangements, however political this task is taken to be. Pursuing a relational conception of justice would involve identifying those groups or individuals who benefit from health inequity, and the structures that make this possible.
} 


\section{Chapter 5: Barriers to Health Equity}

While health equity has increasingly become a chief goal to be achieved through public health policies and practices, action on health equity is troubled by the following problem: As 'inequalities that are unfair or unjust and avoidable or unnecessary', health equity has a measurable disparity component which derives its moral importance from some idea of fairness or justice, but this idea of fairness as socially determined has not become the object of measurement, analysis, or normative ethical deliberation within public health. While a disparity or inequality is an inequity warranting special moral attention to the extent that it is unfair/unjust, in practice, this disparity is not identified in relation to unjust social relations that produce it in the first place. As a result, it remains unclear as to which inequalities are unfair or unjust, which are the most morally worthy of tackling, and how equity-as-fairness will be pursued. This signals the epistemological dependence of justice as much as it signals the need to engage with normative ethic to ensure its evidentiary support.

This chapter will outline some of the barriers to progress on health equity and SDOH that I identified in my analysis of the existing empirical literature on health equity. These barriers are related to the following attributes and inadequacies of policy and knowledge production within public health: 1) Flexibility and failure to articulate policy goals in relation to some clear and consistent conception of equity as fairness; 2) Evidence-informed decision making (EIDM) and performance management; 3) The reorientation of equity-related practices toward population health ends. After using examples from the empirical literature on health equity to illustrate each of these impediments, this chapter will theorize these barriers as a configuration unified by four highly compatible rationalities which shape its component parts. These rationalities can be delineated as organizational, programmatic, epistemological, and ethical in nature. 


\section{Embedding Explicit Language of Social justice within Public Health Policy}

In Ontario, a lack of strong guidance combined with ample flexibility afforded by the language of priority populations in the OPHS has been found to hinder action on health equity and SDOH (Rizzi, 2014; Tyler and Hassen, 2015; Hassen and Tyler, 2017). Public health leaders find the priority populations mandate (PPM) lacks specificity with respect to how the new language of priority populations are related to $\mathrm{SDOH}$, what constitutes a priority population, and what kinds of action should be taken (Hassen and Tyler, 2017). The upshot of the new language was a de-emphasis on social justice and advocacy as some policy makers did not understand how health equity and SDOH are related to priority populations (5). Health equity was also perceived by some as "not crucial in PPM" and "not the most important outcome" (5). Introducing the term priority populations was also perceived to weaken the connection to health equity because of differences in opinion regarding the term, 'social justice' (9). This lack of conceptual clarity affirms the value of clarifying the normative justice component of health equity and making it explicit in practice-guiding policies.

Creating greater clarity among those working in PHUs, requires a firmly guided top-down mandate with clearly defined terminology and strong language. Some PHUs stated they lacked support from Boards of Health who did not want to invest in broader initiatives outside of health services (6). Respondents felt that the Boards of Health, which govern each health unit, would be more likely to accept upstream work if the priority populations mandate had been more strongly worded (6). This insight coincides with the findings of McPherson and colleagues' (2016) case study examining the implementation of 'social determinants of health public health nurses' to address health inequity in Ontario. Their research found that while organizational culture can support SDOH and health equity, ideological tensions within organizations limited the role of the newly-appointed social determinants of health public health nurses' in programme development and implementation. 
Some of the policy makers in Hassen and Tyler's (2017) study felt that the language of social justice should be avoided because it causes a divide. If health equity is inherently valueladen and bound to some conception of social justice, and if others in public health call for stronger language, it seems abandoning the language of social justice would not progress health equity, despite any unity it might ensure among professional practices. Perhaps the tendency for social justice to cause a divide is not simply due to its status as a normative value, but rather, to the inconsistency and lack of specificity with which it is deployed. However, this problem is not merely one of semantic disagreement stemming from equity's inconsistent and vague articulation. Adding to this problem is the way in which equity becomes the object of inquiry within a particular regime of knowledge production, and the related conditions of possibility that shape and constrain its treatment and subsequent deployment.

\section{Barriers to Evidence-Based Practice as Barriers to Health Equity}

Having to use epidemiolocal data and surveillance to identify priority populations and support action has been found to hinder action on health equity and SDOH (Rizzi, 2014). In Ontario, identifying populations based on burden of disease is the only option which meets the goals of population health and fulfills the standardized requirements for action to be supported by epidemiological evidence. Additionally, the OPHS require public health units to support action on heath equity and $\mathrm{SDOH}$ with evidence that a particular $\mathrm{SDOH}$ is causing a negative health outcome within a specific population. When evidence is not available, barriers to producing the kind of evidence required for EIDM become barriers to progress on health equity. This problem is described by front-line staff (FLS) in Ontario as a conflict between the OPHS' emphasis on EIDM and their desire to use practical and theoretical reasoning when identifying priority populations (Rizzi, 2014: 63-5). This supports an important argument in this project that 
advancing a consistent idea of equity is not only dependent on political will, but also by evidentiary imperatives embedded within institutional contexts.

While the OPHS allow for flexibility when identifying local population needs, needs must still be identified through epidemiological surveillance, rather than through practical or intuitive reasoning (63-5). This imperative limits the range of programmes that FLS can implement, often resulting in programme termination. For example, FLS mentioned that many targeted programs aimed at issues of inequity were discontinued because they lacked the necessary evidence to support them. FLS pointed out that these targeted programs were not discontinued because evidence proved the programs ineffective, but because staff could not produce the right kind of evidence which demonstrates the populations' need for the programme (63-5). This illustrates how progress on health equity and $\mathrm{SDOH}$ is compromised by administrative requirements that privilege forms of quantifying knowledge production and exclude practical and theoretical reason.

Rizzi's (2014) insights are corroborated by other research in Ontario which identifies a theoretical divide between those who employ a more objective 'burden of disease' approach to identifying populations, and those who employ a 'health equity first' approach, identifying priority populations qualitatively through community engagement or practitioner experience (Hassen and Tyler, 2017: 7). This divide between can be linked to challenges posed by EIDM. Identifying priority populations qualitatively, based on experience and relationships with communities, rather than epidemiological data, was described as problematic "if it looks like you are just picking a population to try and say[ing] I hope this works" (7). Unfortunately, the alternative use of epidemiological data and surveillance was not seen as possible because PHUs struggled to provide disaggregated epidemiological data at the local level which shows a specific SDOH was causing a particular health outcome. Although the OPHS require local PHUs to consider the 
determinants of health when identifying priority populations, PHUs often could not do so because of the insurmountable burden of evidence needed to justify action on SDOH.

Because of the narrow conceptions of what constitutes evidence, PHUs are unable to exercise experiential knowledge of the local context, and knowledge of SDOH to identify populations while fulfilling the stipulations of EIDM. EIDM requires a particular kind of proof that a SDOH causes a negative health outcome. EIDM privileges quantifying/statistical forms of knowledge production on which it confers authoritative status. However, given the lack of available published evidence in some areas and data gaps, these requirements for evidence were seen as insurmountable. Because "a values and experience based premise for focusing on $\mathrm{HE} / \mathrm{SDOH}[. .$. ] may not be construed as evidence-informed" (7), some practitioners identified priority populations by burden of disease despite acknowledging that it undermines and detracts from action on $\mathrm{HE} / \mathrm{SDOH}$. This shows how EIDM can be a barrier by creating insurmountable data requirements for justifying how practice is organized and resources are directed (5). While the burden of disease approach undermines health equity, it 'works' with dominant epistemological orientations and conceptions of what constitutes evidence-namely, that which is quantifying and statistical. Furthermore, identifying priority populations based on burden of disease meshes well with dominant practices of population health as staff are able to fulfill the directive to identify groups "for which public health interventions may be reasonably considered to have a substantial impact at the population level" (OPHS, 2008: 2).

\section{Achieving Population Health Alongside, or Through Health Equity?}

A health equity lens operates within, rather than alongside population health practices. Instead of standing alone as a distinct goal with importance in and of itself, equity is constructed and understood in relation to population health. When the goals of population health and health equity are conflated, action on health equity tends to be 
instrumentalized as a means to achieving higher population health, and the determinants of health and the social determinants of health become conflated. A final implication is that priority populations are not identified in relation to unfair social relations, but rather, to some neutral and quantifiable metric that permits measurable and optimizable population health outcomes, irrespective of concerns for fairness.

In Pauly and colleague's (2017) study on understandings of health equity among health leaders in BC, participants noted they do not discuss health equity as an explicit term, but instead consider it as an implicit term within discussions about population health. This runs in parallel to the confusion expressed by FLS in Ontario around prioritizing targeted vs universal programs (Rizzi, 2014). While provincial documents state that a balance between targeted and universal approaches should be met, FLS feel they lack guidance for accomplishing this (66). As a result, FLS often adopt a 'targeting within universalism' approach. FLS who are often instructed to design and implement populationlevel public health programs recognized that these programs often do not benefit priority populations and that this can actually widen health inequalities (66). The lack of strong guidance for addressing health inequities is coupled with an explicit focus on the dual aims of health equity and population heath within provincial documents. Several studies have pointed out that parts of the OPHS state achieving health equity is as important as improving overall population health, and secondly, that both goals can be achieved simultaneously (Pinto et al., 2016; Hassen and Tyler, 2017). By seeking to achieve both goals simultaneously through the same programmes of action, health equity becomes valued as an instrumental means to achieving the goals of overall population health.

Under the 2008 OPHS, priority populations are defined as "those populations that are at risk and for whom public health interventions may be reasonably considered to have a 
substantial impact at the population level" (OPHS, 2008: 2). By stating that priority populations are "those populations that are at risk and for which public health interventions may be reasonably considered to have a substantial impact at the population level" (OPHS, 2008: 2 emphasis added), the OPHS suggest that health equity work is to be carried out within a population health mandate, rather than alongside it. This also sets out the ultimate ends of public health action, principally_to have a substantial impact at the population level by raising the average by improving the lower tail of the distribution. Similarly, under the principle of need, the OPHS reads,

It is evident that population health outcomes are often influenced disproportionately by subpopulations who experience inequities in health status and have comparatively less control over factors and conditions that promote, protect, or sustain their health. By tailoring programs and services to meet the needs of priority populations, boards of health contribute to the improvement of overall population health outcomes (OPHS, 2008: 12).

By recognizing that some subpopulations experiencing inequities have comparatively less control over their health, this discourse avoids 'blaming the victim', but this acknowledgement does not clearly speak to how these subpopulations are to be identified in relation to the causes and experiences of inequity. The reasoning behind the identification of priority population, however, is made clear: Applying a health equity lens is an instrumental means to achieving greater aggregate population health.

\section{The Convenient Confluence of Utilitarianism, Population health, Positivism, and New Public Management}

Having described some of the barriers to meaningful action on health equity, this section will theorize how these barriers emerged, and why they 'work', leaving little room for alternative 
approaches to enter the configuration. It remains unclear as to which inequalities are unfair or unjust, which are the most morally worthy of tackling, and how progress will be achieved. It has been argued throughout this chapter that part of the difficulty of determining which inequalities are unfair stems from the dominance of population health, EIDM, and flexible, neutral policy language lacking reference to a clear and instructive conceptualization of social justice. And although Canadian public health institutions have not attempted to conceptualize or communicate equity in relation to coherent conceptions of fairness outlined in moral theory, what appears to be left by default, and not through careful ethical and political deliberation, is an orientation towards classical utilitarianism.

While several health scholars have critiqued utilitarian orientation of public health for its reliance on a single principle of maximal return and for its inadequacy for dealing with injustice or inequity (Beauchamp and Childress, 1994; Powers and Faden, 2006), to my knowledge, no one has elucidated how these inadequacies play out empirically in the context of public health, or how these inadequacies relate to ancillary barriers to progress on health equity and SDOH. Nor has anyone theorized the convergence of these barriers in relation to utilitarianism and their simultaneously guiding and binding rationalities. I suggest that utilitarianism is the only moral orientation that could fit, governmentally within the configuration of rationalities that govern public health institutions' practices in which neutrality and quantifiability are paramount. This configuration can be theorized as a convenient confluence of utilitarianism, positivist epistemology, population health, and new public management. These barriers did not emerge out of the willful intent of any individual or group, but rather, out of a convenient convergence of programmatic ends, administrative management regimes, and epistemological paradigms, each requiring neutral and quantifiable data. 
The practice of maximizing the health of a population as a whole has obvious classical utilitarian underpinnings in that it seeks to maximize overall utility in the form of aggregate population health, regardless of its distribution. As a single principle, utilitarianism is ill-equipped to address issues of inequity or injustice ${ }^{28}$. Classical utilitarianism does not require a fair distribution of benefits and burdens with regards to differential need or responsibility for producing the benefits and burdens in question. Under a classical utilitarian doctrine, one person's need is as worthy as any other's and what makes an action good is that is maximizes good. This is critiqued by John Rawls' when he writes "[u]tilitarianism does not take seriously the distinction between persons (Rawls, 1971: 27). Under a utilitarian perspective, what is taken as good is not a relationship, but an outcome.

If a minority of the population is unfairly disadvantaged to the benefit of the majority, this could be morally just under a utilitarian doctrine. Likewise, if priority populations are identified as "those populations that are at risk and for whom public health interventions may be reasonably considered to have a substantial impact at the population level" (OPHS, 2008: 2), public health interventions might maximize average population health without addressing health inequities at all. This is especially of concern for those populations experiencing health inequities who are of significant numerical minority but are nonetheless worthy of at least equal moral concern. Simply maximizing aggregate health regardless of distributional and relational factors would be unfair according to many conceptions and principles of justice. This reveals a disjuncture between the ideals of social justice and a utilitarian approach to redressing health inequities.

\footnotetext{
${ }^{28}$ Utilitarianism was not developed to assess fairness or to rectify injustices. It was originally developed for judging social and legal reform during the enlightenment period. It was used to determine which laws and actions were consequentially good and which were bad in an era where objective reason eclipsed both religious doctrines and pre-Christian virtue ethics. This perspective stemmed from liberal political philosophy, which considered natural law approaches to be in violation of liberty and autonomy. At the time, it was a novel perspective to posit that one could understand the moral quality of an action as something to be determined instrumentally and not by virtue of its essential right or wrongness (Driver, 2014).
} 
The utilitarian tendency of not taking seriously the distinction between persons and their relation to social structure 'works' by maintaining political neutrality of population health practices. Additionally, the emphasis on utility maximization works because it dovetails with institutional imperatives to support programmes through EIDM and by demonstrating quantitative output.

The convergence of population health approaches, utilitarianism, positivist epistemology, and performance management standards reminiscent of new public management establishes a formidable barrier to advancing health equity. The convergence between the abovementioned practices and their internal logics operate through quantitative, atheoretical, neutral vectors of knowledge production and translation, replacing a normative sense of 'goodness' with the production of quantifiable and manageable outcomes. As atheoretical practices and logics, their purveyors are only concerned with measuring outcomes, rather than producing an understanding of why there are differences in outcomes. By operating through putatively neutral forms of reason, public health actors do not outstep their organizational boundaries, or disrupt the current social, political, or economic order.

Despite the inadequacy of utilitarianism as a moral theory for addressing health inequity, it works within regimes of new public management which necessitate organizations to quantifiably demonstrate maximum efficiency of output. New public management is an approach to running public service organizations which involves creating greater semblance between private sector and public sector organizational processes. In parallel to utilitarianism's emphasis on accountability and efficiency of consequences, new public management involves a shift from an emphasis on greater accountability of process towards an emphasis on greater accountability of results. There are many distinguishing dimensions of NPM including reconfigured reward structures, short term contracts, efficiency, and the facilitation of 
competition (Hood, 1991: 4-5).$^{29}$ The characteristics most relevant this discussion are those of performance standards, output controls, efficiency, and flexibility afforded by decentralization. These four dimensions of NPM parallel those barriers to action on health equity and SDOH that have been highlighted in the empirical literature on health equity action.

Regarding performance standards and output controls, research reveals how the need for demonstrating numbers to funding agencies hinders health equity and SDOH advocacy work. For example, Cheff (2017) points out that community health clinics (CHCs) in Ontario are primarily funded through regional Local Health Integration Networks (LHINs) which evaluate CHC's performance predominately by using clinical indicators (e.g. client encounters, cancer screening rates). Executive directors of the clinics stated this evaluation regime limits advocacy initiatives aimed at reducing health inequities through action on $\mathrm{SDOH}$. Although having to demonstrate performance by accounting for clinical indicators hinders action on health equity, this performance management regime produces quantitative accountability and assessmentkey requirements within NPM.

Behind the emphasis on quantification required for performance management is the rationality of accountability and efficiency. EIDM supports organizational imperatives for public health organizations to demonstrate accountability and performance through measuring expected and actual efficiency of interventions. This meshes with the utilitarian imperative for ensuring maximal return on investment, irrespective of other aims of justice. Maximizing and communicating utility to stakeholders maintains accountability, and communicating

\footnotetext{
${ }^{29}$ NPM can be contrasted with preceding approach to NPM, new public administration (NPA), in two significant dimensions: First, NPA takes value-neutrality as an impossibility. Because of this, values served through administrative action are to be made transparent. Secondly, social equity is a chief goal of public administration under NPA.
} 
accountability requires the effect of expected or actual outcomes to be calculable. Therefor, even if prevailing institutional arrangements do not maximize utility in either a wider normative sense of the 'good', or in a way that is made perceptible through the use of narrow health outcome indicators, achieving this maximal utility through social change cannot be sold if expected or actual utility is not immediately calculable. Because of the quantitative burden of proof that both EIDM and utilitarianism require to justify an action as efficient or morally good, both are predisposed toward working within the political status quo.

Even though EIDM has been identified as a barrier to action on health equity and SDOH (Rizzi, 2014; Hassen and Tyler, 2017), some public health professionals describe how EIDM supports the 'business case of health equity / social justice' (Hassen and Tyler, 2017: 4) and promotes "objective conclusions that ten[d] to be more favorably received by programme funders and decision makers" (6). Relatedly, PHUs perceived evidence requirements in the priority populations mandate to be important for "organizing practice and directing resources through EIDM in an environment where justification for action on SDOH was challenging" (4). The requirement for epidemiological evidence was well received because it is important to be able to "defend your use of resources during this fiscally tight times" (6). ${ }^{30}$ Even well-meaning public leaders acknowledge that health equity work must be approached strategically by defending actions that provide good value for money. The importance of selling the idea of equity is also seen in the statement that "[i]t will require the right kind of evidence to move funds from health services to preventative work. For example, improving the lives of homeless people

\footnotetext{
${ }^{30}$ Although EIDM was also highlighted as a facilitator to action on $\mathrm{HE}$ and $\mathrm{SDOH}$, a critical reading of these findings would suggest that EIDM is only a facilitating policy attribute in an administrative environment which requires such forms of evidence for action-or, put differently, a system which makes a lack of such evidence a barrier to action. Arguably, action on health equity and SDOH would be better facilitated if organizing practices and directing resources took place in an environment where justification for action on SDOH was not challenging, and where one did not have to make the business case for health equity and social justice.
} 
will result in fewer visits to the emergency room [...] (HQO). The requirements of EIDM, and the need to promote the business case of health equity and social justice illustrates how moral and political issues about fairness and social justice become reduced to technical problems which solely warrant technical solutions based on scientific and economic rationality, and not political and ethical reasoning. It is however noteworthy that the technical character of new public management and population health eclipses political reasoning while still having political effects by maintaining the current state of unfair social relations. If justice becomes a matter of utilitarian calculation devoid of political discussion, it is not effectually any less political even if it appears so. By allowing existing social relations to continue perpetuating inequity, the myopic focus on technical indicators of outcomes it is not neutral, but technical, and in a sense, political-not in its process, but in its effects. In the same way that discourse as process can be operationally distinct from ideology as effect (Poovey, 1998), the dominance of EIDM is technical in its process, but by only permitting decisions based in scientific evidence, actual decisions are limited by what is not captured by relevant modes of evidence production. By maximizing effects within social conditions that are taken as pre-given and unalterable, and by only deploying those actions that are evidence-based, EIDM supports a conservative status quo, including the unfair social relations that preside in it. Furthermore, if the only way that structural determinants of social relations can be considered changeable, is if they are scientifically knowable, and if these conditions cannot be scientifically knowable, then a neutral commitment to EIDM and maximizing utility is ideological in its effects.

The imperative (or wait) for scientific truth and performance evaluation produces an implicit division of risk for which no origin of political intent exists. As Tesh (1988) comments, we have to live with the null hypothesis until proven otherwise. Sometimes the parties with whom the risk resides is clear, while other times it is not. However, when it is clear that some action will benefit the public while inaction will allow some incalculable but known risk for both business 
and the public to persist, policy makers and public health leaders operating through EIDM can opt not to act if the intervention does not lend well to quantitative evaluation. To wait for further evidence would often, at least in effect, sustain a bias toward the interests of business. ${ }^{31}$

As practiced, EIDM acquiesces with the status quo, inadvertently sustaining current economic and socio-political conditions, but it also reproduces the conditions of possibility that precludes open models of knowledge production and theoretical interpretation required for broader policy reform. Achieving social change through policy reform requires knowledge of social relations, domination, and exploitation, and how it is sustained by government decisionmaking. Keeping politics out of public health keeps public health out of politics. What I mean is that by keeping politics—as an object of inquiry—out of public health's models of knowledge production, the substantiated case for healthier, fairer societies is kept out of politics. I am not suggesting that it is desirable to allow the politics of the day to directly influence public health agendas in a unidirectional sense, but politics should be taken as an object to be studied in relation to health. In the words of Porter (2006), I am concerned here "less with the explicit politicization of social science than with the sacrifices required to shore up a reputation for rigor and freedom from ideology" (1274).

\section{Conclusion}

This chapter has highlighted serval barriers to action on health equity including flexibility in provincial standards pertaining to the principle of need, and guidelines for identifying priority populations. This flexibility does not merely block progress. It impedes progress on health equity

\footnotetext{
${ }^{31}$ Of course, one could argue that given resource constraints, to not maximize resources would present a possible opportunity cost, and a possible risk to the public, but as we will see in later chapters, those actions that are deemed most efficient and effective do not necessarily produce the most health, but rather, they produce the highest demonstrated output of many measures (e.g. cognitive constructs of self efficacy or service utilization) whose proximity to greater health achievement is not equally demonstrated.
} 
by discursively producing space for PHU's to identify priority populations based on burden of disease and not SDOH. This flexibility permits a dual but overlapping focus on equity and population health which tends to result in instrumentalizing the health equity lens, and conflating determinants of health and social determinants of health. The most governmental and institutionally embedded barriers are evidentiary imperatives associated with EIDM. Because of a need for local epidemiological evidence to support and evaluate actions, public health workers are constrained in what they can actually do, despite working under a fairly flexible health equity mandate.

This chapter began to explore the institutional and epistemological rationality which produced a particular way of responding to a problem without considering the origin of the problem itself as rooted in social relations which are reproduced and mitigated by government decision making and competing interests. Although pointing out the symmetry between emphases on aggregate population health outcomes and utilitarian logic makes for obvious and unoriginal commentary, a theoretical explanation of the utilitarian orientation of population health has not been advanced by others. This chapter has not argued that this orientation reflects any individual or group's wilful intent following deliberation between moral theories. Nor has it been argued that this assemblage of utilitarianism, NPM, EIDM, and positivism represents the will of individuals seeking to uphold it. It has been argued that logics and/or imperatives of each field all 'work' together, each necessitating the other, forming a configuration which leaves little space for alternative practices. Utilitarianism is the only moral orientation that could fit governmentally within the current configuration of rationalities that govern public health institutions' practices in which neutrality and quantifiability are paramount. The net effect of this well-fitting configuration is that inherently moral and political issues of social justice and literally 
embodied $^{32}$ injustice are reduced to technical issues. Additionally, by acting on and through what is calculable, conservative conditions of possibility are reproduced, ultimately limiting which kinds of interventions can be maximized or implemented at all. This reveals the relationship between epistemology and evidentiary imperatives, rationality, and social justice. While this chapter focuses on institutional/organizational barriers to action, the next chapter will attend closer to the discursive attributes of equity's deployment which lend to its successful ubiquity but also its weakness and inconsistency.

\footnotetext{
${ }^{32}$ See Krieger (1999)
} 


\section{Chapter 6: The Language of Equity: Extendable, Mobile, Quantifiable, and Neutral}

A critical discussion of health equity in discourse and action requires a discussion of the concept of equity itself. Equity can be theorized as both an empty signifier and as a vehicular idea. Used together, these categories offer an analytically useful way for understanding health equity's broad but varied uptake and deployment. What starts out as a potentially politically transformational idea based on an idea of justice and fairness turns into a varied but politicallylimited set of meanings, concerns, actions, targets, and 'lenses' all mobilized under the same signifier that is health equity. To understand both health equity's ubiquity and failure to influence public policy at the level of political economy, we cannot only look toward a lack of political will or resource constraints. While in later chapters I take the relationship between evidentiary imperatives and productivity, and political contestation as my objects (or relations) of inquiry, I will now look specifically at the discursive productivity of the language of health equity.

Claude Lévi-Strauss (1950) originated the term empty signifier (also known as a floating signifier) which was later prominently used by Ernesto Laclau $(1996 ; 2018)$ to make sense of populism and modern democracy for which the empty signifier, linked in a 'chain of equivalences' is crucial. An empty signifier becomes a symbolic 'surface of inscription' through which such an extension of meanings and practices are expressed that it is 'emptied', blurring its connection with the actual content with which it was originally associated (Laclau, 1996: 45). It allows diverse actors with different interests to rally around an idea that is divested of any specific content, allowing its followers to forget the differences between their interests, and between the various meanings of a signifier such as freedom, or equality. For Laclau, the empty signifier performs hegemonic representation of a variety of political demands which are only partially accommodated into an unfulfilled totality in which one signifier subordinates the rest. The shared coextension from concepts like 'freedom' or 'equality' produces an equivalent logic 
(within a chain of equivalences) which erases the relevance of all difference between their various invocations or what Laclau calls 'identities' (43). In less opaque terms, we can think of what he calls 'identities' not just as group identities in the colloquial sense, but as different groups' and individuals' demands, concerns, issues, interests, and the actions and ideas that encompass a commitment to their realizations.

The empty signifier becomes the symbolic form through which so many meanings and positions are expressed that its content is emptied of any consistent meaning, but this capacity to empty and unify constitutes its productive and collectivizing potential:

"[T]he chain of equivalences which are unified around this signifier tend to empty it, and to blur its connection with the actual content with which it was originally associated. Thus, as a result of its very success, the hegemonic operation tends to break its links with the force which was its original promoter and beneficiary" (Laclau, 1996: 45).

On one hand, the empty signifier offers the possibility of "pure cancellation of all difference" (Laclau, 1996: 38), allowing many disparate actors with their own particular interests to rally around one idea. This is why populist movements of both the right and the left require empty signifiers. However, the longer the chain of equivalences is, the less concrete this 'something equally present' will be (42). Whether this emptiness and partial fixation is a problem depends on who benefits from the hegemonic (partial) representation and (partial) realization of points in the chain (taken as legitimate proxies for the content of the empty signifier).

Looked at as an empty signifier, we can understand health equity's flexibility and dampened but wide adoption in terms of how it is discursively extendable within a chain of 
equivalences. As an empty signifier, equity becomes understood and associated with so many different meanings and practices that it is emptied of any enduring content to which it signifies. Now emptied and extendable, equity is anything but left out of public health discourse. Instead, health equity produces a field of legitimacy by erasing difference. However distant from a realization of its original content, the different meanings and practices share relationships to equity which each enjoy some minimum quality of legitimacy. The content of these meanings and practices can be different from one another while all operating under the same signifier. As a result, actors from various fields can successfully practice some legitimate version of health equity. The elements of the chain that are accommodated and reproduced the most are those that are the least politically and economically disruptive, and those that are the most compatible with quantitative modes of evaluation and representation.

Osborne's category of vehicular ideas is complimentary to an analysis of health equity as an empty signifier. Others have used the category of vehicular ideas to make sense of the wide support for Anthony Gidden's Third Way, and the prominence of social capital in political discourse, social theory, and population health research (Osborne and McLennan, 2003; McLennan, 2004; Denny, 2008). McLennan (2004) observes that Third Way discourse remains ambivalently gestural, lacking any definite substance while connoting an air of progressiveness (487). McLennan further notes a shift in Giddens's discourse in Third Way thinking away "from normative discourse to one governed by practical imperatives" (490) while socio-ethical concerns lose priority as "having been either fully settled upon or relegated in importance" (490). In a similar way that Anthony Giddens' Third Way has shifted from "a normative contribution to fundamental values towards a pragmatic realism" (491) about the world, limiting possibilities for political transformation, the idea of health equity shifts away from a normative contribution to fundamental values toward a pragmatic realism which forecloses possibilities for political transformation. 
An ineliminable vagueness, indeterminacy, and inclusiveness of vehicular ideas afford them their mobility. Vehicular ideas can be contrasted with 'final' moral and theoretical vocabularies by carrying multiple interpretations imbued by different actors (485). Vehicular ideas contain some minimal amount of principled theory or committed ideology to them, however they are resistant to rigorous theorization (485). While others have shown that a lack of clear and consistent practical definition is a barrier to action on health equity (Rizzi, 2014; Hassen and Tyler, 2017; Pauly et al., 2017), we can also understand how equity can move about the public health field because it is resistant to clear strong definition. However, this resistance is not just intrinsic to the idea of equity as fairness, but also extrinsic to it, as the resistance is created by the peculiar atheoretical and apolitical reason of the field in which in which it operates.

As a vehicular idea, health equity contains some minimal commitment to the idea that there should not be significant differences in health statuses between groups, and that avoidable, socially determined health inequality is unfair. Whether this minimal commitment to equality translates to equal opportunity/means, or outcomes is left as untheorized as what constitutes 'equal opportunity' or a 'socially determined' inequality. Furthermore, health equity has been resistant to rigorous theorization in public health discourse, but also in contemporary general theories of justice (Marchand, 1998)—although this has not been entirely neglected when 'justice', rather than 'equity', is used as the surface for inscription (see Powers and Faden, 2006).

Vehicular ideas get you from point $A$ to $B$, but as I show, it is not always a defined end, and this open-endedness is actually functional within sociopolitical conditions characterized by uncertainty and inevitable change. The end goal may be largely undefined, so B should not be 
thought of as a final destination, but an on-going assurance that public health institutions are imbued with a general progressive moral character-whatever practices they enact at a given point in time. As a vehicular idea, health equity sustains public health's moral character and legitimacy without being socially disruptive. In this way, health equity-as opposed to social justice-may be read as a conservative reconciliatory vehicle within neoliberal economic and sociopolitical conditions of late modernity.

At other times, some idea of health equity can be achieved as a final destination within specific fields, for example by creating a best practice which can be categorized as a health equity intervention. Conversely, by creating health equity stratifiers when tasked with the job of creating a way to empirically objectify dimensions of population health inequalities, some goal is reached within a specific field of practice, but the actions required for rectifying the sources of inequity remain open-ended. In this way, health equity does not merely play a decorative role, or one that guides action without outlining concrete objectives. Instead, its truncated use is successfully achieved within the field of practice that sets out the truncated journey and the benchmarks of successful arrival. Vehicular ideas, like empty signifiers and their chain of equivalences, are "inclusive umbrellas under which quite a range of advocates can shelter, trade and shift their alignments and allegiances" (McLennan, 2004: 485). The meaning of equity and its markers of achievement change between contexts and owners.

For decades, health scholars have problematized the concept of health equity for its muddiness as a normative concept, and called for its clarification (Mooney, 1987; Chang, 2002; Smith, 2014). While these authors' calls for clarification and posited frameworks for doing so offer useful and illuminating commentary from which my study follows, I also consider how health equity's conceptual muddiness and flexibility allows for its successful extension and productivity. Equity operates as a sort of proxy for justice, and an additional expansive (and 
expanding) set of practices and concepts are employed by a wide range of actors as equally legitimate proxies for equity. While justice is a defining component of equity, it hides behind equity in its definition (as inequalities that are unfair or unjust). And while equity could be considered an equally normative and 'fuzzy' concept as justice, it still enjoys a definition—albeit one which is circular and also lacking conceptual clarity. Disturbingly, its most integral defining component-justice/fairness—escapes definition itself. Not only does justice escape definitions following those of health equity, but also in the recently emerging research on the concept of health equity, wherein it is considered merely subjective, plural, and incomprehensible. ${ }^{33}$ The ubiquity of equity can be explained by its equivalences' ability to operate in place of justice, hiding its political and normative underpinnings. This is unfortunate because social justice is in fact a comprehensible and meaningful concept which ought to be clarified so that it can decisively drive policy action and public health practices. While equity and justice are indistinguishable in normative theory, the language of equity assumes a blunted, quantifiable, and flexible form of justice. By extension of its flexibility and indeterminacy, the language of equity produces an inclusive and expansive discursive field through which many advocates can assemble.

One does not have to look far for examples outside of public health to see how the language of equity dampens the strong aims of justice and opens it to cooptation. For example, the term equity has been described as 'derailing the environmental justice movement' when, in November of 1992, the United States' Environmental Protection Agency formed an Office of Environmental Equity one year after the Principles of Environmental Justice were written (Ewall,

\footnotetext{
${ }^{33}$ One exception is Smith (2016), who seeks greater conceptual clarity arrived at through engaging with normative ethical theory. Another exception is Pauly and colleagues (2017) who, instead of drawing on normative moral theory, engage with an understanding of social justice which addresses historical and contemporary intersections of unfair social relations produced along the lines of race, class, and gender.
} 
2012). ${ }^{34}$ Lacking any legislative teeth to back up these 'equity posing as justice' policies, environmental agencies in the USA used these policies to appear responsive to environmental justice concerns while doing little to address the root causes of environmental injustice.

In terms of regulatory action, equity translated to mere equality of enforcement of existing regulations rather than further regulation, prohibition, or social change. On the other hand, the environmental justice movement has adopted more profound aims focused on "phasing out inappropriate technologies that ought not exist in any community" (5). As the authors point out, the significance of 'equity versus justice framing' is more than mere semantics. It represents the fundamental difference between the idea of "poison people equally" and "stop poisoning people, period!" (4). As an issue of equity, the disproportionate exposure to toxins experienced by African Americans is not articulated in political terms (e.g. as a racial issue) (12). Just as the concept of equity in environmental policy translates to fairness in the distribution of socially beneficial goods such as access to parks and public transit, equity in public health policy predominantly translates to equal access to socially beneficial goods in the form of health services. Although a SDOH approach would also be concerned with the fair distribution of the abovementioned social goods, neither examples take up relational considerations or what some call the remedial aim of justice- - that is, those corrective efforts which target actors and the systemic features which (re)produce injustice in the first place (See Powers and Faden, 2006).

\footnotetext{
34 Later, in 1994, the EPA changed the name of the office to the Office of Environmental Justice in response to public criticism. In spite of this reform, the EPA, and numerous state environmental agencies still bunted and coopted this bolder "justice" agenda by setting up offices and working groups around environmental "equity" (Ewall, 2012).
} 
As a vehicular idea, we can understand health equity's flexibility and dampened but wide adoption in terms of how it is discursively and practically extendable within a chain of equivalences. Health equity becomes understood and associated with different meanings and practices whose coextended relationship to equity affords these proxies some minimum quality of legitimacy as stand ins for action on health equity. This extension lends mobility to the moral and political character of equity, allowing it to maintain a place in the wake of changing values and organizational currents. Actors from various fields can successfully practice some legitimate version of health equity without contesting the fields' constraints. The elements of the chain that are adopted and reproduced the most are those that are politically and economically the least disruptive, and those that are the most compatible with quantitative modes of evaluation and representation.

In public health literature, social justice is often linked with a range of concepts including equity, health equity, human rights, empowerment, environmental justice, social determinants of health, democracy, social development, poverty reduction, fairness, and social responsibility (Edwards and Davison, 2007: 131). Each of these concepts may be employed respectively at different times within different cultural and political contexts to create discursive space for moving some idea of fairness into public health aims. The flexibility of a concept like equity may also allow it to carry the language of fairness through policies, mandates, mission statements, and values statements without having to direct social change led through politically contentious policy action. This flexibility afforded by equity may not be afforded by the strong language of social justice. As a vague, flexible concept, equity can translate into anything or nothing. As a discursively blunted form of justice, equity does not have to take on what some justice scholars term a remedial or negative duty of justice (see Powers and Faden, 2006; Pogge, 2008$)^{35}$.

\footnotetext{
35 This also closely resembles what Tom Beauchamp calls a 'counter-ethic' For all three of these prominent justice scholars, these are indispensable, integral elements of the job of justice.
} 
Because flexibility afforded by the concept of equity does not require it to carry the negative duty of justice, it remains politically neutral and open to co-optation. As a result, health equity action can serve downstream distributive aims of justice alone by attempting to mitigate the effects of unfair relations through ensuring access to health services. This does not address the root causes of unfair health disparities, which often must be comprehended politically and historically.

Free of commitment to these 'active', 'remedial', 'negative', or 'relational' jobs of justice, equity becomes absorbed into technical programmes of action which exclude those actions without a quantifiable and often independent effect. ${ }^{36}$ The idea that equity is more workable in a policy environment by virtue of its quantifiability and neutrality is apparent in Smith's (2016) research on public health policy makers' perceptions of social justice in the context of their daily work. Participants thought equity and social justice were related, but they were more comfortable speaking about equity in their daily work because the concept of equity appeared more objective, measurable, quantifiable and less political than the concept of social justice (133-4). This quantifiable nature of equity rendered it a safe alternative to social justice, with one policy maker noting, "It feels more neutral. It feels more, uh, quantit-uh, quantifiable..." (160). When asked why equity has worked so well as a concept, another policymaker responded that "you can count some dimension of equity. Like, social justice seems to have a little more qualitative feel" (160). This resonates with responses from policymakers involved in public health emergency preparedness and response who noted the "objective or quantifiable" character of equity, while describing social justice as concerning "-isms" (for example, racism, sexism, colonialism) and political and structural issues (160-1). Participants felt health equity

\footnotetext{
${ }^{36}$ This is not to suggest that public health practices aimed at reducing health inequities are absorbed into downstream technical programmes of action because it is 'free' from a commitment to relational aims of justice, but it is able to be reproduced as free from these aims without standing conspicuously out of line with the goal of reducing unjust health inequalities.
} 
operates primarily at a programmatic level while social justice operates at the level of politics (163). In this way, social justice seems to invoke relational justice considerations in terms of structural disadvantage while equity seems to invoke distributive justice considerations in terms of equitable access to resources and services. These findings provide insights into how the language of health equity is more workable than that of social justice, because it is less political, less qualitative, and more objective and quantifiable.

When equity is deployed as a quantifiable, putatively neutral, floating signifier, its power to address fundamental "why" questions is diminished. This matters because it is not only important to measure what the distributions of capital and their relationship to unequal health outcomes are, but also why those unequal distribution of determinants of health exist in the first place. Although the primary task of health equity action should be, by common definition, identifying and reducing those health inequalities that are unjust, programmatic action is able to neglect this role without appearing inadequate. In other words, the ambiguity and flexibility of equity ensures its own survival in a system that curtails the possibility of meaningful progress.

The idea that the language of equity obscures justice is evident in Canadian health system leaders' recognition that "[a]ll this is in the guise in my mind, of its backdoor way of trying to talk about justice. Right? And, and so, what are we really talking about? (in Pauly et al., 2017: 504). Others expressed that health equity does not represent anything substantially new and is "just another fad term" (504). Public health system leaders acknowledge that even though health equity has been repackaged into a new term, it really encapsulates a concern with justice. Like in the field of environmental justice, the value of bringing justice out of hiding is more than just semantics. It means the fundamental difference between ensuring equal opportunity to health care and ensuring equal opportunity to health. Of course, regardless of which term is used, any stand in for justice must be conceptualized in relation to some 
consistent and transparent normative theoretical conception of fairness which is supported and critiqued with knowledge about how health is socially determined, and why inequities persist.

Below the level of policy implications, bringing justice out of hiding affects how individual public health leaders understand their role in advancing health equity. Pauly and colleagues (2016) show how some public health leaders in BC felt more empowered to critically engage with dimensions of health in relation to their structural determinants when discussing public health issues by using language of justice rather than language of equity. That they were not only empowered in their understanding of health, but also in the extent to which their own role could play in reducing health inequities (505), speaks to the importance of clarifying our commitment to health equity as a commitment to social justice. If health equity "has become an umbrella term that was gaining momentum without clarity as to definition or application" (504), and if, "by understanding health equity through the frame of justice or social justice, participants appeared more comfortable to speak about the term, hypothesize on its application and identify having a role to play in relation to it" (505), it seems a clearer conceptualization of equity in relation to its roots in social justice would produce a more empowered system of health workers and advocates.

Despite recognizing the importance of social justice in reducing health inequities, public health leaders also acknowledge that the language used to move the aims of social justice through mandates is crucial. For example, the belief that 'social justice causes a divide' became a salient theme in Tyler and Hassen's (2015) interviews with policy makers and staff within Ontario Public Health Units. This is illustrated by the statement that "[i]t doesn't mean you can't use the approach, because I think increasing health equity and reducing health inequities is your overall goal, but the words you use when trying to achieve those goals are important to pay 
attention to" (111). The following sub-sections in this chapter will further explore the imperative to use neutral language and how it intersects with models of knowledge production.

\section{The Language and Practice of Making up Populations}

It has been shown that a mandated part of applying a health equity lens in BC and Ontario takes the form of identifying populations, and that variously termed populations are considered proxies for those experiencing health inequities (Pinto et al., 2012; Rizzi, 2014; Hassen and Tyler, 2017; Pauly et al., 2017). In light of these findings, it is not only important to interrogate the language of equity, but also the language and practices of making up populations. If some specially-termed population is to become a proxy for those experiencing health inequity, and if health inequalities are inequities to the extent that they are the result of unfair social relations, any programmatic term for these populations ought to be articulated in relation to their unjust determinants. Secondly, beyond their formal discursive treatment, it is crucial to understand how subpopulations' disadvantages are (re)produced by present and historical social relations. Unfortunately, institutional requirements for value-neutral data take precedence over health equity's substantial requirement for knowledge about which inequalities are unfair, and how they are produced. As a result, identifying priority populations may not achieve the task of measuring unfair health inequalities.

Recent research on how those in public health interpret the language and practice of identifying populations has highlighted that the neutral language of 'priority' in the OPHS both facilitates and hinders action on health equity and SDOH (Hassen and Tyler, 2017). As a facilitating policy attribute, policy makers and PHUs in Ontario perceive the value-neutral language of the new term, 'priority populations' as more empowering to the identified 
populations (4). ${ }^{37}$ This was contrasted with the terms 'disadvantaged', 'marginalized' or 'vulnerable' which were perceived as value-laden. Participants felt that using these terms places blame on groups by failing to acknowledge systemic issues such as racism, ableism, and sexism, among others, that may cause disadvantage (4). In contrast, identifying populations as 'priorities' was favoured for implying that some populations are disadvantaged because they lack access to appropriate services, to no fault of their own (4). Language of priority was also valued for appearing to transfer responsibility for ensuring healthy populations to the public health sector (4). Because of these attributes, the new term was considered "more proactive and actionable language than other terms such as 'disadvantaged', 'marginalized' or 'vulnerable'" (4). That the 'proactive', 'value-neutral', language, of PPM was found to facilitate discussion about health equity and raise awareness about building HE capacity within PHUs is peculiar. The same aspects of PPM language that were perceived to facilitate action on $\mathrm{HE} / \mathrm{SDOH}$ were also found to hinder action by limiting the ability for researchers to identify populations actually experiencing inequities, and by limiting the type of action that can follow the identification of populations.

Terms like priority populations or health equity are reduced to a category independent of power relations, history, and experience. A more critical alternative view might hold that the terms 'disadvantaged' or 'marginalized' ought to be used. While still lacking in specificity, these terms lend themselves to identifying groups in relation to the broader sociopolitical and economic relations which (re)produce their disadvantage. In turn, these relational processes can become the upstream targets of intervention.

\footnotetext{
${ }^{37}$ This preference implies that the worse-off populations should assume an active role in bringing about change. Rather than looking at how terminology facilitates individual responsibility, a more critical criterion for evaluating policy language might include its role in facilitating more upstream policy action. One may ask, 'why is empowerment through language seen as important when a lack of empowerment is not what led to disadvantage, vulnerability, or marginalization?'.
} 
Brown (2011) explains that using the term vulnerable to classify and manage people is potentially patronizing and damaging to the pursuit of social justice, however she also highlights several ways the language of vulnerability can function as a route to social justice by legitimizing claims to resources. As a resource-legitimating classification, the concept has a transformative quality that can advance social justice and freedom (Goodin, 1985 in Brown, 2011: 317). The moral potency of the term vulnerability may circumvent a person or group's condemnation or ascribed blame for their states (318). As Goodin (1985) suggests, vulnerability spurs moral duty because it connotes an inability or lack of opportunity to help one's self (129).

On the other hand, vulnerability has the potential to emphasize either structural or individual reasons for disadvantage or need (318). Indeed, this is why any practice of classifying people must be handled with care. Invoking the term vulnerability has the potential to foster the presumption of vulnerability as inherent or as a consequence of one's free choice. The same potential exists when using the term risk. And so, if the potential problem with using these valueimplicit concepts is in failing to articulate the structural sources of vulnerability—or risk-then the problem is not the value-implicit character of the term, but the specific values it connotes and the target to which it applies. Given this potential for circumventing moral blame and pursuing social justice, it is important to clearly articulate the relational character of populations.

Beyond using stronger language with greater specificity, we must produce and use knowledge about the source of these unjust causes if anything is to be done when inequities are found. In addition to changing how public health produces knowledge, this requires using theoretical and value rationality to interpret and use knowledge. As justice scholars Powers and Faden (2006) remark: "Without knowing anything about the groups and why they differ, it is not possible to make judgements about which inequalities are the most morally important to 
address" (62). This marks the crucial intersection between knowledge production and social justice.

Facts, values, and theory in the history of social science. At the core of this project's analysis of current health equity action is the link between facts and values. Taking this relationship seriously is integral to public health's capacity to do the job of justice. By measuring populations which become the targeted benefactors of some programme of action, public health practitioners are 'making up' populations without theorizing them in relation to some shared set of formative social relations. Vulnerable or priority populations can be those sharing a similar burden of disease, or just those shown to be statistically at risk of having worse health outcomes than others. When populations are made up in this way, they are conceptualized independently of any shared social determinant or relational dynamic. As one front-line staff in Ontario remarks:

[...] but new parents are vulnerable too. They're not, maybe not new immigrants or maybe they speak English, and maybe they have lots of money, but it doesn't mean that they know everything about raising a baby or how to feed them... Just because they're not a vulnerable group doesn't mean that they don't need information (in Rizzi, 2014: 49).

Indeed, new parents can be made up into a group which, as a whole, will benefit from information, and few would argue against providing such information. However, this should not be considered action on health equity because the population in question is not a population by virtue of a shared relationship to some inequitable experience or the social determinants of health. If priority populations are used as a proxy for action on health equity via action on $\mathrm{SDOH}$, this category of population, like those based on burden of disease alone, are not 
necessarily relational populations which public policy could take as the beneficiary of a remedial or distributive goal of justice.

While subpopulations are sometimes measured according to some known correlate of ill health and disadvantage such as income, education level, or immigration status (Rizzi, 2014: 49), there is no focus on why these groups are disadvantaged because of unjust social relations. show the importance of identifying populations in relation to their structuring social conditions. Questions about the root causes of inequity are important, and they are acknowledged by some public health workers in studies on perceptions of health equity. For example, Pauly and colleagues' (2017) found that some health system leaders in BC demonstrated a critical understanding of the tension between identifying populations, and addressing the structural conditions that produce their 'vulnerability', or 'risk' of experiencing inequity:

"But I think that, now, if equity is going to be a...if there's traction there, then from a society value piece then we need to be...that dialogue needs to be broad in terms of what's our responsibility to the vulnerable segments of our population? and why are some segments of the population vulnerable? is it their doing, or is it the way that things are structured? And it's those conversations that I think are still very challenging" (405).

In another study by Smith (2016), a policy maker remarking on the distinction between social justice and equity in practice, states that social justice accounts for "why you have differences in outcomes according to income, or according to ethnicity..." (161). Asking why as this participant did, is a key advance over current conventions of representing the problem of health inequity as statistical associations between individual-level indicators 
and health outcomes. This mode of defining populations—however precise-neglects unequal power relations that create experienced inequity. What is important then, is that populations be considered animate and relational—that is, not fixed or natural—but amenable to change. Moreover, to change populations, interventions should principally target those fundamental structural determinants of illness and probable outcomes. By structural causes, I mean those related to rules, resources, and institutionalized social relations for which government decision making can rectify.

The principal problems marking the current language and practice of making up populations-political neutrality and reduction-mirror those which plagued public health research and population sciences almost two centuries ago. In her (2012) article, Who and What Is a "Population"? Historical Debates, Current Controversies, and Implications for Understanding "Population Health" and Rectifying Health Inequities, Nancy Krieger asks, 'How might a more critical understanding of the substantive nature of real-life populations benefit research on, knowledge about, and policies regarding population health and health inequities?' (659). She argues we must critically assess who constitutes the populations whose means are at issue and secondly, critically consider the dynamic relationships that give rise to population patterns such as health inequities. Most relevant to the task of identifying priority populations, is Krieger's assertion that populations must be defined in relation to the inherent intrinsic and dynamic extrinsic generative relationships by which they are constituted. The upshot of this is that meaningful comparisons of differences in population rates of health-related phenomena require an explicit recognition of populations as inherently relational entities. Additionally, understanding populations as being constituted by dynamic extrinsic relationships permits an understanding of health differentials as socially determined, and thus amenable to change.

Krieger writes that the limited discussion as to what defines populations as technical statistical entities is both remarkable and unremarkable. It is remarkable given their salience in 
human population sciences, yet it is unremarkable given the history and politics of how human population and sample were linked (640). The metaphor of 'I'homme moyen' (the average man) took root in the 1830s, first in an address given by Adolphe Quetelet (1796-1874), the Belgian 'astronomer-turned-statistician-turned-sociologist-turned-nosologist', and later in his 1835 work Sur l'homme et le development de ses facultes, ou essai de physique sociale. It was here where the image of the average man solidified an essentialist idea of populations as innately defined by their intrinsic properties. The idea of the average man was inspired by Quetelet's background in astronomy and meteorology. He inverted the approach to locating the location of stars, a practice which involved averaging the results of observations from multiple observatories, each with some degree of error. He reasoned, analogously, that the distribution of a population's characteristics would reveal its true innate value. The significance of any errors arising between individuals was thought to be eliminated by the law of large numbers (641). The idea was that if based on large enough samples, one could identify if populations' essential characteristics differed. Populations were thought to either differ in their essential characteristics (assuming the same external forces) or because were subjected to different external forces (assuming the same internal essence) (642).

While Quetelet acknowledged the possibility of different external forces, because of growing pressure for emergent social scientists to be seen as objective, his discussion of external forces stayed clear of politics which would challenge prevailing religious and economic beliefs, including increasingly individualist sentiments related to the rise of the liberal freemarket economy (642). By treating attributes such as criminality, education, and occupation as no different than height and weight, population rates and averages were reduced to both "a result and an expression of innate individual characteristics" (642). The enduring result is the implicature that populations' characteristics are taken to reflect the natural essence of its component parts. This implicature obscures the idea of populations as substantive, relational 
beings whose health and wellbeing, and their determinants, are both structurally determined and amenable to change through political action. The now common practice of identifying priority or target populations suffers from some of the same problems which plagued population studies 187 years ago. This includes conflating risk factors or determinants of health with inevitable individual-level attributes, and failing to take external factors seriously, especially when they are political in nature. What is more, is that the current causes of these errors share a resemblance to those experienced by Quetelet in the 1830 s as far as their eschewal of politics is rooted in an imperative to appear objective, precise, and apolitical.

In fulfilling the professional imperative to appear objective, precise, and apolitical, dominant models of knowledge production not only exclude politics from analyses, but also interpretive or theoretical dimensions altogether. This pre-reflexive practice produces knowledge which is predominantly statistical, quantitative, and often descriptive. By representing numbers as descriptions, data are separated from an interpretive and theoretical dimension, allowing their 'owners' to confer greater professional and epistemological authority. Mary Poovey (1998) refers to this narrative as the history of the modern fact. Separating numbers from interpretive narrative reinforced the assumption that numerical accounts were different from analytic accounts of the same object of inquiry. This difference made numbers fit into a different stage of the knowledge producing project—one which could be managed by the professional knowledge producer: "Separating numbers from analytical commentary opened the way for a professional answer to questions raised by the supposition that systematic knowledge should be derived from noninterpretive descriptions" (Poovey, 1998: xv). Historically, the knowledge producer has been partly able to derive their recognized professionalism from their capacity to remove themselves from any interpretive role and present inductively and objectively produced knowledge free from theory and values. 
In her historical exposition of key dimensions of the modern fact, Poovey (1998) writes that in the second half of the $17^{\text {th }}$ century, Robert Boyle, Francis Bacon and other members of the royal society bolstered their own social authority by claiming that facts were value-free and theory-free (xviii). They asserted that through inductive knowledge production, facts could (and should) be separate from any theoretical components used to support government policy, religious sectarianism, and mercantile expertise. At the same time, Thomas Hobbes was reinforcing the distinction between untheoretical data and theoretical knowledge. Hobbes argued that political matters of fact could only be produced through deduction, and that this political knowledge could only be made true though philosophical knowledge authorized by the king (xviii). The assertion that political knowledge (as interpretive/theoretical and normative) and untheoretical inductive knowledge ought to be separated in professional fields of practice mirrors today where professionals within the public health field will only produce knowledge about particulars without generating political matters of fact. Public health institutions and organizations continue to produce descriptive population health data, and it is left not to kings but to political actors outside of public health to use and interpret particulars and their associations to various degrees and to competing ends.

The consequences of transgressing these conventions of knowledge production are apparent as early as 1849 when famous German physician, Rudolph Virchow's political activities led to his discharge from the Charité Hospital, and his banishment from Berlin by order of the king (Mackenbach, 2009: 11). In early 1848, a typhus epidemic had claimed 16,000 lives in Upper-Silesia. Fearing social unrest, the Prussian Bureaucracy commissioned Virchow to conduct an official investigation into the causes of the epidemic (8). In addition to identifying a medical diagnosis of the disease, he also identified its political roots. Knowing that this type of typhus was associated with hunger and war, Virchow declared that the root cause of this epidemic, and ill health generally, was not only socially, but politically determined. Thinking 
historically, he posited that the direct cause of the epidemic was the previous years' famine. While the famine was due to crop failures because of bad weather, its effects were concentrated among the poor, who were predominantly Polish peasants (9). Virchow analysed this concentration of poverty, which was closely associated with their lack of schooling, as the result of political oppression by the ruling bureaucracy, and from economic oppression by the local aristocracy (9). In November of 1848, Virchow famously stated that 'medicine is a social science, and politics nothing but medicine at a larger scale'. Virchow remained very politically active, participating in democratic, republican and socialist movements, fighting to elevate the material and governmental position of the working class (10).

Virchow's work illustrates the importance of theoretical knowledge for understanding health in relation to its distinctly relational determinants-particularly those determinants that involve competing but unequal group interests. By identifying the problem as the distribution of political and economic power in the region and not a strictly medical problem, resolving the problem required land reform, housing reform, water regulation and other public interventions. These measures would have reduced the power of the property owners who held the land, the water, the real estate and other commodities. Outraged by Virchow's proposals, these landowning groups rebuked: 'This document is not a medical document. It is a political document'. Virchow's banishment and the treatment of his work reveal how what constitutes professional authority and legitimate medical evidence is partially its refrain from political and theoretical reasoning.

The reason why I bring up Virchow is not just to romanticize the past, but to show how interpretive and theoretical knowledge can be socially disruptive in a way that is potentially beneficial for the worse off, and disruptive for the most powerful. Virchow's interpretative/theoretical knowledge diverged from the state's requirement for politically neutral 
knowledge. As I show in the next chapter, neutral and atheoretical knowledge often fails to weight various determinants of health differently, or account for their genesis, consequently allowing for a façade of government care without having to disrupt power relations. By edging theory and interpretation out of view, knowledge remains politically neutral. While Virchow was banished, what kept Quetelet and others within nascent fields of professional expertise in $19^{\text {th }}$ century neutral was the thrust to be recognized as objective and legitimate scientists. These same forces shape today's models of knowledge production.

\section{Relational conceptions of justice require relational conceptions of population.}

Following Krieger, a more critical understanding of the substantive, relational, and dynamic nature of real-life populations can help produce knowledge and policies which improve health inequities. I would add that this marks the crucial intersection of facts, values, and theory where producing social knowledge about the relational production of unfair health distributions allows for public institutions to address relational concerns of justice. Attending to these relational concerns of justice are integral to acting on any strong conception of equity or social justice. If health inequities are to be meaningfully addressed, the job of justice cannot be reduced to altering distributional factors within the current state of affairs which (re)produce those unfair distributions in the first place.

\section{Conclusion}

This chapter provided an analysis of equity's discursive qualities, and the historical and contemporary evidentiary norms that govern the deployment of equity in the construction of populations. This provided some insights into how to understand both the discursive and technical constraints, possibilities, and strategies of mobilizing equity and constructing populations. 
The language of health equity and its proxies constitute what Ernesto Laclau (1996) calls a chain of equivalences. From this chain of equivalences, as an expanding discursive field, various groups can develop or select from any number of actionable strategies to secure their role in achieving some legitimated goal of equity. The range of alternative practices vary in their impact on health inequities but are equally acceptable at face value. As an empty signifier supporting a chain of equivalences, health equity produces the discursive conditions for actors of different fields to successfully mobilize the concept within their particular field's constraints. It produces a way of discussing, measuring, representing, and acting upon health inequity regardless of who 'owns' the concept at a given point in time, or the constraints that structure action within a particular field (for example, institutional, political, epistemological, etcetera). Different versions or elements of equity are espoused and acted upon as the concept travels from its origin in $\mathrm{WHO}$, between $\mathrm{PHAC}$ and $\mathrm{CIHI}$ models of knowledge production and representation, provincial public health standards and those who use them to identify priority populations, and other public health and third sector groups' development, implementation, and evaluation of health equity-oriented interventions. Without engaging with normative ethics or considering the problem of inequity, health equity can be proactive in an infinitude of ways without being counteractive. Engaging with normative ethics allows would allow public institutions to impose some concrete content on the idea of equity thereby reducing its capacity to function as an empty signifier.

Finally, in highlighting the contemporary context in which health priority populations constructed and acted upon, this chapter pointed toward the importance of including political factors, and theoretical reason in analyses of relational social phenomena like health inequalities. I have also highlighted some of the historical challenges that continue to shape the role of the professional expert, and their capacity to produce accurate accounts of the real-world phenomena that we are trying to comprehend. The next chapter will analyze how the ways in 
which health inequality is quantified produce a precise, but inaccurate and incomplete representation of the problem. After that, I analyze how these modes of objectification and evaluation shape and limit the way which the problem of inequity and its actionable solutions are talked about in public health discourse. 


\section{Part 2: An Introduction}

The next three chapters pursue several lines of inquiry driven by the following central questions: 'What counts as evidence?', 'What kinds of knowledge are excluded from evidencebased decision making?', 'How does this produce a particular understanding of the problem of inequity', 'How does this shape and exclude opportunities for social change?', and 'What ways forward do these evidentiary imperatives and their associated evidentiary productivity leave us with?'. The way we produce knowledge about the problem of health inequity forecloses a more accurate and complete understanding of the problem we are trying to comprehend. An incapacity to understand the actual problem of inequity hinders the achievement of an ethically consistent and transparent goal of equity. Additionally, as a positive, proactive goal and object of research, health equity is deployed and researched within an actionable knowledge regime that limits what is possible to change, on the basis of what is scientifically knowable, effectually foreclosing possibilities of political contestation.

The actionable knowledge regime operates as an evidentiary system of empirical indicators and testable interventions (Henderson and Denny, 2015). The idea is analytically useful for making sense of the cognitive, pragmatic, and optimistic character of health equity interventions. By understanding health equity in relation to an actionable knowledge regime, we can understand the lack of politics in health equity discourse and action in relation to modes of representation. This perspective allows us to look at how modes of scientific objectification, which have increasingly taken a primary role as public reason since the $18^{\text {th }}$ century, but increasingly in the $20^{\text {th }}$ (Porter, 2006), determine contemporary trajectories of researching and responding to social problems.

Central to the originality of my analysis is that I do not reduce an explanation of health equity's under-realization to resource constraints, or a lack of political will. While not discounting 
political will as greatly significant, central to my analysis is that how we produce knowledge, what counts as evidence, and what can be made knowable circumscribes possibilities for social change and social justice. Secondly, I do not call for a discursive return, in line with a previous discourse of health promotion, to an emphasis on community empowerment and individual agency. Instead, I highlight how community—and the civic moralizations it connotes-are used within a broader chain of discourse which allows health equity action to legitimately avoid attending to structural determinants of health inequity at the level of political economy. The persistence_or perhaps re-emergence_of community discourse and action is socio-politically palatable as it produces a progressive feel without disrupting exploitative economic relations. Additionally, as a local territory which is amenable not only to political containment, but technical closure, it is a fitting site for enacting, evaluating, and optimizing actionable interventions.

To understand the significance of the actionable knowledge regime, it is important to discuss it in relation to conditions of post-democracy as articulated by the original innovators of the idea. Henderson and Denny (2015) borrow from Jacques Ranciére (1999) to situate resiliency science, operating under an actionable knowledge regime, within 'post-democracy', a term which signifies conditions of broader depoliticization of today's democracies. Postdemocracy refers to the conditions in which political contestation are eroded by what Ranciér refers to as a 'determined regime of the perceptible' in which the quantitative knowledges that objectify the world as calculable end up dampening democratic participation (Henderson and Denny, 2015: 373). Ranciér illustrates this insight by pointing to opinion poling and statistical surveys for their role in reproducing diminished political contestation. Henderson and Denny point to longitudinal surveys, randomized controlled trials, neuroscientific studies measuring resilience, and human development indices as important modes of measuring and representing us as perceptible to ourselves. 
Resilience research and resultant interventions naturalize risk by redirecting inquiry away from risk itself in social conditions to a focus on how these risks are dealt with by the individual (372). The project of producing resilient selves entails strengthening developmental resources of the self to adapt to ostensibly immutable threats such as poverty. The self is treated as intervenable while structured threats such as poverty are represented as unchangeable. In the face of seemingly immutable risks, resilience is framed as a practical and optimistic object of science. In similarity to resilience research, the closed models used by PHAC for representing health inequality naturalize threats such as poverty. Furthermore, this project's analysis of health equity interventions within PHAC's best and promising practices portal and available evaluations reveals that most interventions are based on strengthening developmental resources of the self.

An evidentiary system of empirical indicators, testable interventions, and genetics research used to support resilience science and resilience-enhancing interventions has secured its influential role in social policymaking of neoliberal governments (Henderson and Denny, 2015). Against this reductive, asocial, and technical character of the actionable knowledge regime, the project of resilience carries an affective and progressive tone. Similarly, as I will elaborate in chapter seven, health equity is deployed as an affectively adorned evidence-based project which often celebrates assets_-including resilience-instead of investigating structured deficits. ${ }^{38}$ In parallel to Henderson and Denny's (2015) critique of resiliency science, it could be said that action on health equity consists of a "pragmatic, evidence-based pursuit of a kind of best-practices for justice" (373). In similarity to resilience, health equity projects maintain a progressive appearance by emphasizing the role of empowered individuals and communities

\footnotetext{
${ }^{38}$ See 'Measuring positive mental health in Canada' (PHAC, 2016); the call to celebrate assets, and measure broad indicators related to poverty such as resilience (instead of just poverty) and to 'document, communicate, and celebrate' them (NCCDH, 2012: 9); and the call to measure broad protective factors such as resilience and self determination in order to empower individuals and communities (PHAC, 2018: 7).
} 
within an optimistic discourse of empowerment and self determination. However underrealized its socially transformative potential is, an overlap with evidence, community, inclusion, and engagement allows equity to carry the charge of fair, enlightened, democratic, but pragmatic action.

Although the evidence-based actionable knowledge leaves little room for the political, the project of producing resilient selves carries a progressive feel by enlisting an affective component that celebrates the agency of individuals. This celebration of agency and empowerment does not translate into collective political action for this progressive ethos is "deployed within a political field restricted by the logic of investment and the actionable knowledge regime's criteria for evidence-based, practical knowledge" (373). The logic of this field leaves us with no way to critique injustice and engage in political contestation. It becomes increasingly difficult to critique "the realities of injustices which cannot be made visible" through equity's actionable regime of knowledge production which, just like that of resilience's, "defines what is feasible to change" (373). What we are left with are indicators and outcomes relating to individual capabilities (373). The sources of injustice and inequality are hidden out of view at the same time as a legitimate regime of practices is produced. 


\section{Chapter 7: Representing Health Inequality and Naturalizing Risk}

It has already been argued that a more meaningful conceptualization and operationalization of population would treat populations as substantive, relational social phenomena whose structuring structures are amenable to change. Furthermore, it has been argued that this is crucial because priority populations are used as proxies for those experiencing health inequity. Most importantly, conceptualizing populations in relation to changeable, open systems permits an understanding of how and why inequity is socially produced within and between groups. Failing to do so assumes features of prevailing sociopolitical arrangements are inevitable, reproducing a conservative social imaginary. This pervasive social imaginary of static conceptualizations of society and the social determinants of health is reproduced by a dominant evidentiary system of empirical indicators and testable interventions. This section analyses the very constructs and models used by PHAC and $\mathrm{CIHI}$ in the measurement, surveillance, and representation of health inequity in Canada to answer the questions, 'How is social injustice naturalized through the measurement and representation of health equity?' and, 'What is represented as static and dynamic in the regime of knowledge production that health equity actions depend on?'.

\section{Structural Factors: Indicating or Explaining?}

The ways that health equity is made knowable through measurement and representation naturalizes social insecurity and mystifies its causes. Structural stratifiers, indicators, determinants, or factors used in multicausal epidemiological models of measuring and representing inequity never represent actual structuring factors. The individual level attributes used to represent structural factors are often actually structured manifestations (e.g., food insecurity) of structural (that is, structuring) factors. When used in this way, structural factors are presented as pre-structured rather than as actively structuring. Other times, as with sex and 
gender, representations of structural factors are not manifestations, but merely individual-level attributes associated with differential health outcomes. What is not represented are the structural relations underlying the relationship between these individual-level attributives qua factors/indicators and unfair health inequalities. This matters because representing structural factors as individual level states mystifies their place in social relations as well as what makes them meaningful and changeable. As an ideological function, this closed representation stabilizes and perpetuates relations of power and domination by masking their existence through their exclusion from systems of knowledge production that make them knowable to policy leaders. The closed representation of inequalities precludes possibilities for realizing particular conceptions of justice, particularly those relational conceptions of justice whose fulfilment requires attending to the active production of injustice or inequity.

The 'health determinant indicators' used by PHAC (2018) to measure health inequalities in Canada shifts sights away from those active processes external to individuals which create conditions of socioeconomic precarity and insecurity onto abstracted, isolated, stable particularities of individuals. The indicators list used in the report is made up of seventeen 'health outcome indictors' which can be characterized as biomedical. In addition to 'health outcome indictors', the list includes seven 'health determinant indicators', all delineated by 'indicator domain'. This includes 'Health determinants A: Daily living conditions' and 'Health determinants B: Structural drivers'. 'Health Determinants A' are demarcated as daily living conditions, including 'alcohol use—heavy drinking'; 'smoking'; 'core housing need'; and 'exposure to second-hand smoke in the home'. 'Health Determinants B: Structural Drivers' include, 'early childhood development'; 'food insecurity'; and 'working poor' (PHAC, 2018: 6). With the exception of housing needs, all health determinants under the category of daily living conditions are represented as lifestyle behaviours. Although housing needs is listed, what are not represented are those processes and features of market-state interaction that produce 
unmet housing needs. By failing to provide a theoretical account of these determinants and indictors in relation to wider social phenomena outside of the model, the PHAC model of measurement objectifies health and its social determinants within a closed system.

The factors in health determinants B, such as 'food insecurity' and 'working poor', which are intended to represent structural drivers, are actually additional aspects of daily living conditions. Both categories of health determinants fail to operationalize their content's real-world structural drivers. These categories merely represent aspects of living and working conditions which are relevant to health. What is left out, are those structural drivers of the very 'health determinants' (both A and B) that are said to be important to health. This illustrates how PHAC's model produces an incomplete representation of the real-world problem. By doing so, it masks those relations that create and benefit from inequalities. These are the ideological effects of knowledge production.

Furthermore, the predominantly descriptive character of PHAC's model stabilizes those risk factors termed 'health determinant indicators'. Just as Coburn and colleagues (2003) critique the SES approach within population health for "tend[ing] to ignore the structural determinants of the very inequalities that SES so accurately describes" (395), the "health determinant indicators' used by PHAC—like the structural factors deployed in the OPHSignore the real structural determinants of the inequalities that they describe (for example, those inequalities categorized along the lines of housing needs, food insecurity, education, gender, etc.). The term 'health determinant indicator' itself is an odd marriage of description (indicating a dimension of inequality) and theory (explaining why the inequality exists). Despite the analytic or theoretic half of this coupling, it does not appear to be used in a way that accounts for any of the factors needed to theorize the various health determinants. 
Furthermore, the PHAC report does not suggest a particular origin or pathway by which a given health determinant drives another. This is crucial for a sociological account of health which examines health inequality as a relational phenomenon in terms of historicized agency and structure. Although the PHAC report states that "structural drivers, for example, household food insecurity and working poverty, can be health determinant indicators" (PHAC, 2018: 6), these factors remain asocial indictors which can only be represented in descriptive statistical associations. By categorizing household food insecurity and working poverty as structural drivers, they are not represented as the result of sociopolitical and economic relations, in effect mystifying their evitability and their very structural character. In fact, it is not clear what structural level working poverty (or any of the other structural drivers) operates at. The determinant's own genesis, its own role, and weight in determining other health-relevant determinants are unclear and perhaps unknowable within the model that it operates within. Even if some factor such as working poverty is taken as the highest-level structural driver, by default it forms the analytical ceiling, foreclosing an understanding of its genesis and mutability. When operationalized within this closed system, structural drivers constitute, at least operationally, the limits of understanding and action. As a result, the real-world structural drivers are masked and unintentionally sustained.

While population descriptions of inequality are useful for demonstrating the extent of health inequality and the many dimensions along which it exists, failing to move past description leads to implicit and inconsistent theoretical assumptions. Consider how when health and its determinants are discussed as clusters and related outcomes, it remains unclear as to why unequal achievements are produced in the first place, why factors are meaningfully related, how their force should be weighted, and what should be done. 
"In most cases, structural factors, behavioural factors, and health outcomes tended to cluster-upstream factors such as low income and education are associated with structural factors such as food insecurity and unmet core housing needs, unhealthy behaviours such as smoking, unhealthy health conditions such as obesity, and adverse health outcomes such as diabetes" [emphasis added] (PHAC 2018: 421).

It is unclear why low income and education are discussed as structural factors while food insecurity and unmet housing needs are discussed as upstream factors. One may posit that the term 'structural' suggests a more fundamental, causal role in determining the upstream factors, but given the truncated representation of structural and upstream factors, and a general neglect of theory, the weight of their role is unclear. In this case, one could theorize that low income and education cause food insecurity and unmet housing needs, or one could theorize an inverse relationship. However, without theorizing the direction and relative importance of these factors, this model of what I call 'asocial associations' would constitute 'a maze with no dead ends', to borrow from Tesh's (1988) critique of the multicausal model. Finally, without identifying the social relations underlying these factors, it is unclear where action should be directed. The descriptive character of associations produced by this model of knowledge production carries theoretical implications which leave readers to interpret the weight, causal interaction, source, and evitability of the factors.

What is absent is any account of which structural factors produce low income or which underlie the association between determinants/indicators such as education and food insecurity and unmet housing needs. For example, using the described associations above, one is left with the following questions: Is low income and education meaningfully related to food insecurity and unmet housing needs (and finally to health) because food insecurity causes people to have trouble attending school, resulting in a low income and unmet housing needs? Or, are they 
meaningfully related because citizens operate under conditions dominated by a neoliberal market logic that influences the price of labour, education, food, and housing, and because most citizens' ability to obtain education, food, and housing depend on the price of their labour and the goods they must consume? A model using these factors (operationalized as asocial associations) does not say that one explanation is more valid than the other per se, but by mystifying the origin of the various indicators—such as food insecurity-and the social relations that make these stratifiers meaningfully related, all that is produced are descriptions of associations between factors below the level of political economy and ideology, implicitly representing political economic factors as inevitable, or at least unknowable. In terms of policy implications, including an analytical account of social relations means the difference between only implementing a school lunch programme to increase educational attainment, and challenging neoliberal ideology that makes us (unequally) sick. Other concrete actions supported by a more open model of representation and theoretical reason might include creating healthy public policy by implementing redistributive and progressive taxation, raising employment standards, planning urban housing development to ensure affordable housing, decommodifying higher education, and strengthening social security generally.

An analysis of equity stratifiers ${ }^{39}$, and the criteria used to select the constructs representing them also reveal implicit assumptions about the mutability of the social world. This is important because these assumptions reproduce a truncated representation of social relations, sustaining an ideological account of social reality. A partial and closed representation is produced through a descriptive account of the world which only describes what can be

\footnotetext{
39 "An equity stratifier refers to a characteristic such as a demographic, social, economic, racial or geographic descriptor that can identify population subgroups for the purpose of measuring differences in health and health care that may be considered unfair or unjust" (CIHI, 2018: 7).
} 
empirically identified and acted upon with tested and testable interventions. For example, the criteria used for selecting constructs for capturing equity stratifiers is based on five factors: use, strength of evidence, relevance, actionability, and feasibility (CIHI, 2018: 9). Some of the criteria carry implicit assumptions, shaping which data is produced, and which actions become possible. For example, indicators may be selected based on whether they "reveal inequalities that are particularly pronounced and widespread across population groups; cover a range of health outcomes, health behaviours and broader social determinants of health; and allow for systematic disaggregation of data across key population groups and are policy-relevant and actionable [emphasis added]" (6). Selecting constructs for capturing equity stratifiers based on whether they are policy relevant and actionable carries an assumption about what is policy relevant and actionable, appealing to the constraints of existing policies, thus limiting what is measured, made knowable, and changeable.

The descriptive character of dominant models of knowledge production and representation in public health is also present in the common use of income quintiles when representing relative income inequality. Income quintiles are made by ranking people within a population according to their income, from lowest to highest, then dividing the ranked population into five groups of equal size known as quintiles. In Canada, income quintiles are commonly used by national organizations such as $\mathrm{CIHI}$ and $\mathrm{PHAC}$ as well as by provincial and regional organizations to measure inequalities (CIHI, 2018: 21). While descriptions of relative income inequality are indispensable for offering insights into the degree to which income inequality correlates with health inequality, the use of these alone do not explain why there are stratifications in the first place (Coburn et al., 2003), and as a result, implicitly naturalizes current 
inequality. Canada's income quintiles do not, for example, become ranked relative to other countries' income quintiles. ${ }^{40}$

A consistent finding of this study is that health equity discourse and practice focuses on the availability and production of data. An implicit theory of social change and power relations is carried by the assumption that continued monitoring and reporting will naturally lead to greater health equity. This assumption is illustrated by the following excerpt: "In the long term, more consistent and routine monitoring and reporting of health inequalities will contribute to more equitable health care access, quality and outcomes for vulnerable populations" (CIHI, 2018: 8). This is valuable information to have, but it assumes a pluralist ideal of power relations and a linear translation of knowledge to policy action. This conflict-free pluralist treatment of society is not only carried by assumptions around knowledge translation, but also by what is not included in models of population health measurement.

\section{Data Fit for Science and Politics: Empirical, Discrete, and Meaningless in Themselves}

The blind spots in the above conventions of knowledge production produce an idealized view of society as a space without conflicts of interest. Critically vacant is any discursive or technical space for representing the conflict between public interest in health and wellbeing on one hand, and market interests in controlling and expanding concentrations of capital on the

\footnotetext{
${ }^{40}$ The quintile regime also imposes a particular construction of reality in which society consists of five equal groups. While standard deviations from each quintile's average are available, they are not typically visible without referring to supplementary data in indices or otherwise fine print. Without referring to these, this mode of objectification masks the actual amount of inequality within a society. This is especially an issue for understanding the upper quintile, considering that there is not even a ceiling for its range, whereas for the others, the ranges' limits are set by the next quintile's floor. If the top tier is indicated by incomes over $\$ 200,000$, the amount of inequality within the top tier is hidden along with the inequality between the particular members of the top tier and the rest of society. So, the quintile regime imposes a construction of society as one that is divisible into five parts, masking the actual degrees of inequality in society, as well as the amount of capital in the top tier that is available for redistribution.
} 
other. Because political relations cannot be easily grasped empirically, they do not enter the field of inquiry, and because they do not enter the field of inquiry, they do not enter the field of evidenced-based public policy. Despite academic research from outside of public health institutions which would support broad-based policy action to address SDOH equity, one cannot isolate and analyze the disaggregated empirical effects to determine the interventions' effectiveness.

PHAC's model resembles the multi causal model of causation in several ways that I have highlighted. These include its closure, aimlessness, and the range of unranked determinants. Tesh (1988) critiques this model for leaving no clear guidelines for action, only more factors which " [...] all subdivide, point to yet other causal factors, double back on one another, go both ways at once, and never lead out anywhere. The multifactorial model would be a maze except that there are no dead ends: everything is linked to everything else" (62). This closed aimlessness produces a governmentally useful flexibility-albeit one which is left politically constrained by its own internal technical parameters. ${ }^{41}$

By presenting many causes—albeit in isolation from their roots in public policies-this 'complete' picture allows organizations to appear neutral on the question of policy. Organizations can present the facts in descriptive form, leaving decision-making to policy makers. Tesh (1988) argues that this flexibility afforded by the aimlessness of the multicausal model is actually what constitutes its strength. By refraining from identifying one cause, action can be diffused into myriad of programs attacking a range of factors which are socially nondisruptive. Public policy makers and other institutional actors can opt for seemingly politically-

\footnotetext{
${ }^{41}$ To clarify, constraints on political action are not necessarily externally imposed by political actors, or even necessarily by self-disciplining scientists who understand the rules of the game (although I do recognize this reality). Instead, this politically closed-off flexibility is a technical product (with ideological effects) of particular epistemological and methodological, and ultimately evidentiary commitments.
} 
neutral actions. By presenting a range of determinants of health which require different commitments from research and governments, but which are not accompanied by a sufficient analytical account to justify one over another, broad-based public policy is more likely to be shaped by individualist ideology than scientific knowledge. The descriptive multi-factorial model can support a regime of equally important actions in which targeted factors are assigned equal importance to each aspect of causality, making it easy to direct action to ineffective but socially nondisruptive programs (62-64). Well meaning but politically cautious and evidence-driven leaders of organizations can "pick and choose freely among a "balanced" list of options" (64). When SDOH such as poverty and food insecurity carry equal weight, public health agencies lacking the data and legitimate capacity to exercise theoretical knowledge required to suggest opting for one over the other, can intervene in food insecurity through the temporary provision of food vouchers. These interventions indeed improve lives, but the social structure that continually reproduces poverty and malnutrition remains undisrupted. This is highlighted in the following section which discusses successful interventions such as the Canadian Prenatal Nutrition Program and the Fruit and Vegetable Subsidy Programme-both of which simultaneously target income and food insecurity respectively, but only by directly intervening on malnutrition, thus obscuring the relationship between the two, and between them and their structural determinants.

The flexibility and aimlessness of this commonly used multifactorial model, combined with its closure and generally descriptive objectivity render its effects inherently conservative. This is because the causal stream's upper limit is set by what the model excludes-namely, relational political economic factors. The upper (political) limit of intervention is also fixed by the model's basis in the methodological and epistemological commitments of social epidemiology. The methodological and epistemological commitments of social epidemiology shape how we think about the social determinants of health (Denny, 2008: 137). Social epidemiology's 
methodological and epistemological commitments are based on reductive statistical approaches that use quantitative proxies such as SES to objectify social phenomena in combination with sophisticated mathematical techniques to 'disentangle' social complexity in order to isolate the separate effects of various compositional and contextual variables (137). Despite its precision, the social epidemiological model cannot objectify social phenomena accurately as they actually exist in the real-world—-that is, within open, interdependent and dynamic systems. SES, operating as a proxy for a person or family's relative social and economic position, can be precisely related to health. This precision comes at the cost of accuracy as SES is presented as a hierarchy of assets existing without roots in social relations or conflicting group interests and the power dynamics through which interests are unequally served. Also absent is an account of how this ranking of individuals' assets and human capital is tied to exploitative labour relations and the operation of markets (138). By leaving these relational antecedents to SES and its relation to health, the social epidemiological use of SES produces an inaccurate representation of health inequality.

Within a closed model, even operationalising a concept like SES in relation to health inequality does not reveal what or if we ought to do something about equalizing SES to some degree as the primary means of tackling health inequity. By enlisting the concept of SES, public health leaders are still able to use the language of inequality without talking about how it is fundamentally related to those social relations that are its political and economic determinants. This is what Denny (2008) refers to as the left wing effect in population health. Along a similar vein of insight, Tesh (1988) notes that although politics and economic power can be seen in public health discourse at times, actual analyses can only employ empirical phenomena (66).

"So the textbooks that begin with the observations that a multitude of empirical and nonempirical phenomena interact to produce disease, progress to examples that reduce 
the causes to phenomena expressible in numbers. Common among them are age, sex, geographic location, socioeconomic status, diet, years of education, race, cigarette consumption, exposure to disease agents, and so on" (67).

Purveyors of this discourse necessarily leave out exactly those nonquantifiable phenomena that cannot be isolated in any one factor (66). As a relationship and not a thing, political power cannot be included in a strictly scientific analysis of health determinants (66). Among the analysed documents, the existence of unequal power relations and a need for political will or commitment is commonly acknowledged, but they are absent from any models of knowledge production, or actionable discussion of 'ways forward' or 'what works'. ${ }^{42}$ What is left are constructs that reduce the determinants of health inequity to non-relational phenomena expressible in numbers. This can be understood as a trade-off between accuracy and precision.

The appeal of quantitative social information typically derives from its degree of precision which exceeds its capacity to provide an accurate and complete representation of the real world (Porter, 2006: 1280). Historically, social science has been preoccupied with precision and neutral information, despite whether what gets measured and represented is exactly what we are trying to comprehend (1274). Throughout this project, I have pointed out how this trade off of accuracy for precision characterizes public health practices and comprises its commitment to equity. Committing to precision means assuring the definite and unambiguous information which does not necessarily signify correctness (1280). In contrast, accuracy signifies the validity of a number in regard to the completeness, location, and quality of the thing we are trying to

\footnotetext{
42 In the rare cases when politics are mentioned in the reviewed documents, it is always reduced to a general political commitment/will, rather than something that involves normative deliberation and the active modulation of conflicting groups' interests. Secondly, while political will is articulated as important to further action, it does not become measured or analyzed as an object of inquiry.
} 
comprehend (1280). This chapter has shown how the location of the source of health inequity is misplaced in endless, aimless associations represented in a closed and therefore necessarily incomplete model. By opening up our models of representation so that they produce a more accurate and complete portrayal of the problem, we see that the magnitude and location of the problem changes as well.

Precision implies nothing other than tight clustering of the measurements, which, like the bullet holes made by a marksman with a bias, may be very near to each other but some distance from the bull's eye. The densest concentration of shot in the face of the vice president's hunting partner will yet bring down no quail (Porter, 2006: 1280).

Even the most precise measurement of clusters of associations between individual-level risk factors and health will remain at a distance from the actual sources of inequity, and even the densest cluster will not tackle inequity. Population health models leave out crucial aspects of what they even purport to describe, in effect, not only producing descriptions and leaving interpretation open, but also foreclosing the very possibility of comprehending the whole. By omitting politics from population health models, and by precluding interpretations of data which locate the chief cause of inequity in political economy, we are left with a precise account of something that is not what we actually need to understand-the causes of health inequity.

\section{Conclusion}

This chapter showed how we objectify the phenomenon of health inequalities. I have analyzed common models of knowledge production used by national public health institutions in Canada to show how the ways in which we objectify the problem of inequality and inequity produce a precise, but incomplete and therefore inaccurate representation of the actual problem 
that we are trying to comprehend. By conflating determinants and indicators of health as prestructured 'structural determinants' while neglecting those processes that actively structure those 'determinant indicators' and 'equity stratifiers', social inequality and insecurity are implicitly naturalized. As a closed and necessarily incomplete social epidemiological model, what are left out are those structural and relational social phenomena that determine the rates and/or relevance of what are implicitly taken as pregiven 'health determinant indicators' or 'health equity stratifiers', such as SES, working poverty, and food insecurity. These blind spots leave out welfare state characteristics and the very policies that rein in or enable economic exploitation and unhealth living and working conditions. An alternative, more critical and open model of knowledge production would employ international and historical comparisons. Historical and comparative policy analyses can examine the effects of particular policies and political ideologies on health outcomes and SDOH. If aided by theoretical reason, this line of inquiry would permit an understanding of power relations located in social relations between state, market, and citizens. Furthermore, this research would allow for analyses of different institutional arrangements and their relation to not only health outcomes, but the very SDOH that the multifactorial model operationalizes as relevant but remains unable to explain in any meaningful way.

What does this mean for equity as social justice? Beyond leaving us with little evidence to support transformative actions, the epidemiological model limits our capacity to determine which inequalities are unfair, and which are the most morally important to address. By default, this leads to a passive distributive form of justice because it allows for moral attention to be focused on those who already experience some form of health-associated inequality, but not the individuals or social relations that produce unjust suffering. According to Powers and Faden (2006), the inequalities that matter most are those that cause cascading and interacting effects on deprivation (70), or those systematically overlapping social determinants that affect multiple 
dimensions of wellbeing are the most urgent to address (72). Answering the question, 'which inequalities matter most?' will depend on contextual information about how actual institutional practices and social arrangements affect differentially socially situated persons and groups in various ways (31). This parallels the words written by Margaret Whitehead following her famous definition of health equity: "So, in order to describe a certain situation as inequitable, the cause has to be examined and judged to be unfair in the context of what is going on in the rest of society" (1991: 219). Because the models analysed within this chapter do not measure actual institutional practices and social arrangements (what is going on in the rest of society), or how they affect differentially socially situated persons in various ways, we are left with no way to examine or judge which inequalities are the most morally important to address.

As stated in chapter three, an active concept of justice, relational justice diverts some distributional attention from those experiencing justice or injustice to those who produce them (Pogge, 2004). Under a relational justice scheme, we should be concerned with how social institutions that people are involved in shape, uphold, and contribute to the incidence and exacerbation of medical conditions. Because the knowledge regime discussed in this chapter represents inequality without conflict in interest, and because it fails to show how social institutions that people are involved in shape, uphold, and contribute to the incidence and exacerbation of negative health outcomes, we are unable to assess variable opportunity, need, blame, and responsibility as requisites to pursuing a relational form of justice.

The closed representation of inequalities precludes possibilities for realizing particular conceptions of justice, particularly those relational conceptions of justice whose fulfilment typically requires attending to the active production of injustice or inequity. This is consistent with the central finding that health equity discourse and practice does not attend to inequity. In previous chapters, it was noted that equity, rather than social justice is more successfully 
accommodated into public health discourse and practice for being quantifiable and neutral. This chapter shows how it is easier to identify the empirical effects of inequity without actually producing an understanding of its sources. Promoting equity rather than attending to inequity is not only a politically safe move. It is also easier to produce and mobilize knowledge which focuses on equity. This is the connection between evidentiary norms, knowledge, discourse, and the realization of values. The takeaway is that we cannot only theorize the lack of progress on health equity as a matter of political aversion to what is required to rectify injustice. We must also understand the lack of progress as the result of a technical neglect which is perhaps shaped by technical imperatives as much as, but separately from, political imperatives to be neutral. This is important because it means that if progress is going to be made, we have to reform the political-value ethic of public health and governance more generally, as well as the evidentiary regimes that it operates through.

The next chapter will support the argument that what counts as evidence shapes what is possible, ultimately limiting opportunities for directing political action toward those processes that actively (re)create inequity. While this chapter focused only on how we use quantitative measurement to objectify the problem of inequity, the next chapter will look at how we objectify the efficacy and efficiency of actions which seek to produce more equity. 


\section{Chapter 8: Representing Health Equity in Action: A Dearth of Evidence, or a Dearth of Politics?}

In this chapter, I analyse the PHAC publication, Key health inequalities in Canada: A national portrait (2018) to show how actual and potential actions for tackling health inequities and ameliorating SDOH are analysed and/or represented in public health discourse. I analyse how evidentiary productivity and norms around what counts as evidence shapes the extent to which interventions are represented as feasible or actionable. When upstream actions requiring changes to the economy and labour market are mentioned, they are accompanied by caveats that more evaluative research is needed. Conversely, when upstream actions are represented as successful and actionable, they take the form of a less transformative, but more assessable intervention. To further support my findings, I draw from the entire catalogue of health equity interventions listed in the PHAC's Best Practices Portal to show that evidentiary requirements for interventions to be amenable to scientific evaluation partially explain the dearth of upstream interventions. My analysis of public health documents and best practices reveals that health equity interventions are not only limited by a lack of political will, the dominance of biomedical perspectives, or a neoliberal drift towards responsibilizing individuals for their health (see Lupton, 1995). I argue that the large number of rather downstream interventions exist not only because they are socially non-disruptive, but because of their evidentiary productivity and their compatibility with dominant modes of evaluation. By attending to how structural determinants of health and health in/equity are represented in discourse, I highlight how the authority of particular kinds of evidence, and the capacity of particular interventions to produce that evidence result in actions which are exempt from political argument.

\section{Evidentiary imperatives and cautious discursive treatment of the social}

When upstream or structural determinants are mentioned, they are often acknowledged as important, but they are rarely communicated as actionable. Instead, they are discussed with 
cautious language in a context of evidentiary uncertainty. Stating that 'some [emphasis added] types of [upstream] interventions may [emphasis added] reduce inequalities' (PHAC, 2018: 426) is typical of this cautious language. This hesitance to firmly state the upstream determinants of health and related solutions is recurrently articulated in relation to evidentiary uncertainty. The statement that "there is suggestive evidence that housing change may positively affect physical and mental health, but the actual effects may be small" (426) illustrates this well. On another page, after acknowledging income and poverty as a $\mathrm{SDOH} /$ equity, the document states: "However, the value of increasing the minimum wage to fight poverty remains contested, as there is some evidence that increases in minimum wage are associated with higher unemployment rates" (425). This further illustrates how when the structural determinants of health are acknowledged, they are followed by the caveat that there is a paucity of evidence.

Again, the transformative potential of acknowledging the structural determinants of health are couched in evidentiary uncertainty:

"Overall, however, there remain substantial gaps in the evidence base on the effectiveness of broad policies in a range of sectors, including education, health care, and food and agriculture. There is also a paucity of evidence on the influence of macro-level policies on health inequalities, such as measures to ensure legal and human rights, 'healthier' macroeconomic and labour market policies, the encouragement of cultural values promoting equal opportunities and environmental hazard control (including upholding international obligations and treaties in this field" (426).

This illustrates how upholding international obligations and treaties, ensuring legal and human rights, and legislating healthier macroeconomic and labour market policies is contingent on the 
right kind of evidence. There may be a 'paucity of evidence' demonstrating the quantified and disaggregated effectiveness of particular policies on improving specific aspects of health, however significant knowledge exists on the relationship between health and broad-based policies, including macroeconomic and labour market policies (Scott-Samuel et al., 2015). This knowledge and its transformative potential are excluded by the requirement for knowing and demonstrating the precise effectiveness and causal pathways of policy actions. The problem is not a lack of evidence, but a lack of a particular kind of evidence which demonstrates effectiveness and leads to programmes which are compatible with scientific evaluation. In other words, the problem is not a dearth of evidence, but the very requirement for particular forms of evidentiary support and productivity. Under the actionable knowledge regime, politics are excluded as both a solution and as an object of measurement.

As Porter (2006) notes, 'doubt can be sown anywhere', and it is now "not academic postmodernists or social constructivists, but research institutes sponsored by tobacco and oil companies [that] have most effectively challenged or befogged the public voice of science. Anything less than rigorous demonstration, they tell us, amounts to mere opinion, and so cannot provide a suitable basis for decisions that will harm business interests, their own. "Doubt is our product" in the celebrated words of a tobacco executive, and doubt can be sown anywhere" (1291). Deferring action on the basis of evidentiary doubt is an effective strategy for advancing interests under the guise of a commitment to detached, scientific idealism. I am not suggesting that behind the campaign for scientific precision reside efforts to discredit science, or at least particular findings whose validity and fallibility is dependent on scientific claims. The deferral of action is now self-imposed by public health organizations perhaps to maintain their own legitimacy, and as a way to efface the state's role in decision-making, but it still creates an implicit division of risk. 
Health in all policies (HiAP) is an approach reflecting a recognition that harmful health impacts are rooted in government decision making: "HiAP seeks to systematically take into account the health implications of government decisions in order to better avoid harmful health impacts and improve population health and health equity" (432). Although HiAP is touted by PHAC as a 'key principle for taking action on health inequities' (428), it is only represented as a speculative line of work, because of a lack of evidence: "Despite promising early results, however, HiAP remains an emerging practice, and more evaluative research is needed, particularly related to implementation strategies and longer-term health and health equity outcomes" (428). This demonstrates how what counts as evidence shapes the representation of HiAP as an emerging (but not actionable) practice. This is important because those actions deemed 'best practices' may be the most compatible with dominant methods of evaluation, but not the most impactful.

This demonstrates a policy paradox. The cautious treatment of HiAP also shows how the evidentiary standards inscribed within some policy principles create conflicts with other equityoriented policy principles. To illustrate, in addition to HiAP, PHAC's (2018) third principle for action on health inequities-'Intervene on both proximal (downstream) and distal (upstream) determinants of health and health equity'-and the fifth principle-'Address both material contexts (living, working, and environmental conditions) and sociocultural processes of power, privilege, and exclusion (how social inequalities are maintained across the life course and across generations)' - may conflict with the second principle-'Intervene across the life course with evidence-informed policies and culturally safe health and social services'-as well as the seventh-'Carry out ongoing monitoring and evaluation' which further stipulates that "[i]mproving population health and health equity requires current, systematic, and robust evidence to inform policy actors, practitioners, community organizations, and citizens about how 
health and its determinants are distributed across subpopulations, and how policies and interventions affect health and health equity" (11). ${ }^{43}$

The potential for conflict between policy principles exists because the most important knowledge on the fundamental SDOH does not show how specific policies and interventions affect health, and therefore cannot be used to implement HiAP. International studies of the relationship between sociopolitical arrangements and health (See Navarro and Shi, 2001) will likely fall short of fulfilling the evidentiary criteria, even though these sources of knowledge provide the theoretical grounds for achieving the greatest progress on both population health and health equity. Without analysing and challenging broader structures and the forces that influence public policy and healthy human conditions, the progressive principle of HiAP is limited to all policies within current sociopolitical conditions and related constraints. Without reflexively analyzing and challenging institutionally reproduced evidentiary imperatives, dominant methods of evaluation, and ideas about what constitutes evidence, health equity interventions will remain proximal (downstream) rather than distal (upstream).

\section{Drifting Downstream and Local}

So, what is represented as a feasible, actionable and best practice? Interventions that are compatible with evidentiary standards tend to be less than transformational. Most do not involve changes to broader public policy, instead operating as regionalized programmes. The majority of health equity interventions target individual behaviour and psychological capabilities, but they are also employed territorially at the local level. As an exception, the PHAC (2018) Key

\footnotetext{
${ }^{43}$ As I have shown in the previous sections and throughout, although included is 'how policies and interventions affect health and health equity', the actual measures used do not capture these active processes beyond the local level of health service-related policies and interventions. What is produced is programme evaluations, and descriptions of distributions and associations between health outcomes and stratifiers.
} 
health inequalities document discusses two successful changes to broader public policy. These include mandatory seatbelt use and increasing cigarette taxes. These are discussed as examples of successful interventions based on the health equity policy principle to intervene on both proximal (downstream) and distal (upstream) determinants of health and health equity'. Although regulatory, these interventions target individual behaviour by introducing disincentives in the form of taxation and punitive measures (PHAC, 2018: 426). These are considered successful action on SDOH and health inequity because reviews of these policies tend to show that those among the lowest income categories respond to them (426). I am not so much trying to draw attention to the validation of interventions aimed at behaviour as I am trying to draw attention to how their ubiquity can be attributed significantly in part to evidentiary imperatives and their compatibility with legitimate methods of evaluation. What becomes successfully shown through legitimate means of assessment as demonstrably effective shapes possibilities of upstream action while excluding others which do not lend well to dominants regimes of quantitative assessment. As a result, remaining actionable ideas classified as 'upstream' or 'structural' interventions are not actually structurally transformative.

In other instances where 'structural stressors' are mentioned, including ideology, they are confined to the local organizational, programmatic, and individual level of action. Examples of initiatives include 'collaborative gender equity, anti-racism and broad anti-oppression initiatives; training in health equity, cultural safety, and trauma- and violence-in- formed care' (427). The following excerpt shows how these initiatives are represented as actionable because they are compatible with quantitative forms of empirical evidence and assessment:

There has been limited study of possible interventions to reduce the structural stressors that induce inequitable health outcomes; however, some empirical evidence is emerging about what might help change the ideological mindsets, relationships, and environments 
that trigger physiological stress in marginalized groups. [...] Some examples of work that can alleviate exclusion are collaborative gender equity, anti-racism, and broad antioppression initiatives; training in health equity, cultural safety, and trauma- and violencein- formed care (427).

The quantifying discourse is seen where structural stressors are discussed (instead of structural relations) as something that can be reduced (instead of changed or restructured). Furthermore, interventions which reduce structural stressors that induce-or reproduce-inequitable health outcomes are represented as uncertainly known. Ideology becomes represented as something that manifests in interpersonal relations, triggering physiological stress, rather than something that manifests in public policy, reproducing the distribution of political power and ultimately shaping healthy material living and working conditions. The focus on the point of psychological trigger becomes a primary target of health equity-oriented interventions. While interpersonal racism does trigger physiological stress (Krieger and Sidney, 1996), the above invocation of ideology, power, and processes does not mention material manifestations of ideology, such as shrinking welfare states, under-regulated markets, and exploitative economic relations. This reflects a wider research trend identified by Bailey and colleagues (2017) in which health equity research tends to focus on interpersonal racism rather than institutional and structural racism.

Structural and institutional sources of racism at the level of political economy are important to correct because evidence shows that particular political forces and different 'worlds of welfare capitalism' produce very different levels and distributions of population health (Navarro and Shi, 2001; Bambra, 2006; Chung and Muntaner, 2007). By focusing on noneconomic and non-structural 'sociocultural processes of power, privilege, and exclusion' in $\mathrm{HiAP}$, understandings of power remain at an organizational and interpersonal level which is discursively closed off from structurally-influential sociopolitical and institutional processes of 
power, privilege and exclusion. The emphasis on interpersonal level of power may be accounted for by virtue of its politically non-disruptive operation, but we can theorize the neglect another way as well. Structural sources_or relations_of power and privilege are temporally and institutionally more distal from individuals than interpersonal-level manifestations of power and privilege. Equity impact assessments are more capable of measuring the effects of actions such as cultural safety, and trauma- and violence-in- formed care than they are measuring the effects of other interventions - as independent variables-which are deployed further away from the dependent variable.

Health equity-based interventions decisively deemed successful by PHAC are those that are compatible with methods of evaluation in ways that broader reforms could not be. My review of all interventions in the PHAC's best practices portal reveals that these interventions tend to operate downstream, rarely provide material resources, and instead focus on skills-building and teaching cognitive behavioural practices to build resiliency and self regulation. This includes those health equity interventions listed as operating at the societal/institutional and healthy public policy level of health promotion, and those aimed at addressing income, social status, and income inequality as determinants of health.

The PHAC best practices portal contains 70 health equity interventions, 38 of which are ranked as best or promising practices. In addition to determinant of health, health equity interventions are also categorized by health promotion strategy. These strategies range across those that are 'Individual (Developing personal skills)', 'Organization (Creating supportive environments)', and 'Societal/Institutional (Building healthy public policy). ${ }^{44} \mathrm{~A}$ search for (best

\footnotetext{
${ }^{44}$ The category of Societal/Institutional (Building healthy public policy) is described by PHAC as follows: "These interventions empower citizens through the process of conferring decision-making capacity upon those who previously had been unable to decide matters for themselves or had limited ability to do so via advocacy, policy, and legislation development" (Category page in PHAC, 2016).
} 
practice) health equity interventions which target income and social status as a determinant of health only yielded 6 practices, while a search for (best practice) health equity interventions which target personal health practices and coping skills as a determinant of health yielded 22 practices. There are no health equity interventions listed at the societal and institutional level of health promotion (including those practices not categorized as best or promising practices) which address income and social status as a determinant of health. Neither are there any health equity interventions listed at the societal and institutional level of health promotion as targeting employment and working conditions. Conversely, at the individual level, there are 6 programs categorized as health equity which target income and social status as a social determinant of health. The point is that there is a dearth of programs which target those determinants of health most related to economic social relations which require action at the societal and institutional level of health promotion.

Those extant health equity interventions which target material social determinants of health—income, employment, and working conditions—not only fail to create healthy public policy, but predominantly operate by instilling self regulation, and rarely offer material resources to the citizen-turned-participant. Interventions focusing on income and social status as a determinant of health primarily focus on building coping skills. By targeting individuals with low income or social status, these interventions are able to maintain their place in the determinants of health category of income and social status even when they only teach and evaluate coping skills to determine programme success. Only two health equity interventions focusing on income and social status as a determinant of health provide material resources to participants. These include At Home/Chez Soi, modelled after housing first, and the Fruit and Vegetable Subsidy Programme, which has not been implemented in Canada. 
Total Number of Best Practices Interventions Categorized by Determinant of Health ${ }^{45}$

\begin{tabular}{|l|c|}
\hline \multicolumn{1}{|c|}{ Determinant of Health } & \multicolumn{1}{|c|}{$\begin{array}{c}\text { Total Number of } \\
\text { Interventions }\end{array}$} \\
\hline Employment and Working Conditions & 2 \\
\hline Physical Environment & 3 \\
\hline Food Security & 5 \\
\hline Income and Social Status & 6 \\
\hline Personal Health Practices and Coping & 22 \\
Skills & 2 \\
\hline
\end{tabular}

Total Number of Interventions Categorized by Health Promotion Strategy

\begin{tabular}{|l|c|}
\hline \multicolumn{1}{|c|}{ Health Promotion Strategy } & $\begin{array}{c}\text { Total Number of } \\
\text { Interventions }\end{array}$ \\
\hline $\begin{array}{l}\text { Societal/Institutional (Building Healthy } \\
\text { Public Policy) }\end{array}$ & 1 \\
\hline Community & 5 \\
\hline Organizational & 13 \\
\hline Individual & 23 \\
\hline
\end{tabular}

From citizen to participant. To further elucidate what we are left with after the evidentiary hurdles are cleared, what follows is a critical exposition of five best and promising practices touted by PHAC as health equity interventions targeting different determinants of

\footnotetext{
${ }^{45}$ The number of interventions in each column do not total to 35 because many interventions formally target one or more determinant of health and/or health promotion target.
} 
health at various levels of health promotion. In addition to illustrating the dominant focus on building coping skills and resilience, these examples also reveal the reconfiguration of the social and the citizen-subject. Rather than building an evidence base to support broad changes in public policy, these programs operate as experiments which are designed to be widely implementable and testable, but not necessarily to be useful for political contestation and policy and social change. In contrast to previous eras of nation building in which the state plans to secure citizens' social rights (or healthy living conditions) through policy-making, the ideal citizen is increasingly constructed as the entrepreneurial citizen (Broadie, 2002). I suggest there is another shift as well in which those non-ideal citizens-those who fail as ideal entrepreneurial subjects-can receive help as participants in experimental programs rather than as citizens of a generous welfare state. The homeless can enter At Home/Soi Chez (modelled after housing first and deployed as a randomized controlled trial) and hope to be drawn as the experimental participants. While others have shone light on the socio-political and economic contexts which precluded any further national, universal welfare policies following the introduction of universal healthcare in Canada (Poland et al., 1998), I want to shine a critical light on what operates in place of a comprehensive welfare state and how these technical projects are secured less by the public's moral commitment than they are by their own evidentiary productivity.

Triple P-Positive Parenting Program. Triple $\mathrm{P}$ is a parenting programme listed as a best practice in the Canadian Best Practices Portal. I have identified this programme for closer scrutiny because it is presented in Key health inequalities in Canada: A national portrait as an effective programme for 'intervening across the life course with evidence-informed policies and culturally safe health and social services'-a 'key principle for action that can advance health equity within Canada' (2018: 424). The equity focus in Triple $P$ is enacted in reference to target population rather than to a particular source or even manifestation of inequity: "People living in conditions of disadvantage are explicitly stated to be a target population of the intervention" 
(Outcomes and Impact Chart in PHAC, 2016b). As an intervention goal, Triple P is listed as targeting the community, individual, interpersonal, and societal levels (PHAC, 2016b). In evaluation its level of impact is limited to the interpersonal level (Outcomes and Impact Chart in PHAC, 2016b).

My review of best practices revealed that many practices primarily involve instilling self regulation. The founder of Triple-P, Matthew Sanders, states that self regulation is the central goal and the unifying framework for Triple-P (2008: 508). Self regulation is operationalized to include promoting self-sufficiency; increasing parental self-efficacy; using self-management tools; promoting personal agency; and promoting problem solving (508). These five dimensions of self regulation/core positive parenting principles "that form the basis of the programme were selected to address specific risk and protective factors known to predict positive developmental and mental health outcomes in children" (509). ${ }^{46}$

While political empowerment is absent from the programme itself, there are hints of a particular kind of political empowerment in the founder's discussion of 'sociopolitical context', and in his concluding 'cautionary note'. At the end of a promotional article in Journal of Family Psychology, he expresses his hopes that "[w]ell-informed parents will create consumer-driven pressure on government services and agencies to deliver quality evidence-based programs in ways that are cost efficient and convenient for parents to receive" (515). Furthermore, Sanders

\footnotetext{
${ }^{46}$ Academics have pointed out several problems relating to conflicts of interest and methodology that compromise the validity of Triple P's evaluation. First, the program is a multimillion-dollar enterprise which generates royalties for both the contributory authors of Triple $\mathrm{P}$, and the University of Queensland Faculty of Social and Behavioural Sciences, School of Psychology, Parenting and Family Support Centre (Coyne et al., 2013; Eisner, 2014). Moreover, Triple $P$ has been criticized for producing the majority of its own evaluation studies, and for paying for third party evaluations whose authors fail to disclose conflict of interest (Coyne et al., 2013; Eisner, 2014). Critics also cite flaws in the studies with some finding no effect of Triple P (Little et al., 2012; Eisner, 2014). Triple $\mathrm{P}$ has also been criticized for having paid-spokespersons silence and threaten critics in their workplace (Coyne, 2014).
} 
frames the need for programme advocates and consumer advocates explicitly as a sociopolitical problem. This signals the reconfiguration of the sociopolitical and governmental context itself. This reconfiguration is characterized by the replacement of a deliberative and reformist policy landscape in which social change and social rights are at stake, with a programmatic and managerial landscape in which the number and cost-efficiency of on-going, temporarily deployed evidence-based programs are at stake.

The Jobs Program. Jobs has been evaluated in two controlled field experiments and PHAC identifies it as a promising practice. I selected this programme for analysis because it is one of three health equity interventions that focus on income and social status, and the only health equity programme which is directed at working conditions as well as income and social status. ${ }^{47}$ Together, these SDOH comprise both the relation and manifestation of exploitative economic relations which so easily evade programmatic public health intervention. Founded in 1984, Jobs teaches active learning and brain storming to diagnose problems and suggest 'active coping solutions' as ways to overcome potential obstacles or barriers to employment. The programme encourages participants to 'analyze their situation for problems or potential difficulties, and to generate their own solutions'. On the Jobs website, the program's cofounder, Amiram Vinokur explains, "[a] person who feels he or she 'owns' the solution to a problem will be more committed to implementing the solution" (Jobs, 2003). Jobs emphasizes a theorydriven approach derived from research on vigilant coping 'that shows that people under pressure often narrow their search for solutions and tend to become prematurely invested in a certain course of action' (Jobs, 2003). Theory on self efficacy and social resources also drive the intervention. In addition to diagnosing unemployment problems and generating alternatives for re-employment, participants receive "inoculation against setbacks that protects their

\footnotetext{
${ }^{47} \mathrm{Jobs}$ is also listed as a program directed at personal health practices and coping skills, and education, literacy and life-long learning.
} 
motivation and mental health when setbacks occur" (Jobs, 2003). PHAC adopts this language where it highlights that the programme 'inoculates participants against feelings of helplessness, anxiety, depression, and other stress-related mental health problems' (2016c). The theory is that "[p]eople need to anticipate setbacks and build up repertoires to cope with counterpressures" (Caplan in Jobs, 2003). This discourse represents unemployment and social precarity as inevitable life encounters that proactive individuals can overcome by learning the right coping skills.

As with the rest of the programmatic landscape that I have been describing, Jobs does not focus on tackling income inequality and/or unemployment at the level of public policy. Also characteristic of this landscape of diffuse, disparate, and temporary programmes, Jobs is developed to be widely implementable and testable. As another one of the founders, Robert Caplan states, "we wanted to discover some generic principles of intervention, and methods of evaluation, which could be more widely used in preventive intervention" (in Jobs, 2003). This illustrates how programs termed best or promising practices are those that lend well to experimental evaluation and replication.

Canada Prenatal Nutrition Program (CPNP). The Canada Prenatal Nutrition Program (CPNP) targets marginalized pregnant women through initiatives that include education and counselling in prenatal and lifestyle, breastfeeding, food preparation and infant care, as well as the provision of vitamins, food and food coupons to improve maternal-infant health. Women with high exposure to the CPNP have been found more likely to improve their health behaviours and less likely to give birth to a premature or small-for-gestational-age baby (PHAC, 2018: 424). According to the 2009 Summative Evaluation Report, the programme reaches those pregnant women 'most at risk for poor birth outcomes and who are often least likely to participate in traditional prenatal programming'. 
While this programme evidently provides information and food coupons to mothers in need (who happen to be enlisted into the programme), the programme's evaluation reveals how human problems of health, wellbeing, and social justice are instrumentalized. The scope of the evaluation is limited to the three dimensions of the program: relevance, impact, and costeffectiveness. Relevance addresses whether the programme addresses an actual need, and whether the programme is consistent with government priorities. Impact is based on successfully reaching pregnant women facing conditions of risk; identifying changes in disparities between participants and the general population; and determining the extent to which CPNP projects implement a population health approach. The first question of relevance is the only one which measures the extent to which threats (such as poverty) to the health of pregnant women, their infants, and families persists. However, the fact that "[t]he question of relevance addresses whether there is a continuing need for CPNP" further reveals that these programs do not aim to demonstrate a need for broader policy, but only the need for continual deployment and evaluation of programs. The evaluation determined that poverty and unemployment continued among vulnerable populations, including CPNP participants, however this did not lead to a call for political action. Instead, this finding only affirmed the programs' relevance: "As such, the ongoing relevance of CPNP, which endeavors to mitigate these risks and improve infant outcomes, is apparent". The final question of the summative evaluation focusing on costefficiency and cost-effectiveness-'Are Canadians getting value for their tax dollars from this program?'-is answered by assessing the cost efficiency (cost per participant); cost effectiveness of healthy birth weights; and cost effectiveness of breastfeeding. These assessments indicate a weighted average cost per birth difference between $\$ 2004.32$ (average birth in Canada) and $\$ 1915.07$ (births in CPNP) for a cost-savings per birth for CPNP of \$89.24. 
All six final recommendations suggest further data collection to refine evaluation and expand the program. These final recommendations primarily discuss further monitoring the relationship between programme exposure and risk factors (including poverty) to further evaluate programme effectiveness. Other recommendations call for assessing the adequacy of funding. This claim is grounded in the argument that the programme has operated for 13 years without increased funding, and the programme needs to be rolled out wider into more communities since it is proven to be cost effective. None of the recommendations call for tackling the very risk factors (through policy action) that support the programme's relevance. The recommendation to monitor threats (including SES) is articulated as instrumental to programme change rather than social change where it states monitoring threats is important "so as to inform implementation and enable the programme to adapt and respond to emerging health priorities". The neglect of social change, the emphasis on cost effectiveness and accuracy of evaluation, and the instrumental treatment of risk-as a means of affirming and expanding the programme-is unfortunate given that 51 percent of CPNP participants reported an annual household income of under $\$ 15,000$ and 69 percent had achieved a high school diploma or less (Participant profile in PHAC, 2011). Rather than using this knowledge to advance policy action that reduces the root causes of poverty and low educational attainment, this knowledge is used to promote and expand the programme into more communities as a cost savings measure.

Fruit and Vegetable Subsidy Programme. The Fruit and Vegetable Subsidy Programme provides participating indigenous families with weekly 40 to 60 -dollar boxes of vegetables and five dollars. Participants also receive nutritional information, and the option of taking part in cooking classes. The programme is listed as a promising health equity practice in the Canadian Best Practices Portal which targets income inequality and social status in addition to food security, access to health services, and healthy child development. The programme has been 
evaluated as successful at the individual and community levels of impact. At the community level, families showed increased engagement with health services and preventive health activities, and at the individual level there were significant increases in biomarkers of fruit and vegetable intake, as measured by an increase in plasma carotenoids (including plasma carotenoids and vitamin C) (Outcomes and Impact chart in PHAC, 2016d). I have chosen to highlight this intervention because it illustrates how a programme can be represented as a legitimate means to addressing a range of determinants of health for which income inequality is one by merely demonstrating a temporary biological effect on disadvantaged populations without actually attending to the problem of income inequality and social status. I have also chosen to highlight the outcomes of this intervention because they illustrate how temporary, downstream, experimental programs can quickly produce precise forms of evidence such as changes in biomarker levels that structural interventions cannot easily produce.

Home start. Home start is a health equity intervention that targets the following determinants of Health: Income and social status (including gap between rich and poor); personal health practices and coping skills; social support networks; and healthy child development. The programme focuses on encouraging confidence and independence, and helping parents build their own networks of friends and social support (PHAC, 2016e). Specific activities of the intervention include enlisting volunteers to visit families' homes and offer emotional and practical, non-financial support in their homes by volunteers. It is aimed at reducing stress levels within families, enhancing parental self-esteem, and improving parents' social relations. Like many of the interventions in the Canadian Best Practices Portal, Home start is a psychosocial intervention, but in this case, its theoretical link to addressing material determinants of health that it purports to target is unclear. Despite ambiguity around the material dimension of Home start's effects, the programme produces precise evidence about its shortterm psychosocial effects. 
Home start's effects on parental characteristics including feeling of competence, responsiveness, rejection, and consistency were evaluated. According to the program's Outcomes and Impact Chart (in PHAC, 2016e), all measures were significant at post-test when compared to the community and control sample $(p .=00, p .=02)$. A positive outcome for feeling of competence was sustained at a three-year follow up point, but these effects were no longer present at 10 years post intervention. Evaluation of the program's effects on child behaviour shows a decrease in internalizing problems for the Home Start children during and directly after intervention (affective problems $p .=01$; anxious $p .=00$; oppositional $p .=01)$ with affective problems significantly decreasing until the three-year follow-up ( $(\mathrm{p}=01)$. However, no further change was observed at 10-year follow-up. Furthermore, positive change in externalizing behavior until 10-year follow-up was observed for both the experimental group and the control group.

Like other interventions in the best and promising practices portal, this intervention is evaluated by quantifying psychological constructs that are turned into scientific-looking indicators. This matters because the recognized success of these programs lie in an inaccurate regime of assessment in which effects on such measures as 'feelings of competence' are precisely quantified. The actual link between feelings of competence and health equity are no less theoretical, and far less substantiated than the relationship between state political tradition and population health outcomes. But, however unsubstantiated the link between 'feelings of competence' and health equity is, the evaluation of a program's effect on such a psychosocial construct is immediately productive. The temporality of evidentiary productivity is crucial to whether an intervention is actionable. In fact, in the case of Home Start, the evaluation actually showed that the intervention does not produce long-term effects. However, because the programme 
produces a significant effect on something, even if only in the short-term, it can be deemed successful.

Temporal constraints on action intersect with evidentiary imperatives, ultimately curtailing the very possibility of meaningful action that might target the fundamental causes of inequity. Although improving health equity requires long-term actions, efforts to reduce inequities are generally plagued by political short-termism (Orton, 2011; Farrer, 2015). We can understand this short-termism by looking at how the intersection of evidentiary productivity and political imperatives ultimately create evidentiary imperatives for public health actors. Johnson (2009), writing from the Alberta context, notes that because governments face re-election every three to five years, they tend to favor shortterm objectives that are easier to achieve and demonstrate. In the Ontario context, progress on the HiaP approach has been limited by political timelines to achieve goals (Lahey, et al. 2017). Adding to this political short-termism are the organizational-level requirements for finding activities that are easy to evaluate and demonstrate (Farrer, 2015; Cheff, 2017; Hassen and Tyler, 2017; Anne et al., 2018).

\section{Conclusion}

In this chapter, I analysed the PHAC publication, Key health inequalities in Canada: A national portrait (2018) to show how actual and potential actions for tackling health inequities and ameliorating SDOH are analysed and represented in public health discourse. I analysed how evidentiary productivity and norms around what counts as evidence shapes the extent to which interventions are represented as feasible or actionable. By attending to how structural $\mathrm{SDOH}$ and equity are represented in discourse, I highlight how the role of particular kinds of evidence, and the capacity of particular interventions to produce that evidence construct the problem of health inequity and its solutions in a way that keeps health inequity pre-political (in 
the overtly dialogical sense). I also drew from the catalogue of health equity interventions listed in PHAC's Best Practices Portal to further explore and then corroborate my emerging argument that evidentiary requirements for scientific evaluation results in a dearth of upstream interventions. Interventions predominantly operate by instilling self regulation, and rarely offer material resources to the citizen-turned-participant. I argue that the large number of rather downstream interventions exist not only because they are socially non-disruptive, but because they are compatible with dominant modes of evaluation necessitating short-term, precise, and quantifiable evidence.

However progressive seeming, best practices and programs like CPNP fail to even advocate for tackling the very risk factors (through policy action) that support the programme's relevance. Instead of advancing the case for healthy public policy, the continual surveillance of risk factors is pursued to affirm and reaffirm the programs relevance and expansion. I suggest that the proliferation of programs as a solution to issues of human welfare should not be taken for granted. Non-ideal citizens—-those who fail as ideal entrepreneurial subjects—can receive help as participants in experimental programs rather than as citizens of a generous welfare state. The deployment of programmatic action, and the deferral of policy action or even analysis indicates the reconfiguration of the sociopolitical and governmental context itself. This reconfiguration is characterized by the replacement of a deliberative and reformist policy landscape with a programmatic and managerial field of practice. This governmental context strays from post World War II growth of the welfare state when issues of human need became policy issues inserted into political deliberation. While gesturing to the neoliberal decline of the welfare state is now an obvious observation, there has been less attention paid to the ways in which the very practice of identifying a social problem is supplanted by the deployment of actionable, optimistic, temporary, and evidence-based projects. 
The under-theorized problem of health inequity is met with technical projects and little to no engagement with normative considerations of social justice. Adolphe Quetelet is reputed to have spoken of legislation as a social experiment which legislators could use statistics to determine if the correct course of action was to proceed further in the same direction, to introduce modifications, or to try something else entirely (Porter, 2006: 1277). Only now, at least in the case of action on health in/equity, it seems legislation is not part of the repertoire of actions at all, even in its experimental form that Quetelet spoke of. Even legislative ambitions in Canada such as HiaP have not moved beyond gathering evidence (Lahey et al., 2017: 71). What operates in its place of experimental legislation, appear to be social experiments, divorced from any ambitions of legislative reform.

The incessant deferral of policy action and simultaneous constant expansion of programs and their accompanied evaluation reveals how human problems of health, wellbeing, and social justice are instrumentalized. The implicit normative ethical orientation of these actionable practices differs from the practices enacted through $\mathrm{CHCs}$ and codified in provincial health standards. In chapter four, I suggested that in absence of engagement with the field of normative ethics in epidemiological characterizations of health in/equity, the default response is distributive/mitigating rather than fundamentally relational/corrective. In contrast, my analysis of best practices indicates that programmes categorized as health equity interventions often do not even achieve this limited ethical orientation. Rather than being mitigative or distributive, they are productive in two ways. First, they produce evidence to demonstrate their own effects.

Secondly, as technologies of agency (See Dean, 2014), these interventions seek to produce agency through empowerment and other cognitive-based, immaterial means of assistance. Because they explicitly derive their 'equity focus' by targeting disadvantaged populations, it could be said that these best practices are mitigative, however they fall short of approximating any normative ethical orientation. They do not alter distributive mechanisms or patterns of social 
goods, and neither do they alter the kinds of goods available for distribution. Finally, they do not intervene in those processes that actively create unequal need, opportunity, and health outcomes.

The next chapter will continue to look at how action is diffused downward by examining community as a nodal point in health equity discourse which functions as a reconciliatory vehicle and territory through which public health can carry a progressive civic appearance in neoliberal conditions in a way that discourse of the responsible individual could not. 


\section{Chapter 9: Health Equity and the Community}

Community and inclusion are prominent themes in all documents and websites examined this project. My analysis of the deployment of 'community engagement' in the PHAC and NCCDH documents draws out three themes in which equity is articulated in relation to community: 1) Surveilling and evaluating 2) Empowering and producing active, responsible, networked, and resilient communities 3 ) Identifying community needs and working with or on behalf of localities to influence government policy. These themes are not exclusive to respective documents in which they are found, as several themes are present in the same documents at times. However, some themes are more dominant than others both in the prevalence and vigour with which they are invoked. These three themes represent/reproduce different relationships between citizen, community, society, and public health. Each of these relationships require different commitments from one another, and as a result, produce different ideal citizen-subjects and allocations of responsibility. As a whole, the discourse of community produces a communitarian citizen-subject which contains possibilities for action to various planes below the level of the competitive nation state or political economy. This is the product of an actionable knowledge regime which does not produce the knowledge required for representing health inequity in relation to political economy. Furthermore, this ensuing political containment, operating under a discourse of community and inclusion, reconciles the contradictions between liberalism and the long-standing socialist thread in public health ${ }^{48}$, and more fundamentally, the contradiction between liberalism and democracy.

\footnotetext{
${ }^{48} \mathrm{I}$ make this generalization based on several historical and contemporary features of public health. First, the public ownership and provision of health services-something which could be commodified and sold to those who are willing and able to pay-imbue public health with a socialist thread. In addition to the obvious public ownership and funding of public health institutions and provision of essential health care in Canada, we also see a
} 


\section{Community-organization-government policy liaison}

Community engagement/empowerment/inclusion/collaboration can take the form of collective political mobilization at the level of community which focuses on directly influencing broader government policy outside of health policy. Although both discourse and concrete actions of this theme were the least common, they offer a countervailing discourse which is worth mentioning. Overcoming Poverty Together was a strategy praised within the National Collaborating Centre for the Determinants of Health's (NCCDH) (2012) New Brunswick case study, Bridging the Gap between Research and Practice: Empower the Community. Overcoming Poverty Together involved advocacy work aimed at securing an increase in minimum wage, and a prescription drug plan for all uninsured citizens by 2012. However, this initiative is not headed by any public health institution, but instead the Economic and Social Inclusion Corporation. In contrast, the Saskatoon Health Region focused directly on addressing poverty. Their collaborative work resulted in tax credits, increased programing for mental health promotion, funding for affordable housing, investment in several inner-city schools, and an increase the minimum wage from 8.60 to 9.25 an hour. Finally, the LHIN discussion paper discussed consulting communities about which broader policy issues to support at various levels of government (See Gardner, 2008). These examples are not only important to mention because they represent counter examples to the larger narrative identified in my analysis of public health documents. They also exemplify a type of collaborative action which attempts to

\footnotetext{
general commitment to the common good, a commitment which supersedes individual liberty at times. The contemporary field of public health is characterized in terms of "its values of social justice and fairness for all, and its focus on the collective actions of interdependent and empowered peoples and their communities" (Horton et al., 2014: 847). One can also interpret a host of social reforms during the industrial revolution as a commitment to the common good over individual freedom (in the negative sense of freedom). At every step of the way, advancing public health historically required some concern for the public good to be addressed through collective actions, either as working-class groups, or as public institutions providing de-commodified services. Although the motivations behind these measures can also be traced to requirements for healthy and productive pool of labour, they still required collective action and social provision of goods.
} 
grapple with public policy as a determinant of health. When community engagement takes this form of action, responsibility is put on the state to prioritize the interests of the public over those of capital. This type of action not only demonstrates an awareness of the relationship between individual and society, but also forges a healthier, and fairer relationship.

\section{Surveilling and evaluating}

Community inclusion is often discussed as a way of gaining insights which can be used to refine indicators used for surveillance and evaluation of local population health and programme performance. In addition to enhancing surveillance and evaluation tools, communities are also enlisted in programme development and implementation. This kind of community engagement is invoked in the 2018 Health Equity Guidelines where it states community engagement is to be "supported and promoted by encouraging local communities to get involved in all stages of public health planning, implementation, and evaluation" (9). Beyond any instrumental functions of community inclusion in local surveillance- and programmeenhancing action, community inclusion is also discussed as a moral imperative: "Caution must be exercised in implementing targeted interventions. To avoid stigmatizing targeted groups, it is important to consult with those target populations and communities in the development and implementation of policies and programs" (PHAC, 2018: 427). The following excerpt further illustrates how public health organizations engage those who experience inequities to further refine surveillance tools, but also to fulfil (and communicate) a moral imperative.

Those who experience inequities in the social determinants of health and health outcomes can provide important knowledge and insights into the development, implementation and evaluation of data infra-structure, surveillance programs, policies, and interventions. These populations should be meaningfully engaged wherever possible. This is particularly true for the measurement and monitoring of and action on 
health inequalities experienced by First Nations, Inuit, and Métis peoples in Canada (PHAC, 2018: 429).

This reflects the broader theme of employing community or priority population engagement as a means of refining surveillance tools while demonstrating a commitment to democratic inclusion. When the design of policies and interventions are discussed in relation to community inclusion, it is unclear how, which, and to what extent community input is accommodated and influential. As I have shown, given the particular evidentiary imperatives for supporting and evaluating programming, and the governmental level at which these knowledges confine programs to, it is doubtful that including communities in the design of and implementation of interventions will improve their material living and working conditions or lead to any kind of structural change.

The role of public health and its commitment to community consultation is framed as one which will 'lead from behind', by "providing direction on local data and evidence-based actions that are available" (NCCDH, 2012: 8). All that is required of public health is to include or consult communities and share information. Public health is responsible for accounting for needs and drawing on community assets and to come up with proactive and often mitigative solutions. If counteractive and corrective action is pursued, responsibility it placed on the community. As state actors, local public health organizations may provide space or administrative support for community action (Cheff, 2017), but nothing is necessarily required from the state's regulatory interaction with financial markets, industries, employment relations, processes of wealth accumulation, and ultimately, competing interests between those who rely on their own labour performance in the market to achieve wellbeing, and those who stand to gain more, at the expense of others, through exploitation and/or financial derivatives. On the other hand, the role of community is to responsibly take part in their own internal governance by using and sharing information. 


\section{Active communities: responsible and networked}

Through the language of empowerment, collaboration, and inclusion, community engagement produces active and networked communities. Public health agencies assume the role of knowledge brokers who 'lead from behind', while individuals are responsible for forging new relationships between self and community. Communities are provided with information and engaged to help identify local needs, develop plans, draw out community assets, and build community networks of knowledge exchange. The potential for a political relationship between individuals, communities, and society (including the state-economy nexus) is absent from local and trans-local discourses and practices.

In my review of the 2018 Ontario Health Equity Guidelines, an assumption of active responsibility of communities and priority populations is apparent where 'community capacities' (6) and 'community assets' (4) are mentioned as integral to reducing health inequities through community engagement. In the 2018 OHEG glossary, community assets are defined as "include[ing] not only buildings and facilities but also people, with their skills, knowledge, social networks, and relationships" (12). The frequent emphasis on community engagement—and the local generally—in health equity discourse and action constitute a larger theme which has not been attended to in existing empirical literature on health equity. It is unclear to what extent communal input translates into structural change. And so, it is important to critically examine how individuals and communities are put to use, as well as the constraints imposed by the programs that people are enlisted into.

In 2010, the New Brunswick Economic and Social inclusion Act (2010) adopted Overcoming Poverty Together: The New Brunswick Economic and Social Inclusion Plan. The plan was designed to 'empower communities to set and implement their own plans' within 
community inclusion networks in which communities, with the aid of the Economic and Social Inclusion Corporation and paid coordinators, "determine priority issues in their communities and engage local groups and individuals to develop and carry out poverty reduction plans" (In $\mathrm{NCCDH}, 2012: 4)$. This line of community engagement requires communities to overcome the challenge of "generat[ing] and us[ing] knowledge in absence of academic research support" (4). This is reflective of the wider theme of producing active and networked communities in which community engagement translates to "relying on the community to find and act upon its own solutions" (9) and using "[community] leaders' and members' networks to draw out community assets" (7). Mobilizing community assets includes securing both material and human resources such as volunteer labour and financial donation:

"Because sustainability is a keystone of the strategy, the plans must demonstrate the ability of its members to seek and secure resources within their communities. They must gather partner organizations that will host administrative or project activities, deliver inkind resources, such as volunteer labour, and secure financial resources, including donations" (6).

Gathering volunteer labour is a common component of equity-guided programs listed by PHAC as best and promising practices. The Canadian Prenatal Nutrition Program (CPNP) focuses on promoting 'the creation of partnerships within communities and strengthen[ing] community capacity to increase support for vulnerable pregnant women and new mothers' (PHAC, 2015). CPNP sites have demonstrated an ability to attract local support in strengthening CPNP sites through in-kind contributions, additional funding, and discounts on goods and services. The most recent funding data from $2005-2006$ indicates that the 330 CPNP sites received over $\$ 8.6$ million in additional funding from sources outside the Public Health Agency of Canada; nearly 50 percent of total staff hours were in-kind contributions from partnering organizations which are 
valued at over $\$ 9.3$ million; and ninety-seven percent of CPNP sites reported receiving in-kind resources. Additionally, nearly 50 percent of participants are involved in roles such as participating on advisory committees, while 40 percent are peer teachers and 20 percent provide peer outreach.

Human and informational assets within the community are represented as a sort of untapped human capital whose full potential can be activated in a network: "[L]inking similar, local initiatives across the region or province' may support them through shared knowledge and mechanisms of success ('trans-local' scaling up)" (NCCDH, 2012: 9). ${ }^{49}$ A focus on trans-locality configures collective action into an information sharing network rather than into a politically mobilized collective which might elevate its shared interests into the realm of public policy. Rather than emphasizing the potential for political contestation, networks and assets are represented as a means to achieving an emotional form of social capital: "The power of the network is to have members celebrate each other" (10). The goal becomes building "on the informal relationships developed through participants" (10). The ends of collective action are left vague, but optimistic. Discourse of community allows for health equity action to be invoked in relation to ambiguous, but proactive, optimistic, and seemingly progressive possibilities. What gets left out are structurally transformative goals, competing group interests, and the role of the state in modulating them.

\footnotetext{
49 Uvin and Miller (1994) provide a history of the concept of 'scaling up' which dates back to the 1960s where it originated among NGOs and engaged scholars but did not gain broad acceptance until the second half of the 1980 s, albeit in a form which did not involve direct political contestation. Uvin and Miller explain that the bottomup, grassroots model organizes development from below and increases the capacity of poor people and communities to take their fate in their own hands and to change the conditions of their lives by empowering themselves through 'participation in their own development'. While NGO programs following this scaling up strategy are considered to be only capable of acting at the margins by providing relief, and not able to tackle the real issues such as the eradication of hunger and poverty for hundreds of millions of people, they do not compromise their legitimacy in relation to the foreign state they operate in.
} 
As the following excerpt shows, the optimistic sentiment signified by community sets out a pragmatic agenda, limiting communities to do what they can with what they have:

"To achieve their ambitious goals, the Economic and Social Inclusion Corporation hopes to build on the following strengths: Focus on community assets, rather than the deficits portrayed in the poverty data; build on the knowledge of the community provided by the Community Inclusion Networks, and on the informal relationships developed through participants" (10).

Similarly, PHAC critiques deficit-based indictors for creating stigma and discrimination against indigenous peoples, and emphasizes the need for a community-driven approach:

\footnotetext{
"A balanced approach that identifies protective factors such as resilience, selfdetermination, and identity provides a more complete understanding of the issue and can be more effective in empowering and mobilizing individuals or a community towards improving health" (PHAC, 2018: 7).
}

By focusing on assets, rather than the deficits' portrayed in poverty data' this discourse produces active communities through their optimistic representation. This optimistic representation of community as empowered and active lends to measuring feasible, affective interpersonal achievement of success within the community while evading problems of poverty and the social structures outside the community that produce material problems in the first place. It is important to note the productive and restrictive relationship between measurement and an optimistic, actionable discourse of community. 
Combating poverty is still seen as unachievable in some sectors, so it is important to build in processes that will maintain the motivation of participants. Recognizing the magnitude of the issues, it is important to be realistic and set small, achievable goals. It may be important to create broad indicators to measure change and recognize achievements in areas related to poverty, such as resilience or a reduction in risk factors. When success is achieved, it should be documented, communicated and celebrated (NCCDH, 2012: 9).

This illustrates how in order to be actionable and optimistic, researchers lower their sights by broadening measurements of poverty to include "areas related to poverty, such as resilience or a reduction in risk factors" (9) rather than poverty itself. If what gets measured gets managed (and this seems so, given the link between quantitative measurement, evidence, and action), the creation of broad indicators lowers the bar for success. This effectually reproduces those programs of action which demonstrate progress on measures of broad indictors such as resilience and a reduction in risk factors (whose existence is nebulous, infinitely divisible, and thus possibly marginal to begin with) rather than those actions which achieve the poverty reduction strategy's goal of reducing poverty.

Within this broadened range of goals, enhancing the welfare state and reducing economic exploitation is not included. Instead, "[t]he challenge is to shift their thinking to the broader goal, to encourage them to work creatively with others in the network, using the full range of community assets to achieve common objectives" (9). The idea of achieving common objectives at the community level is quite different from achieving common objectives at the level of nation state, but this regionalized idea of the common good is compatible with the tenets of communitarianism, a political philosophy not far off from liberalism.

\section{Accommodation, compromise, and political containment}


The form of liberalism that is reproduced is what Denny (2008) refers to as communitarian liberalism. The intra- and inter- networked community represents a liberal compromise. Invoking and mobilizing social cohesion at the community level accommodates a progressive sentiment of social collectivity, common good, and individual compromise into liberal hegemony at the same time as larger forms of the social-democratic ethic are actively compromised by individualism, responsibilization, political disengagement, growing social precarity, eroding and/or stagnating welfare-states, and increasingly liberalised capitalism. The idea of a civic social cohesion to be realised through active, networked communities and the resources that can be harnessed by the 'power of the network' conveniently and pre-emptively replace a larger idea of common good that might require exactly those forms of social security which are perpetually compromised by neoliberalism. And so, however antithetical to liberalism a discourse of collective action, compromise, and the common good appears, it is easily accommodated-and contained—quite well at the community level.

By "build[ing] on the knowledge of the community provided by the Community Inclusion Networks, and on the informal relationships developed through participants" (NCCDH, 2012: 10), community level action is directed inward and across communities, rather than upward to the state-market nexus. When discourse and practice are kept to the communal plane, even notions of addressing issues such as poverty at a 'deeper level' are not necessarily conceptualized as projects of political contestation.

To achieve real sustainability on poverty reduction efforts means addressing issues at a deeper level than simply alleviating urgent needs. For example, food banks may address the immediate issue of hunger, but establishing a community garden, with local volunteers and resources, will help maintain the solution over the long-term. Linking similar, local 
initiatives across the region or province may support them through shared knowledge and mechanisms of success ('trans-local' scaling up) (9).

This trans-local vision is limited to building community gardens, emotional bonds, and resilience at the individual level, without improving their capacity for doing so by, for example, improving their social security, and their material living and working conditions. This form of community engagement does not create social change by establishing a relationship between politically empowered communities and the state. This illustrates how strategies for addressing deeper issues are reconfigured in practice, discourse, territory, and imagination, as horizontal strategies.

The pervasion of the local and trans-local community discourse and operation are seen in existing public health programs aimed at redressing health inequity. The ubiquity of programmes themselves—rather than universal welfare entitlements—should not be taken for granted. Federal-level initiatives adopting a health equity and SDOH perspective operate at the community level and primarily provide information rather than material resources. For example, the Community Action Program for Children (CAPC), Canada Prenatal Nutrition Program (CPNP), and 'Triple P'-Positive Parenting Program are all public health programs operating at the community level, and for which equity is a guiding principle.

\section{Reconciling a paradox within (neo)liberal democracy}

Democracy relies on an idea of the common good, community, nation, and history while liberalism opposes these sentiments, instead valuing individualism and seeking to minimize the role of the state, even in mediating competing group interests (Mouffe, 2000). This represents what Chantal Mouffe (2000) refers to as the democracy paradox, an enduring compromise between liberal and democratic theory. As neoliberalism becomes more hegemonic, and as 
collective state responses to increasing social precarity erode, democratic discourse of inclusion and community within health equity discourse reconciles, or at least eases this tension without having to resist the liberal thrust to dismantle the nation state's putative commitment to the common good. Furthermore, democratic discourse of community and inclusion is easily accommodated because it contains democratic action at the local level. The idea of the common goal, the territory in which it is pursued, and the sources of resources for achieving it are contained.

The other important point is that discourse of community inclusion-turned-empowermentturned-responsibilization within health equity discourse-and other non-socially disruptive versions of health equity which rely on teaching personal health practices and coping skills, for example-serve as a way of reconciling the democratic and socialist ethos of public health with liberalism. While as Dan Beauchamp (1976) famously wrote, "the historic dream of public health [...] is a dream of social justice" (105), perhaps the historic dream of liberalism is the death of the social. The active and responsible community is both a reconciliatory territory and sentiment of public health discourse used for accommodating not only social justice (under the banner of equity), but perhaps also the continued legitimacy of public health itself into the neoliberal welfare state.

\section{Down and out: Displacing and Diffusing Government}

We are seeing a displacement of social policy and social government. Responsibility of the nation state to citizens is dislocated at the same time that it is relocated within the individual, the family, and the community. Governmental responsibility is downloaded through provincial health organizations onto regionalized PHUs, and finally onto communities. This type of regionalism affords flexibility and responsiveness, but this also reconfigures governmental relations. By mobilizing communities and networks of community programmes, action and 
possibilities for change are pushed down and outwards to the local levels. This is a form of discursive and political closure which is both exclusionary and productive. It creates a legitimate inclusive space (discursively and practically) for localized projects which do not address the relationships between broader economic and socio-political structures and health. By political closure, I gesture to how a focus on health equity at the community level contains research and action at the local level. Specifically, a legitimized focus on the local produces a range of legitimate proxies for acting on health equity, including measurement, surveillance, and assessment of local population needs and interventions. By discursive closure, I mean that this discourse, represented by what it is not, as much as what it is, excludes more radical social imaginaries which might envision policy change.

Public health action establishes a relationship between community and public health for the purpose of enhancing surveillance tools, but it does something else as well by reconfiguring the territory of government and relations of responsibility. Rose (1996) suggests new relations of mutual obligation operate between individual and self, family, and community rather than between individual and state. The relationship between provincial public health organization and community reflects Rose' notion of ethopolitics to the extent that these new moral obligations strengthen relationships between individual and community rather than between individual and state, in effect, diffusing, displacing, and often entirely neglecting the role of social policy and government. This reflects a shift from a state-centred model of social change following the second World War to the late-modern community model of change mediated by local organizations.

This ethopolitical shift is accompanied by what Rose (1996) refers to as reflexive government in which the ends of government turn upon the instruments of government themselves (201). It is now the task of government to govern without governing society (201). 
We see this in the diffusion and standardization of practices that might otherwise involve government decision making — for example, deciding what a priority population is, who it includes, and why. Reflexive government entails displacement in which "the task of national government is less to govern social and economic processes external to itself and more to secure the institutions and mechanisms of social and economic government themselves" (201). In the context of Canadian public health, I suggest this ability to secure the institutions and mechanisms of government themselves is achieved in a number of ways. I have already mentioned the diffusion of public health organizations operating with some amount of autonomy from the state. Moreover, programmatic interventions such as best practices secure communities, families, and individuals themselves as the mechanisms and institutions of social and economic government. But additionally, EIDM, the very tool of a best practice, and the standardized procedures and hierarchies of evidence used for determining what a best practice even is all function as mechanisms of government themselves. These are the more technical means of achieving the task of 'governing without governing society' which I have tried to elucidate in this project.

My analysis of community as a nodal point of health equity discourse follows that pursued by others to understand the popularity of Third Way discourse and the concept of social capital (Rose, 1999; McLennan, 2004; Denny, 2008). Discourse and government of community can be interpreted as a return to a conservative notion of responsibility for family and community rather than a vehicle for radical social change via political contestation. The superficial and conservative civic moralizations of the Third Way deflect our deeper moral attention away from the true 'forces of injustice' today, grounded in exploitation and greed (Rose, 1999: 489-91). As discourse of the social is displaced by the sociology of community, the social it is no longer the central coordinating principle of government, but merely a significant coordinating principle of the family and the community (Denny, 2008: 97). We are now enjoined into intermediate groups, 
such as households, families, associations, consumer groups, and of course, communities, to self manage as group members rather than as members of a social and political community correspondent with the nation state (Dean, 2014: 200). In health equity's deployment, discourse and politics of the social are displaced as they are lowered and dispersed through local projects enlisting individuals, families, and communities, but as Dean notes, these intermediate groups "no longer mediate between society and individual" (200). This represents one way in which government has become more 'multiple, diffuse, facilitative, and empowering' while the state assumes a more coordinative, arbitrative and preventive role as it reduces its directive and distributive role (200).

\section{Technologies of Performance and Technologies of Agency}

Health equity discourse and action often displaces the relationship between individual and state by deploying a range of tested and testable interventions at the community level. With few exceptions, these programs enlist people to work on themselves without additional material resources. This reflects the products of an actionable knowledge regime, wherein social and ethical problems of inequality are recast as technical problems warranting only "narrow technical solutions which affirm the individual self, situated within local ecological niches, as the site for change" (Henderson and Denny, 2015: 374). These products of the actionable knowledge regime can also be understood as technologies of agency. Authoritative expertise is signified by best practices, embodied in their proponents, and attached to strategies of governing.

Technologies of agency is an analytically useful concept because it does not cancel out agency. Instead, it can be used to show how agency is produced and inserted in a 'system of purposes', and how it might overrun the limits established for it by a particular programme (Dean, 2014: 196). Dean (2014) distinguishes between technologies of agency and technologies of performance which make capacities for participation, agreement, and action calculable and comparable so that they can be optimized (202). They both involve putting moral and political 
conduct into play within a system of governmental purposes. This involves instilling a moral obligation to self and community achieved through various means of community engagement.

Dean (2014) points to a series of fragmented and discontinuous agencies which can be public, quasi autonomous, for profit, or from the 'third sector' (199). This may include the New Brunswick Economic and Social Inclusion Corporation which determines priority issues in communities and engages local groups and individuals to develop and carry out poverty reduction plans. The best and promising practices listed in PHAC's portal come from a range of public, quasi autonomous, for profit and 'third sector' agencies. What these fragmented agencies have in common is that they are all charged with dealing with targeted, or at-risk groups (199). What I would add, is that by targeting specific groups, the programs of these fragmented agencies, like the practices of provincial public health organizations, can operate in the name of equity regardless of the content of their actions. By employing technologies of agency, these targeted groups are to be made self managing, to enter into political participation, and to demand action from governments (199). Dean points to the fight against AIDS/HIV, and the creation of communities of victims of crime who are politically reinstated to refuse victimhood and to demand government action related to crime and punishment (199). This politically active governmental construction of community that Dean gestures to is not produced by PHAC best practices, and it is unclear to what extent other community engagement activities pursue this politically active governmental construction of community. As was discussed in this chapter, communities do at times pursue policy change, but often, they are enlisted into programmes of inward action rather than into 'upward' political contestation.

Technologies of agency can also be thought of as technologies of citizenship. They are technologies of government which enhance or deploy possibilities of agency which include techniques of self esteem, of empowerment, and of consultation and negotiation used in a 
range of activities including, but not limited to health promotion campaigns, community development, and social and environmental impact studies (196). Embedding a knowledge broker in each community within the community inclusion network to provide "local evidence as well as examples of actions that have been effective elsewhere" (NCCDH, 2012: 8) exemplifies this well. Even CPNP can also be interpreted as a technology of agency which creates the right kind of citizen, but perhaps the dominance of health equity practices listed as targeting personal health practices and coping skills most obviously represents these technologies of agencyturned technologies of citizenship/health promotion. 


\title{
Chapter 10: Conclusion
}

At this point, I will remind the reader of the research questions that directed the trajectory of this study:

- How is health equity, a normative moral idea, variably accommodated discursively and practically into public health discourse and practice?

In terms of accommodation, several sub questions also directed the course of this study:

- How does the actual practical deployment(s) of equity compare to some idea(s) of social justice as conceptualized in normative ethics theory?

- What role might normative ethics play in lending some concreteness to a more consistent, transparent, and socially and ethically meaningful commitment to health equity? What might the existing barriers be?

\begin{abstract}
A key part of understanding how the concept of health equity is accommodated requires analysing what is not accommodated, and how these lacunae reproduce what is and what is not present in discourse and action around health equity. The following questions were developed to yield insights into these issues of exclusion and discursive production:
\end{abstract}


- How does equity operate as an empty signifier and vehicular idea? And, what does this produce?

- How do evidentiary norms and technical modes of representation produce and preclude particular ways understandings inequity both as an empirical phenomenon, and as a normative ethical problem? And how does this produce and preclude means of correcting it?

- What is represented as static and as dynamic in public health discourse and models of knowledge production?

- How do evidentiary imperatives sustain ideology and the incessant deferral of policy action aimed at health inequity?

- How is health equity instrumentalized? What is the instrumental relationship between health equity and other goals, rationalities, standards, and values?

- How is community engagement (and the deployment of the concept of health equity in public health generally) a discourse/practice which reconciles the difference between the neoliberalism and the positivist field of public health, and public health's socialdemocratic commitment to the common good?

This thesis has shown how health equity is actually deployed in practice. After analysing some of the barriers to advancing health equity identified in the existing empirical literature, I analysed how health equity is represented through modes of knowledge production. This 
includes the process of measuring priority populations, and PHAC's model for objectifying health inequalities. I showed how this closed model naturalizes social precarity by producing precise descriptions of associations between risk factors while obscuring their location in social relations. Throughout this project, I reminded the reader that this knowledge of health inequity as rooted in social relations is key to acting on any relational conception of justice. This marks the crucial interplay between science, facts, and values. I then analysed how health equity interventions are represented in Canadian public health discourse. I showed that upstream interventions are consistently presented as inoperable, not because they are proven to be ineffective, but because of a 'dearth of evidence'. I suggest that the substantive problem is a dearth of political reason, and the very evidentiary imperatives that make a dearth of evidence a barrier to action which could otherwise be supported by theoretical knowledge. By analysing best practices with a 'health equity focus', I was able to show which kinds of interventions are represented as actionable. I argued that these interventions are made legitimate because of their evidentiary productivity rather than their logical relationship to the attainment of some normative ethical end. By analysing the metrics and values inherent in evaluation processes, I showed that policy-based interventions cannot produce the same kind of immediate and precise evidence. This further exemplifies the relationship between evidentiary norms and imperatives on one hand, and opportunities for advancing social justice on the other. I suggest that this evidence-based regime not only compromises the realization of a meaningful and consistent version of equity-as-justice. It also functions as a mechanism of government which allows the state to efface itself from all decision making. In the final chapter, I critically analyse the deployment of equity in the community, showing that it operates as the sentiment and territory through which political contestation is contained.

Health equity is accommodated into public health discourse and practice as a proactive, narrowly (yet variably) defined, scientific, and progressive but socially non-disruptive ancillary 
commitment. The progressive component of health equity is mainly derived from some discursive commitment to inclusion, and some recognition of disadvantage or unequal agency. Health equity is instrumentalized in several ways. First, health equity is instrumentalized through measuring and acting on priority populations as a proxy for equity, and to meet the population health goal of increasing average population health—specifically by increasing the tails of the distribution. Other standards and values converge with health equity's deployment-for example, the standard that actions are evidence-based, and that they are accountable and efficient.

Because evidentiary norms and technical modes of representation preclude a relational understanding of inequity, we are unable to understand health inequity as a relational problem rooted in social relations, including those that are economic, cultural, and political. Evidentiary imperatives for precise information about the relationship between specific factors leaves us with an inaccurate and incomplete understanding of health equity which ultimately sustains ideology by leaving us ill equipped to deal with the reality of the situation. When knowledge about health in relation to its social determinants is produced within a closed system which excludes political and relational/productive factors, it becomes impossible to ever locate the cause of inequality, or to assign causal weight or direction to factors. Additionally, by including nothing higher in the causal chain, and by abstaining from explicit interpretation, social precarity and inequality are mystified and implicitly naturalized. This explains how evidentiary imperatives sustain ideology and the incessant deferral of policy action. Another way that this happens is through the requirements imposed by EIDM. In conditions in which scientific evidence is needed to support a particular action, there will always be a 'dearth of evidence' to support broad-based policy solutions such as HiaP or 'healthy public policy'. What we are left with are time-bound best practices which most often target individuals and do not offer material assistance. 
I theorize the sheer ubiquity of health equity as well as the inadequacy of its disparate, proactive, but not counteractive forms as a result the infinitely extendable field of legitimate discourse and practice around equity. Equity's capacity for successful extension and mobility was thoroughly addressed in chapter six where I provided an in-depth analysis of health equity as an empty signifier, and as a vehicular idea. I argued that engaging with normative ethics allows public institutions to impose some concrete content on the idea of equity thereby reducing its capacity to function as an empty signifier. But as I showed in chapters seven and eight, we must also transform evidentiary norms and imperatives that shape and limit what kinds of normative ethical ideals are possible to work toward. The twin problems that I have tried to clarify in the study are the technical and discursive barriers which are as productive as they are inadequate. Normative ethics can help lend some concrete content to what we mean by equity, thereby imposing a clear idea of what equity is not, and thereby limiting its disparate and inadequate extension and mobility. In addition to functioning as theoretical anchoring point that makes its drift evident and comprehensible, more engagement with normative ethics also allows us to see when our modes of knowledge production—and the evidentiary norms and imperatives that structure them-fail us by preventing the realization of ideal ethical end. A key task to addressing this dual ethical and technical problem is opening up our models of knowledge production so that both epidemiological description and sociological analysis is possible.

I have highlighted a discursive problem with the very concept of 'health equity', and a technical problem with evidentiary imperatives, and practices, which is tied to evidentiary norms stemming from the historical effacement of the researcher and government, and the rise of scientific reason as public reason, and particularly today in the primacy of institutional and organizational performance management practices which value precision over accuracy. The emptiness of equity is related to the lack of engagement with normative ethics which would 
impose concrete content, providing an anchoring point for which any discordance would be identifiable. I have also suggested that the technical lacunae limit what conception of social justice is possible to realize. Engaging with normative ethics might also play an important role in identifying when our models of representation fail to make what matters knowable.

The most governmental and institutionally embedded barriers are evidentiary norms and imperatives associated with EIDM, the identification of priority populations, the objectification of health inequality, and the development, evaluation, and deployment of best practices. Because of a need for local epidemiological evidence to support and evaluate actions, public health workers are constrained in what they can actually do, despite working under a fairly flexible health equity mandate. Throughout this project, I have pointed out how this trade off of accuracy for precision characterizes public health practices and compromises its commitment to equity. We also see the trade off of accuracy for precision in the way we objectify the problem of health inequality. This produces a web of aimless asocial associations which are precisely quantified. However, their true location or their origin is obscured.

\section{Health Equity in the Community}

My analysis is unique for taking community as a productive nodal point in health equity discourse which hinders a more transformative version of health equity. This stands in contrast to the conventional treatment of community as a progressive and necessary counter-balance to what is critiqued as a de-humanizing field of public health practice. While it is possible to be the site of political contestation wherein communities make transformational demands to the state, it is also the site of under-realized political contestation. Community has become both the territory and sentiment on which individualization and social precarity caused by neoliberalism are eased without actually countering neoliberalism at the level of public policy. 
The local community orientation of discourse and action on health equity can be interpreted as a result of the fragmented regionalized organizational character of Canada's public health system. I would presume that this does explain, at a superficial level, the diffuse and local character of discourse an action, but I have interrogated this further and contributed two novel insights. Regardless a lack of intent, and whether or not this is merely configured in such a regionalized way because it offers flexibility and regionally tailored responses to healthrelevant issues is not so important to understanding its significance. First, like other inadequacies of action on health equity, the fragmented action on health equity is reproduced by technical evidentiary imperatives rather than only by a concerted political effort to sustain its politically-dampened efforts; nor is this sustained by a mere lack of political will to support the change to federally implemented, long term and broad-based healthy public policy agendas.

Secondly, this fragmented and local action, legitimized and deployed through a discourse of community and equity, effectually forecloses the possibility of real healthy public policy, which is constructed as too distal from the bodies experiencing unfair health outcomes that evaluation and measurement target to support such policies. The various types of community action all equally convey a sense of optimism, progressiveness, and a socialdemocratic ethos without overrunning its liberal course. Health equity discourse and action often displaces the relationship between individual and state by deploying a range of tested and testable interventions at the community level. With few exceptions, these programs enlist people to work on themselves without additional material resources.

\section{Making Sense of Health Equity: Flexible and Contained}

Because I did not reduce my explanation health equity's form, continuity, and ubiquity to politics or coercive, manipulative form of power, I was also able to show how health equity's own discursivity produced inclusive conditions for legitimacy in which politically and materially 
impoverished forms of action still constitute a legitimate version of a health equity lens, orientation, principle, goal, policy, or practice. By theorizing it as an empty signifier and as a vehicular idea, I have shown how its very lack of clarity does not simply constitute a barrier to action, but also produces the discursive conditions for its varied uptake, measurement, and deployment. As an empty signifier, equity functions as a vehicular idea, perfectly capable of being deployed, owned, and lauded by range of actors in a diversity of ways under conditions that are as unfixed as its own meaning. I have shown the different ways that health equity is deployed, but I have also produced a new way of making sense of its ubiquity and diversity. This allows us to understand why equity has been able to travel so far from its origins in WHO, and why it is able to move along the way that it does. Furthermore, I have highlighted organizational imperatives reflected in a shift to new public management, ideas about what counts as evidence, epistemological problems with the fundamental source of health inequity as an object of positivist research (namely that it is relational and not compatible with social epidemiology), and the incompatibility of political interventions with experimental evaluation required for best practice designation. I historicize this all as part of an epistemological shift toward quantifying and seemingly neutral rationality in public health.

\section{Science, Values, and Welfare}

As a theoretical contribution to sociological of knowledge, I have highlighted the relationship between discourse, knowledge, politics, and normative values such as social justice. Knowledge production, decision making, and action are pushed 'out and down' as they are pushed away from the state and across a range of localities. Reductive knowledge and contingent actions not only displace action territorially and governmentally, but also shrink thinking and action temporally. For example, best practices take the form of temporary projects before sending participants on their way. I have highlighted this as an example of how the stateknowledge nexus reconfigures the non-ideal citizen-subject as a citizen-participant in scientific 
programmes. We see this in best practices, including Housing First (as At Home/Soi Chez in Canada), but also in the North American Opiate Medication Initiative (NAOMI), and Insite. This falls in contrast to welfare state planning and long-term public policy making. This short-termism characterizing interventions allows for flexible governance in times of uncertainty, and provides immediate results for performance evaluation, but they also reproduce uncertainty for the least well off.

\section{Implications for Understanding Late Modern Government: Science and Government Effacement}

I have shown how a relationship between knowledge production and discourse shapes and limits government policy so that it fits within liberalism, achieving stasis. While the relationship between discourse and knowledge production is not the origin of this power relation, it is a key relational/productive point that I have analyzed and called attention to. In the context of Canadian public health, I suggest the ability to secure the institutions and mechanisms of government themselves is achieved in a number of ways. I have already mentioned the diffusion of public health organizations operating with some amount of autonomy from the state. Moreover, programmatic interventions such as best practices secure communities, families, and individuals themselves as the mechanisms and institutions of social and economic government. But additionally, EIDM, the very tool of a best practice, and the standardized procedures and hierarchies of evidence used for determining what a best practice even is all function as mechanisms of government themselves. These are the more technical means of achieving the task of governing without governing society which I have tried to elucidate in this project.

Just as citizen-subjects are reconfigured to accept precarity, assuming flexible selves in the face of uncertainty, models of knowledge production such as the multicausal theory, (and the wide-spread production of theory-free and ostensibly neutral descriptive representations of 
health differentials) allows the state to remain flexible to the demands of the market. EIDM renders decision-making flexible and politically contained. This flexible containment is key to discourse, knowledge, and programmes alike, from the concept of equity to models of knowledge production which produce atheoretical statistical relations, to the localized interventions and the citizen-subjects that they enlist. Freed from the promises of increasing social security previously lauded under the growing post World War II welfare nation state, the government can remain fluid in the wake of constant change that characterizes what is aptly characterized by Bauman (1999) as liquid modernity.

The evidence-based regime is a key mechanism of government that allows for the state's retreat from identifying and responding to social problems through political deliberation and progressive policy development. Evidence-based practices such as best practices result in short term, proactive solutions, not counteractive solutions. In addition to not having to engage with the origin of social problems, these programs can easily be eliminated unlike public polices. Just like Insite was originally only able operate as a time-bound scientific experiment, we see how a reluctance on the part of government to create legislation (or in the case of InSite, to allow an exception from criminal legislation) results in time-bound actions. As temporary scientific projects, they not only produce short-term evidence, but they are also easier to eliminate, unlike policy actions which, like a ratchet, are difficult to revert. Furthermore, as scientific projects, there is nowhere to direct social/political critique. The ascendancy of governing through regionalized organizations, who in turn, enlist a standardized technical mode of decision making-EIDM—allows the state and to some degree, its public and quasi public organizations, to efface itself from decision making, absolving itself from responsibility for action or inaction. What becomes critiqued is not decision making, opinion, or interpretation, but a technical inadequacy which is traced to data deficits and methodological conflicts. There are no political actors to blame, only scientific truth to pursue and refine. 
Instead of advancing the case for healthy public policy, the continual surveillance of risk factors is pursued to demonstrate efficacy and affirm or reaffirm programme expansion. I suggest that the proliferation of programs as a solution to issues of human welfare should not be taken for granted. Non-ideal citizens—-those who fail as ideal entrepreneurial subjects—can receive help as participants in experimental programs rather than as citizens of a generous welfare state. The deployment of programmatic action, and the deferral of policy action or even analysis indicates the reconfiguration of the sociopolitical and governmental context itself. This reconfiguration is characterized by the replacement of a deliberative and reformist policy landscape with a programmatic and managerial field of practice. This governmental context strays from post World War II growth of the welfare state when issues of human need became policy issues inserted into political deliberation. While gesturing to the neoliberal decline of the welfare state is now an obvious observation, there has been less attention paid to the ways in which the very practice of identifying a social problem is supplanted by the deployment of actionable, optimistic temporary and evidence-based projects.

This project has shined a bit of light on what on might term governance without politics. This is distinct from (but does not challenge) a description of governmentality which relies on disciplined, self-governing citizen-subjects. The evidentiary burdens highlighted as barriers to health equity in this project amount to non-human, seemingly neutral, technical facilitators, mediators, and inhibitors to action. As demonstrated, what does make it over the evidentiary imperatives are conservative, non-political projects. Maintaining a politically non-contesting population in this way does not require force and cannot only be explained by neoliberal regulation of subjectivity. If the relationship between subjectivity and governance comes into play, we must also account for the growing myopic commitment to scientific reason. Even if there were no interests held in preserving conditions of concentrated wealth accumulation, if 
governments and low-level organizations alike are to simply achieve stasis, then a commitment to scientific certainty helps this. Social conditions are governmentally stable in conditions in which people expect, with docility and a sense of inevitability, to live with the null hypothesis until scientifically proven otherwise. This was an unexpected insight that warrants further exploration.

\section{Future Research}

I placed this study in particular governmental conditions in which knowledge plays a role within and in place of possibilities for political contestation. Future research can look at the different evidentiary imperatives imposed on various types of government action. For example, Ontario employment standards were recently reformed despite theoretical knowledge that the reforms would be bad for public health. It would be important to know if there are different evidentiary requirements for regressive and progressive reform in different areas of policy. This would require asking, 'What role does evidence play in different areas, issues, and styles of government decision making?', 'In practice, do progressive issues/decisions require different kinds of evidence than conservative/regressive issues/decisions?'. It is important to track the ways in which knowledge is mobilized within and in place of political argument. This includes examining where knowledge is suppressed or prevented from being produced in the first place. Under Doug Ford's Ontario government, the basic income pilot project was terminated, perhaps to pre-emptively eliminate the possibility of social change-supporting evidence from emerging which, in these technocratic conditions, would be difficult to fight with naked political values. ${ }^{50}$ Future research can explore where political contestation happens, and where it does not, with

\footnotetext{
${ }^{50}$ And of course there are possibilities for securing human wellbeing through scientific projects such as Insite and Housing First, but this constitutes the democratically and ethically impoverished conditions that I am so critical of for its vulnerability to cooptation, termination, instrumentality, mediocrity, and inaction, but most concernedly, for its implicit role in deflecting attention away from the very conditions that produce social injustice, and the need to respond to it in the first place.
} 
critical attention to how knowledge is mobilized in relation to decision making and legitimacyparticularly in areas concerning human wellbeing and values such as equity and social justice. ${ }^{51}$ If there are no signs of the post-democratic 'evidence-based everything' knowledge regime waning in pervasion and influence, this will be important research to pursue in the coming years. This research ought to be designed with phronesis ${ }^{52}$ in mind by employing Bent Flyvbjerg's questions that are integral to 'making social science matter': (1) What is going on and where are we going? (2) Who benefits and who loses, and by which mechanisms of power? (3) Is this desirable? (4) What, if anything, should we do about it?

\section{Practical Contribution to Public Health}

As a practical sociological contribution to public health, I have interrogated the discursive and technical conditions that simultaneously limit a more meaningful and consistent realization of equity-as-justice and produce a flexible yet contained space for a myriad of ineffectual actions that each enjoy some legitimate claim to the proactive project of bolstering health equity. As a proscription, given that equity has been emptied, and that so much work is able to continue with legitimacy while doing very little to address the very causes of health inequity that have been recurrently identified for hundreds of years, and now that I have, in response to others, provided some clarity to what health equity is, and what it could be, our practical imperative from here ought to be clarifying, wherever possible, what health equity is not. This would not mean

\footnotetext{
${ }^{51}$ Porter (2006) notes that while cost-benefit analysis has been systematically applied to government health and environmental regulations, it never seems to apply to missile defense or measures against terrorism (1285). I would point to criminal justice and policing costs which avoid evidence-based scrutiny, perhaps because the rhetoric of the crime problem, however costly, can be paid for by an acquiescing public at no cost to industry, and often to industry benefit. The same cannot be said for social reform, which, while likely to reduce criminal justice expenditures, is unpalatable on all fronts, from the public, to business, to police unions.

52 Phronesis is the lost but complimentary Aristotelian intellectual virtue to episteme. Episteme retains an obvious place (as a close variant) in the modern English lexicon and enjoys a privileged status throughout the age of rationality to present. In contrast, phronesis encompasses a context-based value rationality most relevant to praxis--that is, understanding what is going on in particular cases--rather than producing universal rules--and knowing what is right from wrong.
} 
dislocating those actions in health care from the signification of equity, but perhaps we need to state that equity in health care is not health equity. Neither is merely targeting a population at risk for any intervention working toward health equity. If it is, the instrumental connection between action and normative ethical ends must be clear. It is too easy to deploy actions which meet the short-term goals of one's specific field of practice in complete isolation from any actual or potential broader strategy to reducing health inequities. We need to be clear about the ontological status of health equity and what it is not. And, perhaps a clearer and more meaningfully actionable version of health equity ought to require articulating its distinction and consistency from what health inequity is. This requires overhauling the stature of evidentiary norms as governmental mechanisms, reasserting political deliberation as the means of legitimation, and allowing both sociology and normative ethics to function as the equity lens. By enlisting the sociological imagination, and never losing sight of what is unfair, and how things become unfair, we are less likely to deploy health equity in ways that are totally displaced from those unfair processes that produced a need for intervention in the first place. The first step to progressing health equity should always be, why is there an inequity? Perhaps the most clear and concise proscription comes from the originator of health equity's definition, whose advice continues to be ignored almost three decades later: "So, in order to describe a certain situation as inequitable, the cause has to be examined and judged to be unfair in the context of what is going on in the rest of society" (Whitehead, 1991: 219). 


\section{Bibliography}

Bailey, Z. D., Krieger, N., Agénor, M., Graves, J., Linos, N., \& Bassett, M. T. (2017). Structural racism and health inequities in the USA: Evidence and interventions. The Lancet,389(10077), 1453-1463. doi:10.1016/s0140-6736(17)30569-x

Bambra, C. (2006). Health Status and the Worlds of Welfare. Social Policy and Society, 5(01), 53-62. doi:10.1017/s1474746405002721.

Barnish, M., Tørnes, M., \& Nelson-Horne, B. (2018). How much evidence is there that political factors are related to population health outcomes? An internationally comparative systematic review. BMJ Open,8(10). doi:10.1136/bmjopen-2017-020886

Bauman, Z. (1999). Liquid modernity. Cambridge, UK: Polity Press.

Beauchamp, T. L., \& Childress, J. F. (2016). Principles of biomedical ethics. New York: Oxford University Press.

Braveman, P. (2014). What are Health Disparities and Health Equity? We Need to Be Clear. Public Health Reports,129(1_suppl2), 5-8. doi:10.1177/00333549141291s203

Brassolotto, J., Raphael, D., \& Baldeo, N. (2013). Epistemological barriers to addressing the social determinants of health among public health professionals in Ontario, Canada: A qualitative inquiry. Critical Public Health,24(3), 321-336.

doi:10.1080/09581596.2013.820256

Brodie, J. (2002) 'Three stories of Canadian citizenship', in: R. Adamoski, D. Chunn and R. Menzies (Eds), Constructing Canadian Citizenship: Historical Readings (Peterborough, ON, Broadview), pp. 43-66.

Brown, Kate. "'Vulnerability': Handle with Care." Ethics and Social Welfare5, no. 3 (2011): 31321. doi:10.1080/17496535.2011.597165.

Brunner, E. (1997). Socioeconomic determinants of health: Stress and the biology of inequality. Bmj,314(7092), 1472-1472. doi:10.1136/bmj.314.7092.1472 
Chang, W. (2002). The meaning and goals of equity in health. Journal of Epidemiology \& Community Health,56(7), 488-491. doi:10.1136/jech.56.7.488

Cheff, R. (2017). Making Room for Health Equity. Wellesley Institute,1-18.

Chung, H., \& Muntaner, C. (2007). Welfare state matters: A typological multilevel analysis of wealthy countries. Health Policy,80(2), 328-339. doi:10.1016/j.healthpol.2006.03.004

Coburn, D. (2004). Beyond the income inequality hypothesis: Class, neo-liberalism, and health inequalities. Social Science \& Medicine,58(1), 41-56. doi:10.1016/s02779536(03)00159-x

Coburn, D., Denny, K., Mykhalovskiy, E., Mcdonough, P., Robertson, A., \& Love, R. (2003). Population Health in Canada: A Brief Critique. American Journal of Public Health,93(3), 392-396. doi:10.2105/ajph.93.3.392

Coyne, J. C., \& Kwakkenbos, L. (2013). Triple P-Positive Parenting programs: The folly of basing social policy on underpowered flawed studies. BMC Medicine,11(1). doi:10.1186/1741-7015-11-11

Coyne, J. (2015). Are meta-analyses done by promoters of psychological treatments as tainted as those done by Pharma? Retrieved from https://blogs.plos.org/mindthebrain/2014/05/20/meta-analyses-done-promoterspsychological-treatments-tainted-meta-analyses-done-pharma/

CSDH (2008). Closing the gap in a generation: health equity through action on the social determinants of health. Final Report of the Commission on Social Determinants of Health. Geneva, World Health Organization

Daniels, N. (2007). Just health: Meeting health needs fairly. Cambridge: Cambridge University Press.

Dean, M. (2014). Governmentality power and rule in modern society. Los Angeles, CA: Sage. Denny, K. (2008). Social capital and health: A critical history of a concept. Saarbrücken, Germany: VDM Verlag Dr. Müller. 
Driver, Julia, "The History of Utilitarianism", The Stanford Encyclopedia of Philosophy (Winter 2014 Edition), Edward N. Zalta (ed.), <https://plato.stanford.edu/archives/win2014/entries/utilitarianism-history/>.

Edwards, N. E., \& Davison, C. M. (2008). Social justice and core competencies for public health: Improving the fit. Canadian Journal of Public health, 99(2), 130-132.

Eisner, M. (2014). The South Carolina Triple P System Population Trial to Prevent Child Maltreatment: Seven Reasons to be Sceptical about the Study Results. Violence Research Centre,1-15. Retrieved from https://www.vrc.crim.cam.ac.uk/PDFs/workingtriplep.

Elliott, D. (2014). Debating Safe Injecting Sites in Vancouvers Inner City: Advocacy, Conservatism and Neoliberalism. Contemporary Drug Problems,41(1), 5-40. doi:10.1177/009145091404100102

Elias, N. (1956). Problems of Involvement and Detachment. The British Journal of Sociology, 7(3), 226. doi:10.2307/587994

Esping-Andersen, G. (1990). The three worlds of welfare capitalism. Princeton: Princeton.

Evans, R. G., \& Stoddart, G. L. (1990). Producing health, consuming health care. Social Science \& Medicine,31(12), 1347-1363. doi:10.1016/0277-9536(90)90074-3

Ewal, M. (2012). Legal Tools for Environmental Equity vs. Environmental Justice. Sustainable Development Law \& Policy,13(1), 3-13.Goodin, R. (1985) Protecting the Vulnerable: A Re-analysis of our Social Responsibilities, University of Chicago Press, London.

Fairclough, Norman (2014). General Introduction. In Critical Discourse Analysis: The Critical Study of Language (Second Edition). (pp 1-23). New York: Routledge.

Farrer, L., M.C., Cavaco, Y. K., \& Costongs, C. (2015). Advocacy for Health Equity: A Synthesis Review. Milbank Quarterly, 93(2), 392-437. doi:10.1111/1468-0009.12112 
Flyvbjerg, B., \& Sampson, S. (2001). Making social science matter: Why social inquiry fails and how it can succeed again. Cambridge: Cambridge University Press.

Frankfurt, H. (1987). Equality as a moral Ideal. Ethics, 98(1), pp.21-43.

Gardner, B. (2008). Toronto Central LHIN Health Equity Discussion Paper(pp. 1-53, Publication). Toronto: Ontario.

Giacomini, M., Hurley, J., Gold, I., Smith, P., \& Abelson, J. (2004). The policy analysis of 'values talk': Lessons from Canadian health reform. Health Policy,67(1), 15-24. doi:10.1016/s0168-8510(03)00100-3

Giacomini, M., Kenny, N., \& Dejean, D. (2009). Ethics frameworks in Canadian health policies: Foundation, scaffolding, or window dressing? Health Policy,89(1), 58-71. doi:10.1016/j.healthpol.2008.04.010

Hassen, Nadha, Ingrid Tyler, and Heather Manson. "Influence of Revised Public Health Standards on Health Equity Action: A Qualitative Study in Ontario, Canada." International Journal for Equity in Health16, no. 1 (2017). doi:10.1186/s12939017-0677-9.

Henderson, J., \& Denny, K. (2015). The resilient child, human development and the "postdemocracy". BioSocieties, 10(3), 352-378. doi:10.1057/biosoc.2015.24

Henig, R. (1997). He People's Health A Memoir of Public Health and Its Evolution at Harvard. Washington: Joseph Henry Press.

Hood, C. (1991). A Public Management for all Seasons. Public Administration, 69, 3-11.

Jackson, A. (2009). 'The Unhealthy Canadian Workplace'. In D. Raphael (Ed.), Social Determinants of Health: Canadian Perspectives (pp. 99-113). 2nd edition Toronto: Canadian Scholars' Press

Johnson SA. (2009) Public health advocacy. Edmonton, Alberta: Healthy Public Policy - Alberta Health Services. 
Krieger, N., Sidney, S., \& Coakley, E. (1998). Racial discrimination and skin color in the CARDIA study: Implications for public health research. Coronary Artery Risk Development in Young Adults. American Journal of Public Health,88(9), 1308-1313. doi:10.2105/ajph.88.9.1308

Krieger, N. (1999). Embodying Inequality: A Review of Concepts, Measures, and Methods for Studying Health Consequences of Discrimination. International Journal of Health Services, 29(2), 295-352. doi:10.2190/m11w-vwxe-kqm9-g97q

Krieger, N., \& Krieger, N. (2016). Who and What Is a " Population "? Historical Debates , Current Controversies , and Implications for Understanding "Population Health " and Rectifying Health Inequities Source: The Milbank Quarterly, Vol . 90 , No . 4 (December 2012 ), pp . 634-681 Pub, 90(4), 634-681.

Labonte, R. (1997). The population health/health promotion debate in Canada: The politics of explanation, economics and action. Critical Public Health,7(1-2), 7-27. doi:10.1080/09581599708409075

Laclau, E. (1996). Why do empty signifiers matter to politics. In Emancipation(s)(pp. 36-46). London: Verso.

Laclau, E. (2018). On populist reason. London: Verso.

Lahey, P., Macdermid, J., Kirsh, B., \& Gewurtz, R. (2017). Placing Health in Welfare Policy: A HIAP Approach in Ontario Canada. Canadian Review of Social Policy,77, 67-95.

Lee, L. M. (2012). Public Health Ethics Theory: Review and Path to Convergence. The Journal of Law, Medicine \& Ethics, 40(1), 85-98. doi:10.1111/j.1748-720x.2012.00648.x

Lévi-Strauss, C. (1950) "Introduction à l'oeuvre de Marcel Mauss" in Mauss, Sociologie et Anthropologie, Puf. Paris. 
Little, M., \& Berry, V. (2012). The Impact of Three Evidence-Based Programmes Delivered in Public Systems in Birmingham, UK. International Journal of Conflict and Violence,6(2), 260-272.

Lupton, D. (1997). The imperative of health: public health and the regulated body. London: Sage Publications.

Mackenbach, J. P. (2009). Politics is nothing but medicine at a larger scale: Reflections on public health's biggest idea. Journal of Epidemiology \& Community Health,63(3), 181184. doi:10.1136/jech.2008.077032

Marchand, S., Wikler, D., \& Landesman, B. (1998). Class, Health, and Justice. The Milbank Quarterly,76(3), 449-467. doi:10.1111/1468-0009.00098

Marmot, M. G.; Rose, G.; Shipley, M.; Hamilton, P. J. (1978). "Employment grade and coronary heart disease in British civil servants". Journal of Epidemiology and Community Health. 32 (4): 244-249.

Marmot, M. G.; Davey Smith, G.; Stansfield, S.; et al. (1991). "Health Inequalities among British civil servants: the Whitehall II study". Lancet. 337 (8754): 1387-1393. doi:10.1016/01406736(91)93068-K

Mclennan, G., \& Osborne, T. (2003). Contemporary 'vehicularity' and 'romanticism': Debating the status of ideas and intellectuals. Critical Review of International Social and Political Philosophy, 6(4), 51-66. doi:10.1080/1369823042000241267

Mclennan, G. (2004). Travelling with vehicular ideas: The case of the third Way. Economy and Society,33(4), 484-499. doi:10.1080/0308514042000285251

McPherson, C., Ndumbe-Eyoh, S., Betker, C., Oickle, D., \& Peroff-Johnston, N. (2016).

Swimming against the tide: A Canadian qualitative study examining the implementation of a province-wide public health initiative to address health equity. International Journal for Equity in Health,15(1). doi:10.1186/s12939-016-0419-4 
Mooney, G. H. (1987). What does equity mean? World Health Statistics Quarterly, 40(4), 296303.

Mouffe, C. (2000). The democratic paradox. London: Verso.

Muntaner, C., \& Lynch, J. (1999). Income Inequality, Social Cohesion, and Class Relations: A Critique of Wilkinsons Neo-Durkheimian Research Program. International Journal of Health Services, 29(1), 59-81. doi:10.2190/g8qw-tt09-67pl-qtnc

Muntaner, C., Borrell, C., Ng, E., Chung, H., Espelt, A., Rodriguez-Sanz, M., . . O'Campo, P. (2011). Politics, welfare regimes, and population health: Controversies and evidence. Sociology of Health \& IIIness,33(6), 946-964. doi:10.1111/j.14679566.2011.01339.x

Navarro, V., \& Shi, L. (2001). The political context of social inequalities and health. Social Science \& Medicine,52(3), 481-491. doi:10.1016/s0277-9536(00)00197-0

OECD (2010). Strictness of Employment Protection. Online at: http://stats.oecd.org/lndex.aspx

OHEG (2018). Canada, Population and Public Health Division, Ministry of Health and LongTerm Care. (2018). Health Equity Guideline, 2018.

OPHS. (2018). Ontario public health organizational standards. Toronto: Ministry of Health and Long-Term Care.

Orton, L. C., Lloyd-Williams, F., Taylor-Robinson, D. C., Moonan, M., Oflaherty, M., \& Capewell, S. (2011). Prioritising public health: A qualitative study of decision making to reduce health inequalities. BMC Public Health,11(1). doi:10.1186/1471-2458-11-821

OPCS, 1978: 37- O.P.C.S. Occupational Mortality 1970-72. London, HMSO, 1978.

Pauly, B. B., Shahram, S. Z., Dang, P. T., Marcellus, L., \& Macdonald, M. (2017). Health Equity Talk: Understandings of Health Equity among Health Leaders. AIMS Public Health,4(5), 490-512. doi:10.3934/publichealth.2017.5.490 
Parfit, D. (1998) Equality and priority. In Ideals of equality Ratio Special issues. Edited by A. Mason. Wiley.

Peter, F. (2001). Health Equity and Social Justice. Journal of Applied Philosophy, 18(2), 159170. doi:10.1111/1468-5930.00183

Peter, F. (2004) Health Equity and Social Justice In S. Anand, F. Peter \& A. Sen (Eds.), Public health, ethics, and equity (pp. 93-106). New York: Oxford University Press.

Pinto, Andrew D., Heather Manson, Bernadette Pauly, Joanne Thanos, Amanda Parks, and Amy Cox. (2012) "Equity in Public Health Standards: A Qualitative Document Analysis of Policies from Two Canadian Provinces." International Journal for Equity in Health 11, no. 1: 28. doi:10.1186/1475-9276-11-28.

Pogge, T. W. (2004). Relational conceptions of justice: Responsibilities for health outcomes. In S. Anand, F. Peter \& A. Sen (Eds.), Public health, ethics, and equity (pp. 135-161). New York: Oxford University Press.

Poovey, M. (1998). A History of the Modern Fact Problems of Knowledge in the Sciences of Wealth and Society. Chicago, IL: University of Chicago Press.

Porter, T. (2006). Speaking Precision to Power: The Modern Political Role of Social Science. Politics and Science: An Historical View, 73(4), pp.1273-1294.

Powers, M., \& Faden, R. (2006). Social justice: The moral foundations of public health and health policy. New York: Oxford University Press.

Raphael, D. (2011). A discourse analysis of the social determinants of health. Critical Public Health,21(2), 221-236. doi:10.1080/09581596.2010.485606

Ratcliffe, J. (1978). Social Justice and the Demographic Transition: Lessons from Indias Kerala State. International Journal of Health Services, 8(1), 123-144. doi:10.2190/tkuw-j59Iyhmf-3w5q

Rawls, J. (1993). Political liberalism. New York: Columbia University Press. 
Rawls, J. (1971). A theory of justice. Cambridge, MA: Belknap Press. Rawls, 1993: 283

Rizzi, K. E. (2014). Perceptions about equity in public health: A comparison between frontline staff and informing policy in Ontario. University of Western Ontario.

Rose, N. (1996) The death of the social? Re-figuring the territory of government, International Journal of Human Resource Management, 25:3, 327-356

Rose, N. (1999) 'Inventiveness in politics', Economy \& Society 28(3): 467-93.

Rosiek, J. L., \& Heffernan, J. (2014). Can't Code What the Community Can't See. Qualitative Inquiry, 20(6), 726-733. doi:10.1177/107780041453025

Scott-Samuel, A., Bambra, C., Collins, C., Hunter, D. J., Mccartney, G., \& Smith, K. (2014). The Impact of Thatcherism on Health and Well-Being in Britain. International Journal of Health Services, 44(1), 53-71. doi:10.2190/hs.44.1.d

Sen, A (1979). Equality of what?. The Tanner Lecture on Human Values. Delivered at Stanford University.

Sen, A. (1992). Inequality reexamined. Oxford: Oxford: Clarendon Press.

Sen, A. (1997). Choice, welfare, and measurement. New Delhi: Oxford University Press.

Sen, A. (2002). Why health equity? Health Economics, 11(8), 659-666. https://doi.org/10.1002/hec.762

Smith, M. J. (2014). Health Equity in Public Health: Clarifying our Commitment. Public Health Ethics, 8(2), 173-184. doi:10.1093/phe/phu042

Smith, M. (2016) Public health as social justice? A qualitative study of public health policymakers' perspectives (Doctoral dissertation). University of Toronto, Toronto, Ontario, Canada

Socías ME, Koehoorn M, Shoveller J (2016) Gender inequalities in access to health care among adults living in British Columbia, Canada. Women's Health Issues 26: 74-79. 
Stanhope, V., \& Dunn, K. (2011). The curious case of Housing First: The limits of evidence based policy. International Journal of Law and Psychiatry. doi:10.1016/j.ijlp.2011.07.006

Szreter, S. (1988). The Importance of Social Intervention in Britains Mortality Decline c.1850_ 1914: A Re-interpretation of the Role of Public Health. Social History of Medicine, 1(1), 138. doi:10.1093/shm/1.1.1

Thorne, S., Kirkham, S. R., \& Oflynn-Magee, K. (2004). The Analytic Challenge in Interpretive Description. International Journal of Qualitative Methods,3(1), 1-11. doi:10.1177/160940690400300101

Townsend, B., Schram, A., Baum, F., Labonté, R., \& Friel, S. (2018). How does policy framing enable or constrain inclusion of social determinants of health and health equity on trade policy agendas? Critical Public Health,1-12. doi:10.1080/09581596.2018.1509059

Tyler I, Hassen N. Ontario Agency for Health Protection and Promotion (Public Health Ontario). (2015). Priority populations project: understanding and identifying priority populations for public health in Ontario. Toronto: Queen's Printer for Ontario.

Uvin, P., \& Miller, D. (1994). Scaling Up: Thinking Through the Issues. Global Policy Forum. Retrieved from https://www.globalpolicy.org/component/content/article/177$\underline{\text { un/31630.html }}$

Walby S, (2009) Theorizing Multiple Social Systems. Globalization and Inequalities: Complexity and Contested Modernities. London: Sage

Whitehead, M. (1991). The concepts and principles of equity and health. Health Promotion International,6(3), 217-228. doi:10.1093/heapro/6.3.217

Wilkinson, R. G. (1999). Unhealthy societies: The afflictions of inequality. London: Routledge.

Wilkinson, R. G., \& Pickett, K. (2009). The spirit level: Why more equal societies almost always do better. London: Allen Lane.

\section{Primary Texts}


Canadian Institute for Health Information (2018). In Pursuit of Health Equity: Defining Stratifiers for Measuring Health Inequality — A Focus on Age, Sex, Gender, Income, Education and Geographic Location. Ottawa, ON: CIHI;

National Collaborating Centre for Determinants of Health. (2012). Bridging the Gap between Research and Practice: Empower the Community-New Brunswick's Approach to Overcoming Poverty. Antigonish, NS

National Collaborating Centre for Determinants of Health. (2012b). Bridging the Gap between Research and Practice Making the Case for Health Equity Internally: Winnipeg's Experience. Antigonish, NS

National Collaborating Centre for Determinants of Health. (2013). Let's talk: Populations and the power of language. Antigonish, NS: National Collaborating Centre for Determinants of Health, St. Francis Xavier University.

OPHS. (2008). Ontario public health standards. Retrieved from http://www.health.gov.on.ca/en/pro/programs/publichealth/oph standards/docs/ophs 20 08.pdf

Public Health Agency of Canada. (2018). Key health inequalities in Canada a national portrait(Canada, Public Health Agency of Canada). Ottawa: Public Health Agency of Canada.

Public Health Agency of Canada, (2008) Core Competencies for Public Health in Canada: Release 1.0. Ottawa, ON: Public Health Agency of Canada.

Public Health Agency of Canada. (2010). ARCHIVED - Summative Evaluation of the Canada Prenatal Nutrition Program 2004-2009. Retrieved from https://www.canada.ca/en/publichealth/corporate/mandate/about-agency/office-evaluation/evaluation-reports/summativeevaluation-canada-prenatal-nutrition-program-2004-2009/note-reader.html

Public Health Agency of Canada (2011, January 18). Canada Prenatal Nutrition Program (CPNP) Evaluation. Retrieved from https://www.canada.ca/en/public- 
health/services/health-promotion/childhood-adolescence/programs-initiatives/canadaprenatal-nutrition-program-cpnp/canada-prenatal-nutrition-program-cpnp-evaluation.html Public Health Agency of Canada. (2016). Canadian Best Practices Portal - CBPP. Retrieved from http://cbpp-pcpe.phac-aspc.gc.ca/category/health-promotion-strategy/societalinstitutional/

Public Health Agency of Canada. (2016b). Triple P - Positive Parenting Program. Retrieved from http://cbpp-pcpe.phac-aspc.gc.ca/interventions/triple-p-positive-parenting-program/

Public Health Agency of Canada. (2016c). The Jobs Program. Retrieved from http://cbpppcpe.phac-aspc.gc.ca/ppractice/the-jobs-program/

Public Health Agency of Canada. (2016d). Fruits and Vegetables Subsidy Programme. Retrieved from http://cbpp-pcpe.phac-aspc.gc.ca/ppractice/fruit-and-vegetable-subsidyprogramme/

Public Health Agency of Canada. (2016e). Home Start. Retrieved from http://cbpp-pcpe.phacaspc.gc.ca/ppractice/home-start/

Sanders, M. (2008). Triple P-Positive Parenting Program as a Public Health Approach to Strengthening Parenting. Journal of Family Psychology,22(3), 506-517. doi:10.1037/fam0000060

Vinokur, A. (2003). The Jobs Project for the Unemployed. Retrieved from http://www.isr.umich.edu/src/seh/mprc/jobsupdt.html 
